\title{
FATORES MATERNOS DE RISCO PARA O BAIXO PESO AO NASCER
}

\section{TAQUECO TERUYA UCHIMURA}

Tese de Doutorado apresentada ao Departamento de Nutrição da Faculdade de Saúde Pública da Universidade de São Paulo para obtenção do Título de Doutor.

Área de concentração: Nutrição

Orientador: Prof $f^{a}$ Dra Sophia C. Szarfarc

São Paulo 2000

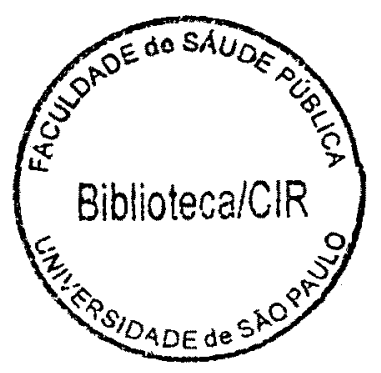


Autorizo, exclusivamente para fins acadêmicos e científicos, a reprodução total ou parcial desta tese, por processos fotocopiadores.

Assinatura:

Data: $16 / 05 / 2000$

$$
361-4 ; x+2
$$




\section{Homenagem Especial}

À todas as mães

" Uma palavra ao mesmo tempo pequena e imensa, cheia de esperança, de amor e de ternura. A mãe é tudo nesta vida: consolo na aflição, luz na desesperança, força na derrota. É a fonte da piedade e da compaixão. Quem perde a sua mãe perde um peito onde reclinar a cabeça, e uma mão que o abençoa e um olho que o protege ..."

Gibran Klalil 


\section{Agradecimento Especial}

Ao Shozo, pela paciência e incentivo nos momentos desanimadores desta caminhada,

As minhas filhas Yurie e Yumi, por nunca terem reclamado minha ausência, muitas vezes roubada para dedicar-se a este trabalho,

Aos meus pais Seitake e Akiko que sempre me incentivaram nas inúmeras viagens realizadas,

Aos meus irmãos e cunhados(as) que me ajudaram direta e indiretamente para a realização deste. 


\section{Agradecimentos}

A Deus, por me dar condições para realizar este trabalho,

À Professora Dra Sophia Cornbluth Szarfarc, pela orientação, amizade e carinho sempre presentes,

À Professora Dra Maria do Rosário Dias Latorre, pelo incentivo, amizade e sugestões tão valiosas para este trabalho,

Aos Professores Luciana Olga Bercini, Nelson Luiz Batista de Oliveira e Iris Maria Hiray Murata, pela colaboração na coleta de dados,

Às Professoras Thaís Aidar de Freitas Mathias, Luciana Olga Bercini e Marta de Campos Cardoso Salvarani, pela amizade, disponibilidade e interesse em colaborar,

Às Professoras Idalina Diair Regla Carolino e Sonia Silva Marcon pela amizade e solidariedade, especialmente no que se refere as disciplinas Nutrição e Dietoterapia I e Enfermagem em Saúde Pública,

À todas as Enfermeiras-Chefes e funcionários dos Postos de Saúde da Secretaria de Saúde do Município de Maringá que não mediram esforços na fase de coleta de dados, 
Ao Núcleo de Processamento de Dados, em especial a Agnes Munhoz Rubira Babata, Eduardo Liquio Takao e Antonio Cesar Alves dos Santos que sempre estiveram prontos na editoração deste trabalho,

À Angela Cuenca da Faculdade de Saúde Publica da USP, pela revisão bibliográfica,

Às Alunas Áurea e Sirleimara, bolsistas do projeto, na colaboração da coleta de dados,

À todas as mães e crianças que participaram deste trabalho,

À CAPES (Cordenadoria de Aperfeiçoamento de Pessoal de Ensino Superior), pela bolsa de estudos recebida durante o período de desenvolvimento deste.

À FAPESP (Fundação de Amparo a Pesquisa do Estado de São Paulo), pelo auxílio parcial ao desenvolvimento do projeto. 


\section{Resumo}

Objetivo: A importância do estudo do baixo peso ao nascer como indicador de saúde vem sendo enfatizada, não só para o estabelecimento de comparações, como para encontrar uma explicação das causas, como base para uma ação preventiva. Neste sentido realizou-se este estudo com o objetivo de verificar a influência de fatores maternos na ocorrência do baixo peso ao nascer. Metodologia: A população amostral foi constituída por todas as mães biológicas e suas crianças menores de 1 ano de idade atendidas em 5 dias úteis nas 22 unidades de saúde do Município de Maringá, em 1998, perfazendo um total de 587. Considerou-se BPN (baixo peso ao nascer) todas as crianças com peso $<2500 \mathrm{~g}$ (OMS). Para o diagnóstico da anemia, utilizou-se a dosagem bioquímica da concentração de hemoglobina pelo método colorimétrico direto, HemoCue, sendo consideradas anêmicas toda a criança com $[\mathrm{Hb}]<11,0 \mathrm{~g} / \mathrm{dL}$, e mães com $[\mathrm{Hb}]<11,9 \mathrm{~g} / \mathrm{dL}$. Resultados: Os fatores de risco para o BPN foram o ganho de peso na gestação $<=9 \mathrm{Kg}$, a idade da mãe menor de 20 anos e as mães que fumavam mais de 5 cigarros por dia. Da população total $14,8 \%$ das mães eram anêmicas e para as crianças este percentual foi de $58 \%$. A desnutrição crônica, identificada pelo índice altura para idade, se apresentou elevada especialmente para as crianças de 0 a 3 meses nascidas de baixo peso. As variáveis que apresentaram associação significativa com o BPN foram: o ganho de peso durante a gestação $(\mathrm{OR}=2,77, \mathrm{p}=0,0082)$, a idade da mãe $<20$ anos $(\mathrm{OR}=2,49$, $\mathrm{p}=0,0401)$, e o fumo para as mães que fumavam mais de 5 cigarros/dia $(\mathrm{OR}=$ $3,39, p=0,0333)$. Apresentaram baixo peso ao nascer $37(6,3 \%)$ crianças e a anemia foi mais prevalente entre elas; igualmente foi maior a prevalência de anemia no segundo semestre de vida $(p=0,0093)$. Conclusões: Embora o índice de BPN na população estudada apresente um percentual semelhante ao de países desenvolvidos, sugere-se a implementação de um serviço de pré-natal para as mulheres de risco visando a redução deste evento que afeta a criança, dificultando o seu crescimento e aumentando o risco de anemia e suas inúmeras consequências deletérias.

Descritores: baixo peso ao nascer, peso insuficiente, hemoglobina, anemia, crescimento, desnutrição. 


\section{ABSTRACT}

Objective: The importance of studying low birthweight as a health indicator has been emphasized, not only to establish comparisons, but also to find explanation for the causes, as basis for a preventive action. For that, a study was carried out with the purpose of verifying the influence of maternal factors in the occurrence of low birthweight. Methology: The sample comprised all biological mothers and their children under 1 year of age assisted for 5 days at 22 health units of Maringá municipality, in 1998. The total of mothers was of 587. It was considered LBW (low birthweight) all children with a weight $<2500 \mathrm{~g}$ (WHO), For the anemia diagnosis, the biochemical dosage of hemoglobin concentration by HemoCue method was used, being considereds anemics all children with $[\mathrm{Hb}]<11.0 \mathrm{~g} / \mathrm{dL}$, and mothers with $[\mathrm{Hb}]$ $<11,9 \mathrm{~g} / \mathrm{dL}$. Results: Risk factors for LBW were weight gain during pregnancy $<=9$ $\mathrm{kg}$, age of a mother under 20 , and mothers who smoked more than 5 cigarettes/day. From the total sample $14.8 \%$ of mothers and $58 \%$ of the children were anemic. The cronic malnutrition, the heigth rate for age was presented high for the children of 0 to 3 months old. The variables that presented significant association with low birthweight were: weight gain during pregnancy $(\mathrm{OR}=2.77, \mathrm{p}=0.0082)$, mother's age $<20(\mathrm{OR}=2.49, \mathrm{p}=0.0401)$, and smoking for the mothers who smoked more than 5 cigarettes/day $(O R=3.39, p=0.0333)$. From the total, 37(6.3\%) presented low birthweight, being the anemia more prevalent in the second semester of life $(p=0.0093)$. Conclusions: Although the LBW rate in the studied group presents a percentage similar to the developed countries, it is necessary to implement a prenatal service for women at risk, aiming at reducing the rate which affects the children, making it difficult the development of their full potential growing and rising the risk for anemia and many deletery consequences.

Key words: low birthweight, inadequate weight, hemoglobin, anemia, growth, malnutrition. 


\section{Índice}

1 -INTRODUÇ̃̃O

2 - OBJETIVOS.

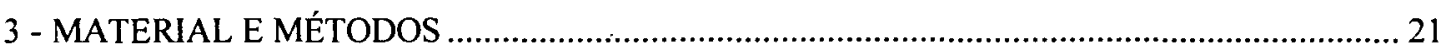

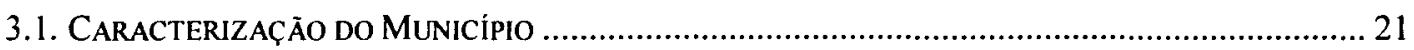

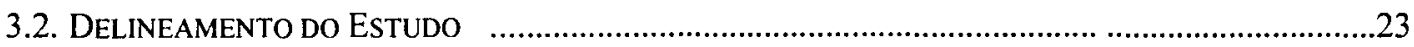

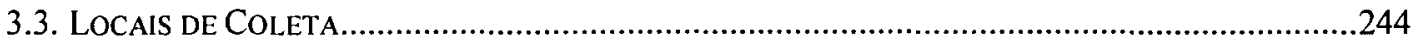

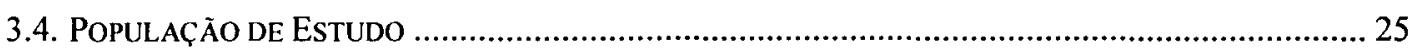

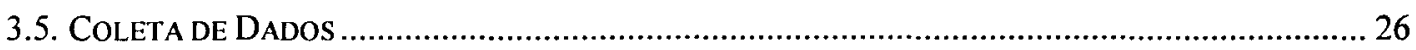

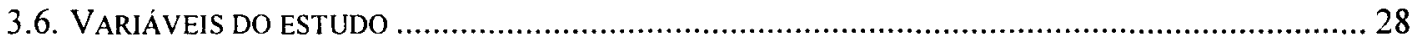

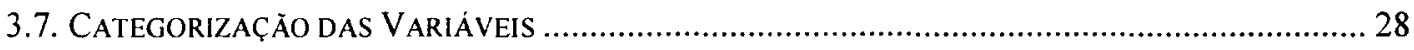

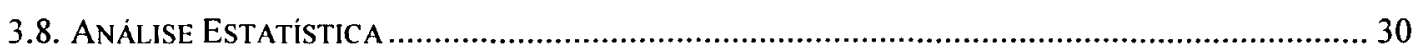

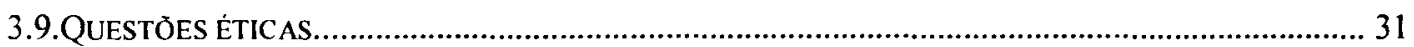

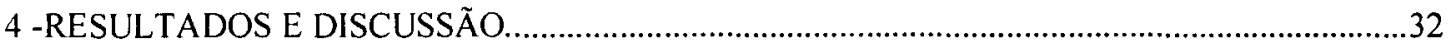

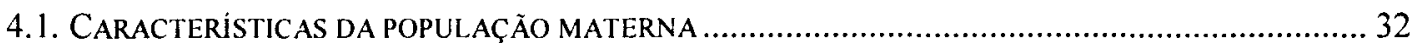

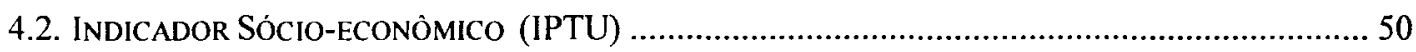

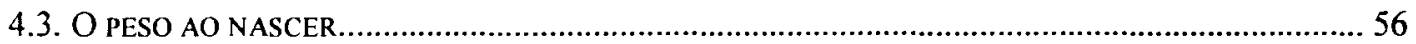

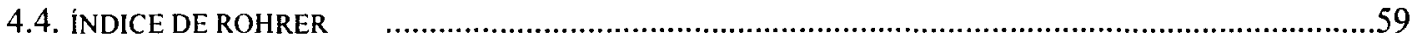

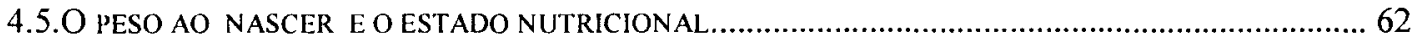

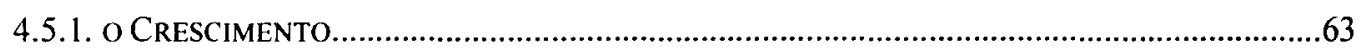

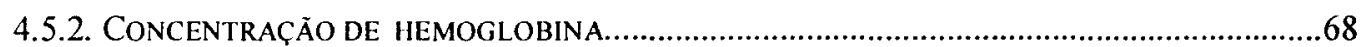

5 -CONCLUSÕES

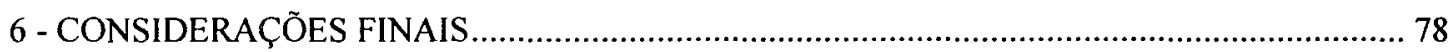

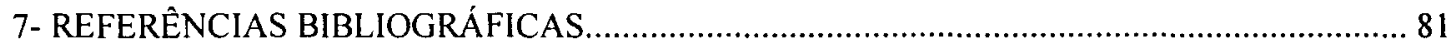

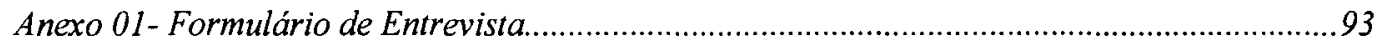

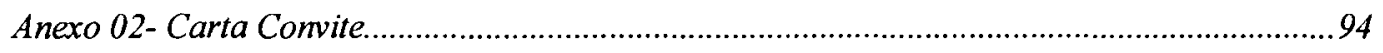

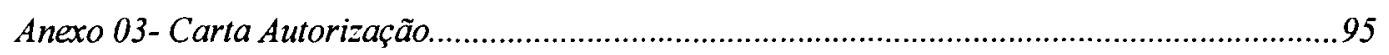

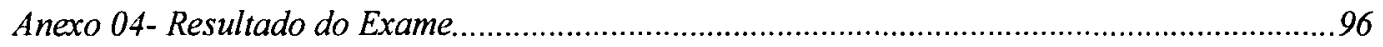

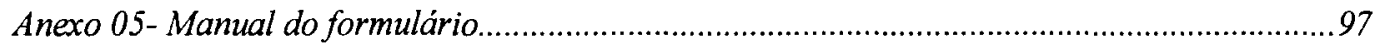

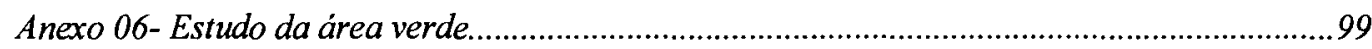

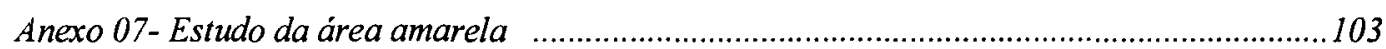

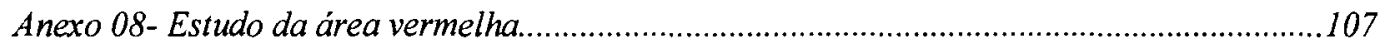




\section{Lista das Tabelas, Quadro e Figuras}

Tabela 1- Coeficiente de Mortalidade Infantil (1000 nascidos vivos) e indice de baixo peso ao nascer segundo os países e regiões .

Tabela 2- Coeficiente de Mortalidade Infantil (1000 nascidos vivos), segundo as regiões do Brasil, segundo sexo.1990.

Tabela 3 - Taxa de crescimento populacional anual de Maringá segundo período.

Tabela 4 - Distribuição \% da população urbana e rural de Maringá por ano. MaringáPR, 1998 .

Tabela 5 - $\mathrm{N}^{\circ}$ e $\%$ de atendimento do mês de julho de crianças menores de 1 ano da rede básica de saúde, segundo áreas do IPTU. Maringá-PR, 1997.

Tabela 6 - Mediana, média, desvio padrão, valores mínimos e máximos para as variáveis relacionadas à fatores maternos. Maringá-PR,1998.

Tabela 7 - Distribuição do $\mathrm{n}^{\circ} \mathrm{e} \%$ de mães, segundo as variáveis independentes e a categoria de peso ao nascer (g). Maringá-PR, 1998.

Tabela 8 - Análise multivariada dos fatores de risco do baixo peso ao nascer. Maringá-PR,1998.

Tabela 9 - Distribuição do $\mathrm{n}^{\circ}$ de crianças, segundo o peso ao nascer, o peso prégetacional e o ganho de peso. Maringá-PR,1998.

Tabela 10 - Análise das medianas, médias e desvio padrão das variáveis maternas entre as três áreas. Maringá-PR, 1998.

Tabela 11 - Distribuição do $n^{0}$ e \% de mães, segundo as áreas e as variáveis independentes. Maringá-PR, 1998.

Tabela 12 - Distribuição do ganho diário de peso, segundo a idade e categoria de peso ao nascer (g). Maringá-PR, 1998.

Tabela 13 - Distribuição do ${ }^{\circ}$ e \% de crianças segundo o sexo e o Índice de Rohrer. Maringá-PR, 1998.

Tabela 14 - Distribuição do $n^{\circ}$ e \% de crianças BPN segundo o sexo e o Índice de Rohrer. Maringá-PR,1998.

Tabela 15 - Distribuição do $n^{\circ}$ e $\%$ de crianças de peso insuficiente, segundo o sexo e o Índice de Rohrer. Maringá-PR,1998. 
Tabela 16 - Distribuição do $n^{\circ}$ e \% de crianças de peso adequado, segundo o sexo e o Índice de Rohrer. Maringá-PR, 1998.

Tabela 17 - Distribuição do $\mathrm{n}^{\circ} \mathrm{e} \%$ de crianças segundo o Índice de Rohrer e o peso ao nascer. Maringá-PR,1998.

Tabela 18 -Prevalência da desnutrição segundo o índice nutricional e a idade atual da criança. Maringá-PR, 1998.

Tabela 19 - Prevalência da desnutrição segundo os grupo de peso ao nascer e o índice nutricional. Maringá-PR,1998.

Tabela 20 - Prevalência da desnutrição segundo os grupos de peso ao nascer e índice nutricional atual. Maringá-PR, 1998.

Tabela 21-Distribuição do $n^{\circ}$ e \% de mães segundo o peso ao nascer da criança e a concentração de hemoglobina da mãe. Maringá-PR,1998.

Tabela 22 - Prevalência de Anemia segundo a idade. Maringá-PR,1998.

Tabela 23 -Mediana, média e desvio padrão das variáveis da Área Verde segundo o peso ao nascer. Maringá-PR,1998.

Tabela 24 - Distribuição do $n^{\circ}$ e \% de mães, segundo a área Verde e o peso ao nascer. Maringá-PR, 1998

Tabela 25 - Mediana, média e desvio padrão das variáveis da Área Amarela segundo o peso ao nascer. Maringá-PR,1998.

Tabela 26- Distribuição do $n^{\circ}$ e \% de mães, segundo a Área Amarela e o peso ao nascer. Maringá-PR, 1998.

Tabela 27 - Mediana, média e desvio padrão das variáveis da Área Vermelha segundo o peso ao nascer. Maringá-PR,1998.

Tabela 28-Distribuição do $n^{\circ}$ e \% de mães, segundo a Área Vermelha e o peso ao nascer. Maringá-PR,1998.

Quadro 1 - Descrição das Variáveis de Estudo

Figu ra 1 - Pirâmides Etárias de Maringá, Paraná e Brasil, 1996

Figura 2 - Mapa de Divisão Geográfica do IPTUde Maringá-PR, 1998. 
Figura 3 - Distribuição \% de mães/pais segundo a escolaridade. Maringá-PR,1998

Figura 4 - Distribuição \% de mães segundo o início do pré-natal. Maringá-PR,1998.

Figura 5 - Distribuição \% de mães segundo o tipo de parto. Maringá-PR, 1998.

Figura 6 - Distribuição \% de mães segundo a área de atendimento e o peso ao nascer da criança. Maringá-PR,1998.

Figura 7 - Distribuição \% das crianças segundo o peso ao nascer e sexo. MaringáPR,1998.

Figura 8 - Distribuição do peso médio atual e peso médio atual das crianças BPN segundo idade em dias. Maringá-PR,1998.

Figura 9-Distribuição \% de crianças BPN segundo o índice escore-Z(Altura/Idade). Maringá-PR, 1998.

Figura 10 - Distribuição \% de crianças com peso insuficiente segundo o índice escore-Z(Altura/ldade). Maringá- 1998.

Figura 11 - Distribuição \% de crianças com peso adequado segundo o índice escoreZ(Altura/ldade). Maringá-PR,1998.

Figura 12 -Evolução (tendência) da $[\mathrm{Hb}]$ da criança e da $[\mathrm{Hb}]$ da mãe. MaringáPR, 1998.

Figura 13 - Distribuição da hemoglobina $(\mathrm{Hb} \mathrm{g} / \mathrm{dL}$ ) média e das crianças BPN segundo a idade. Maringá-PR,1998.

Figura 14 - Distribuição \% das médias de concentração de hemoglobina esperada e observada das crianças BPN segundo a idade. Maringá-PR,1998.

Figura 15 - Distribuição \% das médias de concentração de hemoglobina esperada e observada das crianças com peso insuficiente segundo a idade. Maringá-PR,1998.

Figura 16 - Distribuição \% das médias de concentração de hemoglobina esperada e observada das crianças com peso adequado segundo a idade. Maringá-PR,1998.

Figura 17 - Distribuição \% de crianças da Área Verde segundo peso ao nascer e posto de saúde. Maringá-PR,1998

Figura 18 - Distribuição \% de crianças das Área Amarela segundo peso ao nascer e posto de saúde. Maringá-PR,1998.

Figura 19 - Distribuição \% de crianças da Área Vermelha segundo peso ao nascer e posto de saúde. Maringá-PR,1998. 


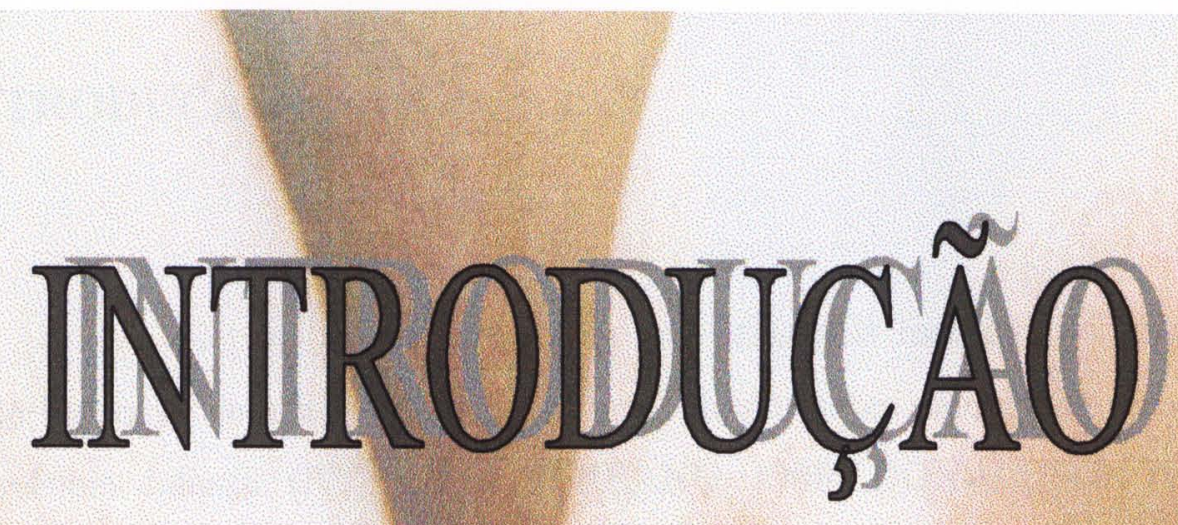




\section{1 - INTRODUÇÃO}

O peso ao nascer é uma das principais medidas do crescimento intra-uterino e se constitui em um dos mais importantes fatores de predição da sobrevivência infantil (PUFFER e SERRANO 1988; DONALDSON 1984). A condição de peso ao nascer é considerada como sendo um dos principais fatores a determinar a probabilidade de sobreviver ao período neonatal e mesmo a todo restante do primeiro ano de vida (BENÍCIO e col. 1985). A relevância do baixo peso ao nascer - BPN (<2.500 gramas) é decorrente da elevada proporção de recémnascidos com esta condição que morrem no periodo neonatal (McCORMICK 1985; MATA 1978). Em países não desenvolvidos, estudos longitudinais demonstram que o peso ao nascer desempenha o papel mais importante na mortalidade infantil, dado que no mundo em desenvolvimento, $10 \%$ a $15 \%$ das crianças nascidas BPN totalizam 30 a $40 \%$ de todos os óbitos durante o primeiro ano de vida. Em outras palavras, os bebês BPN são aproximadamente três vezes mais propensos a morrer antes de um ano do que aqueles nascidos com peso adequado (UNICEF 1984).

O baixo peso ao nascer é o maior problema de saúde pública em crianças nos Estados Unidos, contribuindo substancialmente para a morbimortalidade infantil e as repercussões no desenvolvimento neurológico e intelectual da criança(OMS 1980; BELIZAN 1989). O principal determinante do baixo peso ao nascer é o nascimento pré-termo, sendo este, mais freqüente nos Estados Unidos do que em outros países industrializados, e é o fator responsável mais importante para a alta taxa de mortalidade infantil (PANETH 1995). Sabe-se, contudo, que a prevalência dos componentes de BPN é variável de país para país e de região para região, mas que existe uma tendência ao aumento de retardo de crescimento intrauterino (RCIU) com o aumento de BPN. Portanto, em países não desenvolvidos existe uma maior proporção de crianças com BPN. 
A associação entre a taxa de mortalidade infantil e o baixo peso ao nascer se observa em todo o mundo (Tabela 1). Nos países industrializados estes percentuais são mais reduzidos comparados aos países em desenvolvimento devido à situação sócio-econômica e ambiental, que influencia a condição de saúde da população e conseqüentemente o nascimento.

Tabela 1 - Coeficiente de Mortalidade Infantil (1000 nascidos vivos) e índices de baixo peso ao nascer segundo os países e regiões.

\begin{tabular}{lll}
\hline Países / região & CMI $\left({ }^{\circ} /\right.$ oo nv $)-1993$ & BPN $(\%)-1990$ \\
\hline Bangladesh & 94 & 50 \\
India & 81 & 33 \\
Brasil & 52 & 11 \\
Japão & 5 & 6 \\
Suécia & 5 & 5 \\
Finlândia & 4 & 4 \\
Paraná & $24^{*}$ & $7^{*}$ \\
Maringá & $12^{* *}$ & $7^{* * *}$
\end{tabular}

Fonte: UNICEF/95

* CEPI/ 96 - Centro de Epidemiologia do Paraná/Instituto de Saúde-Curitiba

** SIM/ 96 - Sistema de Informação de Mortalidade - SESA - Maringá

***SINASC/97-Seção de Epidemiologia da Secretaria de Saúde de Maringá (Dados preliminares)

O valor do coeficiente de mortalidade do Brasil tem uma distribuição heterogênea fortemente influenciada pelos coeficientes das regiões Norte e Nordeste ( Tabela 2). A região Sul é aquela com o menor percentual, associando para esta região uma melhor condição de vida, maior disponibilidade de serviços de saúde e maior conscientização da população no que se refere à saúde. 
Tabela 2 - Coeficiente de Mortalidade Infantil (/1000 nascidos vivos), em as regiões do Brasil, segundo o sexo, 1990

\begin{tabular}{llll}
\hline Regiões & Total & Masc & Fem \\
\hline Norte & 53,20 & 60,30 & 45,90 \\
Nordeste & 88,20 & 95,60 & 80,60 \\
Sudeste & 30,0 & 37,0 & 22,80 \\
Sul & 26,70 & 33,60 & 19,60 \\
Centro-oeste & 33,0 & 40,0 & 25,60 \\
\hline
\end{tabular}

Fonte: Fundação IBGE -Anuário estatístico do Brasil/ Indicadores Demográficos, Rio de Janeiro. 1998.

A mortalidade infantil é, tradicionalmente, dividida em dois componentes - a mortalidade neonatal (óbitos ocorridos nos primeiros 27 dias) e mortalidade pós-neonatal (óbitos ocorridos dos 28 aos 364 dias de vida). Em pesquisa realizada em Pelotas foi verificada que de $8,8 \%$ de crianças nascidas com baixo peso $53 \%$ foram a óbito. Para todas as causas juntas, as crianças de baixo peso ao nascer apresentaram um risco de morte neonatal 23,9 vezes maior do que as nascidas com peso adequado, enquanto que para a morte pós-natal o risco foi de 4,3 vezes (VICTORA e col. 1989).

PUFFER e SERRANO (1973), na pesquisa Interamericana de Mortalidade na Infância, verificaram proporção elevada de óbitos de crianças de baixo peso ao nascer e enfatizaram que a mortalidade neonatal depende da frequência de nascimento de baixo peso. MONTEIRO (1981) estimou que $60,9 \%$ das crianças que morreram antes de completar 28 dias, haviam nascido com peso igual ou inferior a $2500 \mathrm{~g}$.

$O$ peso ao nascer tem sido reconhecido como um sensível indicador de saúde perinatal e é determinado pela idade gestacional e o estado de crescimento do feto (RUSH e col. 1972). As crianças BPN não formam um grupo homogêneo, pois incluem aquelas que nasceram prematuras e as que nasceram desnutridas, ou seja, com baixo peso para a idade gestacional ou retardo de crescimento intrauterino 
- RCIU (TANNER 1978), ou um terceiro tipo de criança que se contitui em uma combinação dos dois grupos anteriores, ou seja, RCIU e prematuridade.

Ainda TANNER (1978) refere que a desnutrição fetal pode ser o resultado de um problema ocorrido durante a gravidez e o efeito final depende da magnitude, da duração e do estágio de crescimento no qual este problema ocorreu. Assim, se a privação nutricional materna se estabelece prematuramente na gestação, quando o pico da velocidade de ganhar altura ocorre, o crescimento fetal linear pode estar comprometido .

Se o problema ocorre tardiamente na gestação, quando o pico da velocidade de peso ganho já foi alcançado, o acréscimo de peso pode ser limitado. $O$ recém-nascido com desnutrição gestacional tardia tem um adequado comprimento ao nascer, mas baixo peso para a altura, o que significa ter um baixo índice ponderal (BPI); por sua vez, o neonato com desnutrição gestacional precoce poderá ter um adequado peso para altura ou um adequado índice ponderal (API) (VILLAR e BELIZAN 1982).

Mortalidade precoce elevada é conseqüência muito clara de baixo peso ao nascer e a mortalidade neonatal aumenta nitidamente entre aqueles abaixo de $2.500 \mathrm{~g}$ de peso, mesmo quando nenhuma distinção acerca do tipo de baixo peso ao nascer é feita. Em estudos longitudinais foi observado que a mortalidade em crianças prematuras foi 2,5 vezes superior a de crianças com baixo peso para a idade gestacional, sugerindo que a prematuridade representa um risco maior de não sobrevida do que a desnutrição intra-uterina (VICTORA e col. 1989).

$O$ retardo de crescimento intra-uterino com baixo índice ponderal (RCIU-BPI) e retardo de crescimento intrauterino com adequado índice ponderal (RCIU-API) têm diferentes etiologias e diferentes intervenções são requeridas para seus controles. Este é um importante conceito no planejamento nutricional, porque cada tipo de BPN merece uma intervenção distinta. $\mathrm{O}$ impacto destas intervenções na 
população dependerá da relativa proporção de cada grupo. Os diversos grupos de baixo peso ao nascer têm, também, diferentes prognósticos em termos de sobrevida.

A Organização Mundial da Saúde (OMS-1993) classifica a duração da gestação em pré-termo (menos de 37 semanas completas), a termo (de 37 a 41 semanas) e pós-termo (42 ou mais semanas completas de gestação.). A Federação Internacional de Ginecologia e Obstetrícia (FIGO-1976) conceitua a prematuridade como a interrupção da gravidez antes de 37 semanas completas (259 dias completos). Com o apoio nesses conceitos define-se prematuro como toda a criança nascida viva com período de gestação inferior a 37 semanas completas

A utilização do peso do recém-nascido como indicador do crescimento fetal tem sido rejeitada, pois ele de "per si" não proporciona toda informação necessária a respeito do tamanho e do desenvolvimento potencial do recém-nascido. Assim indica-se o uso da adequação do peso do recém-nascido que envolve, além do peso a idade gestacional (OLIVEIRA 1996).

Atualmente define-se como BPN o recém-nascido com peso menor que 2500 g (OMS 1975; OMS 1993), muito baixo peso (MBP) para os recémnascidos com menos de $1500 \mathrm{~g}$ e como grupo de extremo baixo peso (EBP) os recém-nascidos com menos de $1000 \mathrm{~g}$ e o grupo de recém-nascidos imaturos para aqueles com menos de $750 \mathrm{~g}$.

Desta forma, para muitos autores o peso ao nascer permanece como um bom indicador para definir a assistência de saúde no parto, tão bem como o estado de saúde da mãe no parto ou durante a gestação e também o risco de mortalidade infantil.

Para PUFFER e SERRANO (1988) os recém-nascidos com peso insuficiente $(2500-2999 \mathrm{~g})$ também representam uma proporção considerável de nascidos vivos em alguns países. Neste grupo se encontram muitos com peso insuficiente para a estatura que são considerados como casos de retardo de 
crescimento intra-uterino. Ressalte-se que as crianças deste grupo são muitos vulneráveis à repercussão dos fatores ambientais e sociais e tem um grande risco de morbidade e mortalidade durante o primeiro ano de vida.

Peso ao nascer abaixo de $2500 \mathrm{~g}$ é um razoável ponto de corte para intituir a vigilância e ou referenciar para a detecção e tratamento de complicações precoces de nascimento pré-termo ou RCIU, no entanto, a interação de dois ou mais índices tem sido sugerida proporcionando uma melhor qualidade da informação com a interpretação correta para a tomada de decisões mais precisas.

Segundo a OMS (1995) vários índices de proporcionalidade tem sido usados para relacionar diferentes dimensões do crescimento fetal, particularmente o retardo de crescimento fetal. O mais comumente usado para isto é o Índice Ponderal de Rohrer (IR) o qual é definido como o peso ao nascimento (em gramas) vezes cem, dividido pela estatura no nascimento ao cubo $(\mathrm{em} \mathrm{cm})$. Crianças com alto índice ponderal são relativamente pesadas para a estatura (ou relativamente pequenas para o peso). Aquelas com baixo índice ponderal são magras, ou com baixo peso para a estatura.

Segundo ROSSO e col. (1974) crianças com índice baixo $(<2,51)$ são classificadas como desproporcionadas e com índice normal $(>=2,51)$ como proporcionadas. O IR tem sido utilizado na determinação do tipo de desnutrição que o neonato sofreu no periodo de sua vida intrauterina e a sua relação com a mortalidade neonatal (ARENO 1984).

Desde que a proporção corporal muda durante o curso da gestação, proporcionalidade para o tamanho pode prover um melhor indice que a proporcionalidade para a idade para avaliar o quanto o crescimento, após o início de alguma influência negativa, foi inibido, comparado com o crescimento das crianças que continuam a crescer normalmente. 
A proporcionalidade corporal ao nascimento pode colher informação acerca do momento do retardo de crescimento tão bem quanto o estado nutricional do recém-nato. Estudos recentes indicam que a proporcionalidade entre RCIU é fortemente confundida pela gravidade do retardo de crescimento ou déficit no estado nutricional, e que crianças desproporcionais tendem a apresentar mais gravidade no retardo de crescimento que as outras crianças proporcionais.

No estudo de PETERSEN e col. (1992) utilizando-se três medidas para monitorar o padrão de crescimento fetal de 71 crianças pequenas para a idade gestacional (muitas com adequado índice ponderal) dado o peso de nascimento e a idade gestacional do $\mathrm{RN}$, verificou-se que a proporcionalidade corporal não contribue muito para melhorar a avaliação da taxa de crescimento fetal. Por outro lado, outros estudos de diferentes populações apoiam a independente associação entre indicadores de proporcionalidade corporal ao nascimento e um importante número de resultados de saúde neonatal e infantil.

CONLISK (1993) estudou o risco de mortalidade neonatal, proporcionalidade e desproporcionalidade em crianças e os resultados mostraram que o efeito do peso ao nascer na mortalidade foi significativamente maior para as crianças desproporcionadas comparada às crianças proporcionadas.

Índices de proporcionalidade podem provar ser bem úteis para predizer os resultados das gestações em bebês pequenos para a idade gestacional, particularmente onde não existe informação confiável da idade gestacional.

Assim, um importante campo de ação para a Saúde Pública, a assistência adequada às gestantes, se apresenta como prioritário, em todas as sociedades.

A assistência pré-natal é uma das mais comuns atividades da Saúde Pública na medicina moderna. Seus principais objetivos são o de identificar mulheres de risco que possam apresentar resultados adversos na gestação, prevenir 
complicações, prover tratamento para condições patológicas correntes e promover educação para saúde às mães. Muitos efeitos benéficos na saúde materna e perinatal têm sido atribuídos à assistência pré-natal, mas muitas destas afirmações não têm sido comprovadas.

Os recentes declínios da mortalidade da criança com muito baixo peso ao nascer e/ou pré-termo são atribuídos à alta qualidade das intervenções na assistência pré-natal e não somente ao uso de programas de promoção da assistência pré-natal. Entretanto, a análise de custo-benefício parece ter favorecido a prevenção primária como uma desejável opção para alcançar o objetivo de reduzir a mortalidade infantil. Assim, a assistência pré-natal pode atuar de forma a promover um impacto benéfico na evolução da gestação e a preparar a mulher para o período pós-natal.

O estudo desenvolvido por BARROS e col. (1996) revelou que o nível de adequação quantitativa da assistência pré-natal, medido pelo Indice de Kessner (KESSNER ${ }^{1}$, 1973; SHOWSTACK e col. 1984) apresentou uma associação independente com os resultados adversos da gestação avaliado ou com a ocorrência do nascimento pré-termo ou com baixo peso ao nascer, mostrando afetar, principalmente, duas dimensões do desenvolvimento pré-natal e prognóstico: o tempo de gestação e o peso ao nascer.

Para entender a etiologia dessas condições e desenhar prevenções estratégicas, os fatores que retardam o crescimento necessitam ser distinguidos daqueles que precipitam o parto.

Sabe-se, contudo, que sem a assistência pré-natal, não ocorre nem a identificação, nem a intervenção indispensáveis para prevenir resultados adversos (KRAMER 1987). A assistência pré-natal pode promover comportamentos maternos saudáveis e, também, prover um grande efeito no crescimento intrauterino e na

\footnotetext{
${ }^{1}$ Este índice mede a Adequação da Assistência pré-natal de acordo com a idade gestacional e o número de consultas de pré-natal..
} 
duração da gestação, seja pelo precoce diagnóstico e adequado tratamento das complicações da gravidez, seja pela eliminação dos fatores de risco.

Alguns estudos mostram uma pequena relação entre a utilização da assistência pré-natal, nominalmente expressa pela regulação do tempo e número de visitas e diminuição das taxas de baixo peso ao nascer (KORENBROT 1994; CORIA-SOTO e col 1996). BARROS e col. (1996), embora tenham verificado uma associação independente entre a assistência pré-natal e o baixo peso ao nascer, mostram que um razoável aumento na quantidade das consultas de pré-natal possa ser insuficiente para reduzir substancialmente as taxas de baixo peso ao nascer.

SHOWSTACK e col. (1984) utilizaram o Indice de Kessner modificado definindo que a assistência adequada deve ser iniciada no $1^{\circ}$ trimestre e ter um número suficiente de visitas no pré-natal para um específico tempo de gestação. Nesta classificação a qualidade da assistência não é mensurada. Observaram ainda que as crianças de mães negras com assistência pré-natal adequada apresentaram uma média de $200 \mathrm{~g}$ a mais no peso ao nascer do que as crianças de mães brancas com intermediária ou inadequada assistência.

CORIA-SOTO e col. (1996) observaram que mulheres com um número inadequado de visitas para a idade gestacional tinham um odds ratio $(\mathrm{OR})=$ 1,63 para retardo de crescimento e $\mathrm{OR}=1,51$ para prematuros quando comparadas às mulheres com adequado número de visitas. Mulheres com conteúdo inadequado de procedimentos na assistência apresentaram $\mathrm{OR}=1,76$ para pré-termo.

KESSNER e col. (1973) estudando os efeitos da assistência a saúde na mortalidade infantil pelos risco social e médico de alta mortalidade, verificaram que, dentro de qualquer grupo de risco, a mortalidade variava inversamente com a quantidade da assistência recebida.

Muitos acreditam que a redução da taxa de mortalidade neonatal é atribuída à melhoria da assistência aos recém-nascidos, o que, na maioria das vezes, 
envolve medidas de alto custo tanto em termos financeiros quanto com relação a pessoal habilitado. No entanto, a assistência pré-natal permanece como um essencial instrumento para a prevenção primária do baixo peso ao nascer ou do nascimento pré-termo (KRAMER 1987). Uma comparação de estratégias para reduzir a mortalidade nos Estados Unidos mostrou que o início precoce da assistência prénatal foi o mais efetivo caminho para prevenir as mortes neonatais (JOYCE 1988). O estudo dos nascidos no Missouri Medicaid em 1988 (SCHRAMM 1992) acrescenta que a adequada assistência pré-natal apresenta um custo muito baixo para um amplo benefício.

Assim, observa-se que a assistência pré-natal situa-se como uma das mais importantes atividades da saúde pública, pois permite a identificação de fatores de risco para o binômio mãe-filho e a interação para seus controles.

Estimativas elevadas de risco são encontradas na ausência de prénatal (BROSS e SHAPIRO 1982). BARROS e col. (1996) verificaram que na população com livre acesso à assistência pré-natal, a adequação quantitativa teve um efeito independente no resultado da gestação, se avaliado através da ocorrência de nascimentos pré-termos ou crianças com baixo peso ao nascer.

Para BROWN e col. (1996) mulheres negras, sem assistência prénatal tinham maior probabilidade para gerar filhos BPN. A incidência de baixo peso ao nascer foi de $13,1 \%$ e para as mulheres não participantes do programa foi de $10,2 \%$ comparadas àquelas com assistência $(p<0,05)$, o que foi confirmado em análise univariada. $\mathrm{O}$ risco de BPN foi menor entre mulheres que freqüentaram o serviço de pré-natal $(\mathrm{OR}=0,75, \mathrm{p}<0,05)$. $\mathrm{Na}$ análise multivariada, entretanto, ela não foi significativa indicando que o efeito pode estar sendo explicado pela raça, tempo de entrada no pré-natal e fumo.

Um grande número de fatores atuam antes e durante a gestação e exercem influência no peso ao nascer do neonato. Entre estes fatores situam-se as características biodemográficas da mulher como a idade, paridade, condição 
marital, intervalo interpartal, estado de saúde, as infecções e/ou doenças crônicas, fatores comportamentais como tabagismo, consumo de cafeína e exercícios vigorosos durante a gestação. As variáveis sócio-econômicas como a instrução materna e renda familiar ou ocupação do chefe da familia, dependendo da situação, têm uma forte e negativa influência no peso ao nascer (MARTORELL e GONZALEZ-COSSIO 1987).

Outro indicador bastante importante para a deteç̧ão do risco gravídico é a idade da mãe (LIPPI e col. 1989; BARROS e col. 1987; BENÍCIO e col. 1985), pois as mães adolescentes não apresentam ainda uma formação orgânica adequada para permitir a nutrição adequada da criança. Por estar em fase de crescimento ou adequação corpórea pressupõe-se que não tenham um suporte nutricional adequado para uma gestação, acarretando danos nos resultados gestacionais com nascimentos prematuros ou crianças BPN.

WESSEL e col. (1996) observaram 353 mulheres em um estudo de coorte durante o período de 1 ano e verificaram que a prevalência de BPN foi de $8 \%$. O BPN foi significativamente associado com a idade materna menor ou igual a 19 anos (risco relativo $=3,7$ ), com a nuliparidade (risco relativo $=5,2$ ) e história obstétrica de antecedente BPN (risco relativo $=6,5$ ). Verificaram também que o risco de nascimentos pré-termo aumentava consideravelmente quando a mulher apresentava uma história de hipertensão ou convulsão (risco relativo $=2,6$ ).

NOBREGA e col. (1991) ressaltam que a idade materna é um fator importante na determinação da condição nutricional materna porque engloba uma série de aspectos adversos que vão se acumulando à medida em que a mãe apresenta mais idade e/ou maior número de gestações. Concordando, RODRIGUES e col. (1995) referem que a idade materna influencia no BPN com uma maior incidência para as mães com idade menor ou igual a 19 anos e mães com idade acima de 35 anos. 
O estado nutricional materno durante a gestação é de importância fundamental no peso ao nascer da criança, já que as boas condições do ambiente uterino favorecerão o desenvolvimento fetal adequado.

Sabe-se que a desnutrição materna durante a gestação, principalmente no $3^{\circ}$ trimestre, é comum nas populações de baixa renda e se reflete no deficiente ganho de peso na gestação, com crianças pré-termo e crianças a termo de baixo peso ao nascer. Esta desnutrição se apresenta de forma mais grave em gestantes adolescentes, com baixo peso pré-gestacional, pequeno intervalo intergestacional e outros fatores (FERREIRA 1982; LEADER e col. 1981).

Em estudo com gestantes atendidas em maternidades, SINISTERRA e col. (1991) observaram no Município de São Paulo, 23,6\% de baixo peso ao nascer entre filhos de parturientes desnutridas, valor significativamente diferente dos $10,8 \%$ encontrados em mulheres eutróficas no final da gestação.

A estatura materna é também conhecida por afetar o crescimento fetal independentemente do peso para altura, porque a altura da mãe pode ser particularmente determinada por seu estado nutricional durante a infância, especialmente em países em desenvolvimento. Isto pode ser justificado no tamanho uterino, fluxo sanguíneo placentário e conseqüente liberação de nutrientes placentários; desta forma a estatura materna pode também ser considerada, em parte, como um determinante nutricional. BARROS e col. (1987) verificaram que as mães com altura menor de $1,50 \mathrm{~m}$ apresentavam uma incidência de $12,7 \%$ de BPN e aquelas que mediam $1,65 \mathrm{~m}$ e mais, $3,7 \%$.

A estatura da mulher gestante tem sido reconhecida como um importante fator no resultado gestacional, estando associada com o crescimento intrauterino e a idade gestacional, e que é o melhor indicador do seu estado nutricional prévio e seu efeito independente no peso no início da gestação e do peso ganho durante este mesmo período (HITTEN e col. 1980; HABICHT e col. 1973). 
Para LECHTIG (1976) altas prevalências de baixa estatura em uma população são indicativos de desnutrição durante períodos de crescimento e estas medidas devem ser usadas para identificar mulheres de risco para partos de crianças BPN. O ponto de corte usado para tais propostas dependerá da distribuição da altura materna e da prevalência da baixa estatura materna na população. Isto poderá estabelecer uma idéia que o efeito da estatura no peso ao nascer pode não ser superado pela intervenção durante a maioridade.

Em estudo retrospectivo CIARI Jr. e col. (1975) observaram, em um Centro de Saúde de São Paulo, que as gestantes normais de 38 a 39 semanas de gestação e estatura inferior a $1,50 \mathrm{~m}$ apresentaram um aumento do risco para BPN.O mesmo resultado foi observado por SIQUEIRA e col. (1975).

O baixo peso no início da gestação, controlado para a estatura, tem uma independente influência negativa tanto para o crescimento do feto quanto à idade gestacional no parto (EDWARDS e col. 1979; ANDERSON 1984; BENICIO e col. 1985). Mesmo quando adequado incremento de peso durante a gestação é observado, o efeito do baixo peso pré-gravídico está presente. Este conceito tem duas partes importantes: $1^{\circ}$ ) o peso maternal pré-gravídico, assim como a estatura, podem ser usados para identificar mulheres de risco para gestações de crianças BPN. Novamente, o ponto de corte dependerá da distribuição de peso na população e a prevalência de baixo peso pré-gravídico tão bem como da disponibilidade de recursos para a intervenção terapêutica; $2^{\circ}$ ) o baixo peso para altura, diferente da baixa estatura, é um tipo tratável de desnutrição de adulto, com um importante potencial para diminuir a incidência de BPN em populações malnutridas. Em estudo realizado por BARROS e col. (1987) em mulheres que pesavam menos de $49 \mathrm{Kg}$ no início da gestação, a incidência de baixo peso ao nascer foi de $11,6 \%$, enquanto que para as mulheres com $61 \mathrm{Kg}$ ou mais, a porcentagem foi 3 vezes menor.

CASTILHO e col. (1976) observaram associação estatisticamente significativa entre o peso ao nascer da criança, idade gestacional e peso médio da gestante no $3^{\circ}$ trimestre da gravidez. No estudo realizado em oito áreas do Vietnã, 
DINH e col. (1996) verificaram que a proporção de crianças com baixo peso ao nascer variou de $7,9 \%$ a $12,5 \%$ e que o Indice de Massa Corporal (IMC) das mães, a boa nutrição durante a gestação e a licença maternidade antes do parto foram negativamente associados com a ocorrência do baixo peso ao nascer; acrescente-se que esta associação foi verificada somente em mulheres da zona rural.

COPPER e col. (1995), estudando a relação entre mudança de comportamento da mãe para o ganho de peso durante a gestação e o baixo peso ao nascer verificaram que o peso corporal, medido pelo IMC, foi fortemente associado tanto com o peso ganho quanto com o peso ao nascer. Mulheres obesas apresentavam uma tendência a ter mudanças negativas com relação ao ganho de peso e tinham uma média de peso ganho de $10,2 \mathrm{Kg}$, mas tinham bebês pesados, e mulheres magras tinham mudanças positivas significativas com uma média alta de peso ganho durante a gestação $(14,1 \mathrm{Kg})$ comparadas às obesas. Uma grande proporção de mulheres magras alcançavam o peso recomendado quando comparadas às obesas, mas tinham bebês com média de $3.114 \mathrm{~g}$. Mudanças de comportamento maternas com referência ao peso ganho foram fortemente influenciadas pelo peso pré-gravídico, mulheres magras tendem a ter atitudes positivas com relação ao peso ganho, o mesmo não ocorrendo com as mulheres obesas.

$O$ risco de BPN modifica-se em função do tipo de evolução do estado nutricional durante a gestação. SINISTERRA e col. (1991), comparando diferentes evoluções do estado nutricional na gestação, observaram que, se a desnutrição estiver corrigida no final da gravidez, o risco de baixo peso diminui. Por outro lado, para aquelas que não se recuperaram, o risco relativo foi 2,8 vezes maior.

A instrução da mãe exerce influência na saúde da criança tanto de forma direta quanto indireta. A promoção de cuidados de higiene alimentação da criança é feita de forma mais adequada pela mãe com maior nível de escolaridade. BARROS e col. (1987) observaram que as mães que nunca estudaram tinham uma probabilidade de ter um filho BPN duas vezes maior do que aquelas que estudaram durante 9 anos ou mais. 
NOBREGA e col. (1991) observaram que a condição materna não é influenciada pelo seu nível de escolaridade, mas os diferentes níveis de escolaridade materna influenciaram a condição nutricional da criança, ou seja, quanto maior for o nível educacional da mãe, menor a proporção de crianças desnutridas. A desnutrição é comumente associada ao baixo nível educacional dos pais, embora esta não leve, necessariamente, ao estado nutricional deficiente (KHAN e GUPTA 1977). Muito mais que o nivel educacional materno, a cultura materna determina grande influência na alimentação e, conseqüentemente, no estado nutricional da criança.

COBAS e col. (1996) verificaram que a aculturação afeta de forma indireta a ocorrência do BPN através do fumo e da ingestão dietética, mas não através da paridade. BENER e col. (1996), ao estudar os fatores de risco sociodemográficos, observaram que a ocupação da mãe e local de residência estavam associados com o aumento de risco de baixo peso ao nascer.

Mulheres com antecedentes de filho BPN apresentam um risco aumentado de repetir o nascimento de crianças BPN; esta tendência foi verificada em um estudo longitudinal realizado em Missouri-Estados Unidos, por BAKEWELL e col. (1997), no período de 1978 - 90, com uma tendência de $21 \%$, $(\mathrm{OR}=10,1)$ para nascimentos que foram pré-termo e pequeno para a idade gestacional.

BRATTON e col. (1996) observaram que as mulheres cujo o primeiro filho foi muito baixo peso $(<1500 \mathrm{~g})$ apresentaram um risco relativo $(\mathrm{RR})$ $=11,5\left(\mathrm{IC}_{95 \%}=[5,4-24,4]\right)$ para gerar um filho $\mathrm{BPN}$ e risco aumentado de repetir o muito baixo peso no nascimento $(p<0,0001)$.

Sabe-se que as patologias maternas, como pré-eclâmpsia, eclâmpsia, cardiopatias e colagenoses, interferem no desenvolvimento fetal, levando ao nascimento de recém-nascidos com baixo peso, resultantes da desnutrição fetal e/ou prematuridade (TRINDADE e col. 1981). Os mecanismos que levam a esses 
distúrbios fetais não estão totalmente elucidados, mas, possivelmente, estariam relacionados com a diminuição de suprimentos para o feto em conseqüência de fluxo uterino-placentário diminuído decorrente dessas patologias.

Com relação ao comportamento materno, destaca-se o hábito bastante arraigado em nossa população de consumo de chás e café. $\mathrm{O}$ consumo de 3 ou mais xícaras de café $(>=300 \mathrm{mg}$ de cafeína) por dia pode resultar no aumento da incidência de BPN (NAROD e col. 1991). Confirmando, RONDO e col. (1996) verificaram que o consumo de café na gestação, independente da quantidade consumida, foi um fator de risco para o retardo de crescimento intra uterino.

Normalmente, durante a gestação, as mulheres diminuem o consumo de café e, portanto, consomem menos cafeína do que elas consumiam antes de se tornarem gestantes (WATKINSON e FRIED 1985). Chá, bebidas carbonatadas e alimentos contendo chocolate contribuem proporcionalmente para o total da ingestão de cafeína pela gestante. Tem sido estimado que 70 a $95 \%$ das gestantes consomem cafeína de várias fontes com uma média de ingestão de 99 a $185 \mathrm{mg}$ por dia, (MILLS e col. 1993; SRISUPHAN e col. 1986); 5,7\% a 29,7\% das gestantes são grandes consumidoras de cafeína ( $>=300 \mathrm{mg}$ dia) durante a gestação. $O$ consumo de cafeína em grande quantidade é mais freqüente em mulheres com poucos anos de instrução .

A taxa do metabolismo da cafeína em mulheres gestantes é 3 vezes mais baixa do que em mulheres não gestantes (KNUTTI e col. 1982), resultando em acúmulo na mãe e no feto. Os resultados do trabalho de revisão da literatura realizada por HINDS e col. (1996) sugerem que consumo de $300 \mathrm{mg}$ ou mais de cafeína por dia durante a gestação está associado com pequenas reduções no peso ao nascer que podem ser especialmente prejudiciais para a criança prematura ou baixo peso ao nascer. 
As principais fontes de cafeína são: café, chá e refrigerantes. Vários níveis de cafeína estão também presentes nas medicações tipo analgésicos, produtos alergênicos, dietéticos, estimulantes e agentes controladores de peso. Cada medicação tem diferentes doses, mas o uso crônico pode representar uma significante fonte de cafeina para a gestante que não consome bebidas cafeinadas. Por exemplo, o consumo de 2 comprimidos de um analgésico semi-potente a cada 6 horas por dia representa um consumo diário de $520 \mathrm{mg}$ de cafeína.

A cafeína e seus metabólitos são lentamente eliminados na urina materna. Durante o $2^{\circ}$ e o $3^{\circ}$ trimestres existe um decréscimo na eliminação da cafeína (ALDRIGE e col. 1981). A meia vida da cafeína na mulher gestante muda de 5,3 horas para 18,1 horas durante o $2^{\circ}$ e $3^{\circ}$ trimestre de gestação, o qual é atribuído para as trocas no plasma dos niveis de estrógeno e progesterona. A idade, doenças e hábitos pessoais tais como o fumo e longo tempo de uso de contraceptivos orais utilizados anteriormente a gestação, podem resultar em exposição prolongada materna e fetal para a cafeína e pode ser especialmente significativa para o feto durante o rápido crescimento no $3^{\circ}$ trimestre. Depois de poucas semanas após o nascimento o "clearence" materno da cafeína retorna para os níveis normais (SRISUPHAN e col. 1986).

O fumo é outro fator importante na determinação do peso ao nascer. Os efeitos deletérios do hábito de fumar sobre o evento perinatal já foram demonstrados por vários autores entre os quais LIPPI e col. (1989), BARROS e col. (1984) e SHULER, (1984). No estudo de LIPPI a associação se mostrou verdadeira, independente do número de cigarros fumados e, para BARROS, as taxas de BPN foram duas vezes maiores entre fumantes que as não fumantes.

Para HORTA e col. (1997) o controle do início do tabagismo é o maior desafio da saúde pública no mundo atual dado que ele pode fazer mais pela saúde do homem e sua expectativa de vida do que qualquer outra ação preventiva isolada. O tabagismo durante a gestação pode causar danos à criança principalmente 
no peso ao nascer. GOLDENBERG e col. (1996) observaram que o peso do feto aumenta de maneira semelhante até as últimas semanas de gestação, mas a partir da $34^{\circ}$ semana, aproximadamente, o aumento no peso dos fetos de mães fumantes é inexpressivo quando comparado com o de mães não fumantes e, portanto, quanto mais longa a duração da gestação, maior a diferença ponderal em prejuízo dos primeiros.

Para ROSEMBERG (1981) o efeito nocivo do cigarro sobre o feto é decorrente do nível de monóxido de carbono no sangue materno e, em consequência, na circulação da placenta e no feto, gerando a hipóxia. A diminuição de oxigênio e aumento de carboxihemoglobina, decorrente dos altos níveis de monóxido de carbono, prejudica o feto pela hipóxia, justificando a redução no crescimento do feto e consequentemente o baixo peso ao nascer.

PAPOZ e col. (1982) notaram que a ingestão calórica e o ganho de peso foram maiores em mulheres que fumaram durante toda a gravidez e mais baixos nas que não fumaram. $O$ aumento na ingestão alimentar de fumantes pode intervir ou minimizar os efeitos do fumo sobre o retardo do crescimento. RUSH (1974) e RUSSEL e col. (1968) verificaram que o ganho de peso e o tamanho do perímetro cefálico em bebês de mães não fumantes era significativamente maior que em bebês das mães fumantes. Este aumento de velocidade de crescimento cessou por volta de um ano, embora os bebês de fumantes ainda fossem menores que os de não fumantes.

Considerando a condição marital das mulheres, RODRIGUES e col. (1995) observaram tanto em pré-termos quanto em crianças a termo, que mulheres não casadas apresentavam probabilidades significativamente maiores de ter filhos BPN comparadas às casadas. Do mesmo modo observou uma forte associação para as mulheres que trabalhavam fora comparadas às donas de casa.

SZARFARC e col. (1980), em estudo realizado com duas populações de gestantes com diferentes oportunidades de assistência pré-natal, 
observaram que as características vitais como a idade materna, número de gestações, paridade e intervalo interpartal não podem ser usados como indicadores preditivos de risco, pois os pesos médios dos recém-nascidos nos dois grupos distribuídos segundo níveis de risco atribuiveis não foram estatisticamente diferentes. No entanto, o peso ao nascer foi significativamente maior entre as mulheres com atendimento pré-natal e sem riscos atribuíveis à idade materna, número de gestações e partos. O peso ao nascer de crianças cujas mães não guardaram o intervalo interpartal adequado, mas que frequentaram o pré-natal também foi maior.

CORIA-SOTO e col. (1996) observaram, também, que nascimentos pré-termo poderiam ser prevenidos se na assistência pré-natal fossem incluídos no mínimo medidas ou procedimentos de baixo custo e de fácil execução como os citados anteriormente. Deve ser ressaltado que também compete ao prénatal a orientação para os cuidados que devem ser dados à criança BPN, especialmente quando o risco deste evento tiver sido detectado de forma precoce. A respeito, UCHIMURA e col. (1997) observaram que as crianças nascidas com baixo peso apresentavam um risco maior de serem desnutridas que as crianças nascidas com peso adequado.

BENÍCIO (1983) confirmou, através de análise multivariada, a associação significativa com o peso ao nascer e a ausência da assistência pré-natal segundo a escolaridade materna. Verificou que o risco foi maior em mães com alta escolaridade e concluiu que a não freqüência destas mulheres ao serviço possa estar associada à rejeição da gravidez ou a outros comportamentos igualmente nocivos ao crescimento fetal.

Considerando o exposto e diante dos diferentes fatores que interferem na ocorrência do baixo peso ao nascer (BPN) e, principalmente, seu significado para a evolução do infante, o presente estudo teve por objetivo estimar alguns dos fatores preditivos para o baixo peso ao nascer entre a população atendida na rede básica de saúde de Maringá, PR e seu reflexo na criança. 


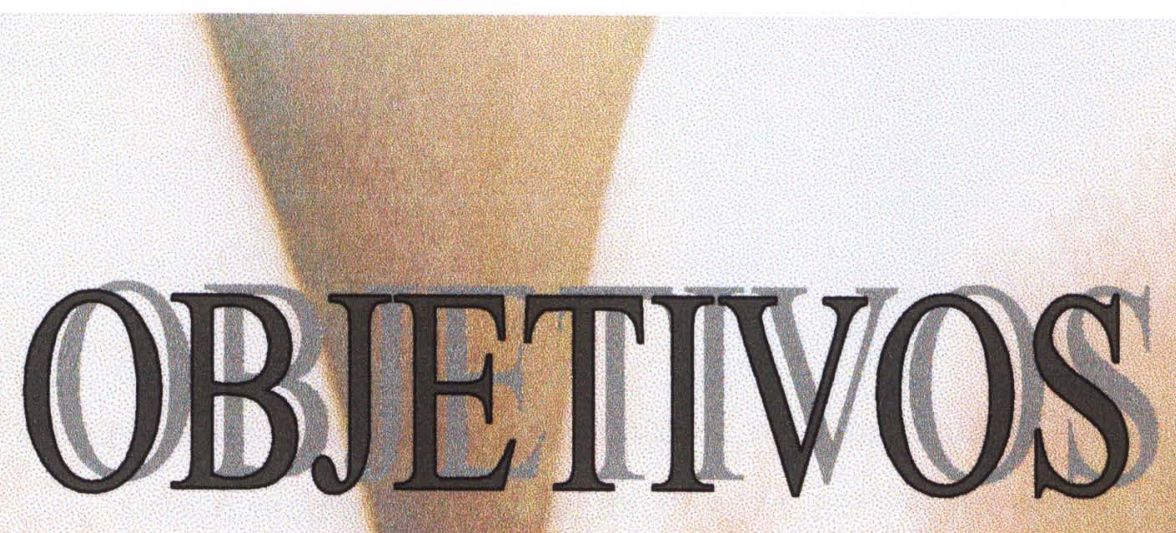




\section{2 -OBJETIVOS}

Geral : Verificar a influência de fatores maternos na ocorrência do baixo peso ao nascer, com vistas a propor medidas de intervenção para o seu controle, entre a população que freqüenta a rede básica de Saúde de Maringá, PR.

\section{Específicos :}

1 - Estudar a distribuição do peso ao nascer das crianças atendidas na rede básica de saúde;

2 - Caracterizar a distribuição do BPN e das variáveis maternas de acordo com o indicador sócio-econômico;

3 - Identificar os fatores de risco para o baixo peso ao nascer; 
MATERIIAISS E MÉTODOS 


\section{3 - MATERIAL E MÉTODOS}

Parte do projeto "Estudo de fatores maternos de risco para o baixo peso ao nascer" foi realizado concomitantemente com o projeto multicêntrico financiado pela FAPESP, "Aleitamento materno, dieta de desmame e anemia no primeiro ano de vida, em crianças atendidas na rede pública de saúde".

\subsection{Caracterização do Município}

O estudo foi realizado no município de Maringá, Estado do Paraná. A cidade tem uma altitude de 554 metros acima do mar, superficie de 509 quilômetros quadrados e está localizada no norte do Paraná a 434 quilômetros de Curitiba. Maringá teve um processo de crescimento populacional vertiginoso, no início da fundação em 1948, motivado pela implantação da cultura cafeeira em solo bastante propício para tal fim. Nas décadas posteriores, as taxas foram menores, todavia sempre positivas, ao contrário de muitos municípios da região que tiveram taxas negativas (Tabela 3 ).

Tabela 3 -Taxa de crescimento populacional anual segundo período. MaringáPR.

\begin{tabular}{lc}
\hline Período & Taxa de crescimento Anual (\%) \\
\hline $1951-1960$ & 10,44 \\
$1961-1970$ & 1,54 \\
$1971-1980$ & 3,31 \\
$1981-1991$ & 3,29 \\
\hline
\end{tabular}

Fonte: IBGE/91 - Maringá

De acordo com o INSTITUTO BRASILEIRO DE GEOGRAFIA E ESTATÍSTICA (IBGE - 1991), verifica-se uma taxa de crescimento populacional negativa para a população rural desde a década de 60 . Este fenômeno é justificado 
pela erradicação dos cafezais e pela implantação da mecanização agrícola, que expulsou o homem do campo. Em 1951, 18,84\% da população de Maringá estava localizada na zona urbana, e no censo de 1991 este percentual passou para 97,42\% (Tabela 4).

Tabela 4 - Distribuição (\%) da população urbana e rural por ano.Maringá-PR.

\begin{tabular}{lllc}
\hline Ano & Pop. Rural (\%) & Pop.Urbana (\%) & Pop. Total \\
\hline 1950 & 81,16 & 18,84 & 38.588 \\
1960 & 54,30 & 45,70 & 104.131 \\
1970 & 17,53 & 82,47 & 121.374 \\
1980 & 4,49 & 95,51 & 168.239 \\
1991 & 2,58 & 97,42 & 240.135 \\
1996 & 2,60 & 97,39 & 267.942 \\
\hline
\end{tabular}

Fonte: IBGE/96

O advento das sucessivas geadas, principalmente a de 1975, fez com que a cultura cafeeira da região fosse praticamente extinta, aliada à dificuldade na comercialização do café no exterior e ao esgotamento dos solos, provocando uma mudança radical no aproveitamento das áreas agrícolas do município, dando lugar ao surto agro-pastoril. Em 1980, com a reformulação das propriedades agrícolas do governo, observou-se a expansão do soja e do trigo com intensa incorporação de tecnologia moderna. Esta mudança provocou uma alteração no quadro agrícola local, onde, como conseqüência, a população rural foi forçada a migrar para a cidade que, por sua vez, não estava dotada de infraestrutura e não apresentava capacidade de absorver esse tipo de mão de obra não qualificada, o que veio a trazer problemas para o município. Com a evasão da população do meio rural, o município conta com $97,39 \%$ de população urbana e $2,60 \%$ de população residente na zona rural, diferenciando do Estado do Paraná com um índice de 77,87\% e 22,12\% de população urbana e rural, respectivamente (IBGE-1996). Maringá apresenta uma densidade demográfica de $545,81 \mathrm{hab} / \mathrm{Km}^{2}$ bastante superior a média do Estado do Paraná com $45,08 \mathrm{hab} / \mathrm{Km}^{2}$. 
No Município, o censo demográfico de 1996 apresentou uma população masculina correspondente a 129.394 habitantes e a feminina 138.548, significando uma razão de 93,39 homens para cada 100 mulheres. Observa-se uma população jovem, 36,5\% abaixo de 15 anos, diferente do Paraná e Brasil que apresentam mais de 40,0\% nesta faixa etária. Para Maringá esta diferença se encontra na faixa de 20-55 anos com um percentual de 56,9\% comparado com 51,3\% e 49,7\% para o Paraná e Brasil rescpectivamente, sugerindo uma melhor qualidade de vida para a população local. Para 60 e mais anos os percentuais não se diferenciam (Figura 1).

Segundo os dados do SINE- Sistema Nacional de Empregos de Maringá (1994), os setores econômicos mais importantes foram: comércio, a indústria de transformação e a construção civil, que perfazem $96,88 \%$ das admissões ocorridas no ano. Conforme os dados comparativos entre municípios do Paraná com mais de 50.000 habitantes em relação à renda individual de chefes de família (IBGE/91), Maringá possui o maior percentual na faixa de $3 \mathrm{SM}$ (salário mínimo) $=59,5 \%$ e menor percentual na faixa de $1 \mathrm{SM}=15,7 \%$, concluindo que o nível de renda dos chefes de família de Maringá é um dos mais elevados do Estado, superado apenas pelo da capital. O Estado do Paraná apresentou, no último censo, o quarto maior índice de chefe de família com rendimento superior a 20 salários mínimos $(1,91 \%)$ e um dos menores percentuais de chefes sem rendimento $(2,99 \%)$.

\subsection{Delineamento do Estudo}

Anteriormente ao início da coleta de dados foi realizado um estudo piloto no Hospital São Marcos de Maringá, visando estruturar o formulário e avaliar a incidência de BPN. Esta instituição havia apresentado o maior número de nascimentos no ano de $1996 \mathrm{com}$ um total de 1555 nascimentos. No período de uma semana observou-se que, do total de 45 partos, não houve nenhum nascimento com baixo peso, ainda que alguns fatores preditivos estivessem presentes. Acrescente-se que parte dos partos SUS são realizados em municípios próximos. A princípio, poder-se-ia pensar que o mês de coleta não fosse o ideal, mas, segundo SOUZA 
Figura 1 - Pirâmides Populacionais de Maringá, Paraná e Brasil - 1996.
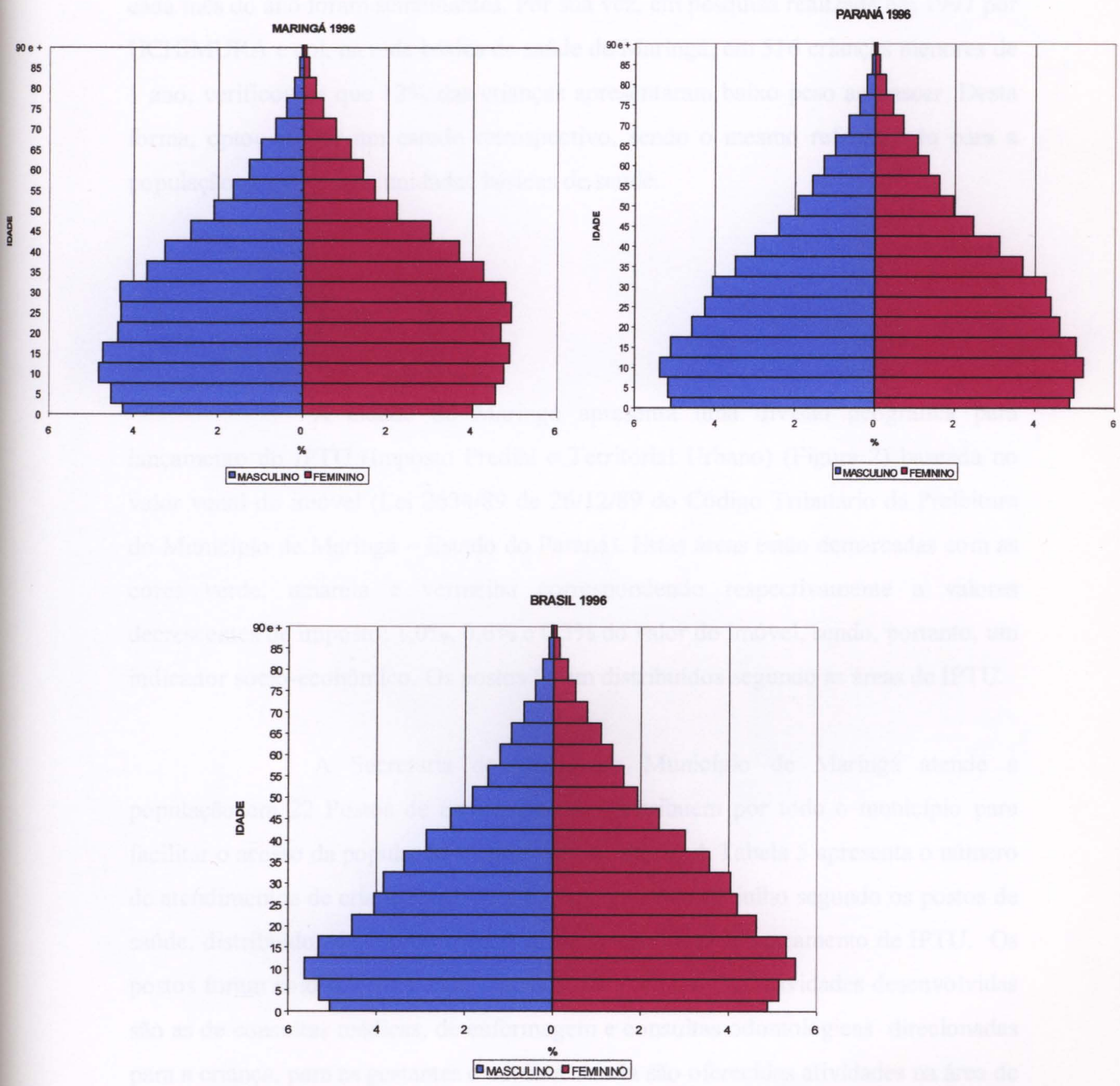

Fonte: IBGE: Anuário Estatístico / Contagem Populacional, Rio de Janeiro, 1996. 
(1989), os nascimentos hospitalares de Maringá distribuem-se de forma uniforme ao longo do ano, não havendo uma sazonalidade, pois, as proporções observadas para cada mês do ano foram semelhantes. Por sua vez, em pesquisa realizada em 1997 por UCHIMURA e col. na rede básica de saúde de Maringá, em 516 crianças menores de 1 ano, verificou-se que $12 \%$ das crianças apresentaram baixo peso ao nascer. Desta forma, optou-se por um estudo retrospectivo, sendo o mesmo referenciado para a população atendida nas unidades básicas de saúde.

\subsection{Locais de Coleta}

A cidade de Maringá apresenta uma divisão geográfica para lançamento do IPTU (Imposto Predial e Territorial Urbano) (Figura 2) baseada no valor venal do imóvel (Lei 2634/89 de 26/12/89 do Código Tributário da Prefeitura do Município de Maringá - Estado do Paraná). Estas áreas estão demarcadas com as cores verde, amarela $\mathrm{e}$ vermelha correspondendo respectivamente a valores decrescentes de imposto: $1,0 \%, 0,6 \%$ e $0,3 \%$ do valor do imóvel, sendo, portanto, um indicador sócio-econômico. Os postos foram distribuídos segundo as áreas de IPTU.

A Secretaria de Saúde do Município de Maringá atende à população em 22 Postos de Saúde, que se distribuem por todo o município para facilitar o acesso da população aos serviços de saúde. A Tabela 5 apresenta o número de atendimentos de crianças menores de 1 ano no mês de julho segundo os postos de saúde, distribuídos de acordo com as áreas geográficas de lançamento de IPTU. Os postos foram colocados segundo a área a que pertence. As atividades desenvolvidas são as de consultas médicas, de enfermagem e consultas odontológicas direcionadas para a criança, para as gestantes e adultos. Ainda são oferecidas atividades na área de prevenção como imunização e tratamentos, como curativos e inalação . 
Tabela 5 - Número e porcentagem de atendimentos do mês de julho de crianças menores de 1 ano na rede básica de Saúde segundo áreas de IPTU. Maringá-PR, 1997.

\begin{tabular}{|c|c|c|c|c|c|}
\hline Posto & $\mathbf{N}^{0}$ & $\%$ & Posto & $\mathbf{N}^{\mathbf{0}}$ & $\%$ \\
\hline Alvorada I & 132 & 6,85 & Ney Braga & 85 & 2,59 \\
\hline Cidade Alta & 79 & 4,10 & \multirow{4}{*}{$\begin{array}{l}\text { Operária } \\
\text { Parigot } \\
\text { Pinheiros } \\
\text { Quebec }\end{array}$} & 81 & 4,20 \\
\hline Floriano & 50 & 2,59 & & 35 & 1,88 \\
\hline Grevílea & 52 & 2,70 & & 132 & 6,85 \\
\hline Iguaçu & 81 & 4,20 & & 151 & 7,84 \\
\hline Iguatemi & 70 & 3,63 & São Silvestre & 50 & 2,59 \\
\hline Industrial & 96 & 4,98 & Tuiuti & 130 & 6,75 \\
\hline Internorte & 61 & 3,16 & Universo & 49 & 2,54 \\
\hline \multirow{3}{*}{$\begin{array}{l}\text { Mandacarú } \\
\text { Maringá Velho } \\
\text { Morangueira }\end{array}$} & 101 & 5,24 & \multirow{2}{*}{$\begin{array}{l}\text { Vila Esperança } \\
\text { Zona Norte }\end{array}$} & 104 & 5,40 \\
\hline & 65 & 3,37 & & 179 & 9,29 \\
\hline & 89 & 4,62 & Zona Sul & 53 & 2,75 \\
\hline
\end{tabular}

Fonte: Secretaria de Saúde de Maringá- 1997

Alguns postos da rede básica de saúde oferecem um atendimento especial às gestantes hipertensas e diabéticas, com o agendamento de consulta mensal, avaliação do estado nutricional e controle do ganho de peso; no entanto, não existe uma atenção especial para as mulheres com características de risco para o baixo peso ao nascer e mesmo para estas crianças.

\subsection{População de Estudo}

Na população de estudo foram incluídas as 587 mães biológicas que tinham filhos menores de 1 ano de idade, de gravidez única e que foram atendidas nos 22 Postos de Saúde da Rede Básica de Maringá, por um período de cinco dias úteis. Desta maneira ficou garantida uma amostra representativa da população que freqüenta o serviço público de saúde de Maringá. Esta coleta foi realizada no período de março a julho de 1998.

A Secretaria Municipal de Saúde de Maringá, com o objetivo de integração hospital - unidade básica, recomenda a todas as mulheres que querem ser atendidas nos postos, após o nascimento de seu filho, que entreguem à unidade de 
saúde uma das vias da Declaração de Nascido Vivo (DNs - cor-de-rosa) para serem integradas à rotina de atendimento da criança para a imunização e avaliação do estado de saúde do RN.

\subsection{Coleta de dados}

A coleta de dados foi precedida por reuniões com Enfermeiras Chefes de cada posto para apresentar os objetivos do projeto e a metodologia a ser seguida.

As entrevistas com as mães foram realizadas por pessoas devidamente treinadas, utilizando um formulário previamente testado (Anexo 1). Os entrevistadores permaneciam em cada Posto por um período de 5 dias úteis e em casos onde a criança comparecia sem a mãe, sua presença era solicitada através de carta convite (Anexo 2), o que ocorreu na maioria das vezes.

As crianças passavam por atividades de rotina de serviço: eram medidas com o antropômetro e, a altura da mãe foi obtida utilizando-se o estadiômetro que foi fixado na parede com fita adesiva a partir da superfície do solo até a altura de 2 metros. A parede deveria ser plana. sem inclinações, sem rodapé, formando um ângulo reto com o piso. As mães foram avaliadas de acordo com as normas de JELLIFE. Após cada 2 pesagens as balanças eram calibradas para evitar erros.

Para o cálculo do Índice de Rohrer foi utilizado o peso ao nascer (em gramas) vezes 100 , dividido pela estatura no nascimento ao cubo (em $\mathrm{cm}) \mathrm{e}$ segundo ROSSO e WINICK (1974) as crianças são classificadas em desproporcionados quando o índice é menor que 2,51 e proporcionados quando o índice é maior ou igual a 2,51 . 
O crescimento das crianças da população amostral de Maringá foi avaliado de acordo com padrão NCHS recomendado pela OMS (1995). As crianças foram analisadas segundo os indicadores nutricionais de altura para a idade (A/I) e peso para a idade $(\mathrm{P} / \mathrm{I})$.

O estado nutricional das crianças foi classificado utilizando-se os sistemas de classificação em percentis e em escore $-Z$. Um escore $-Z$ representa o número de desvios-padrão, acima ou abaixo da mediana da população de referência, que corresponde ao peso ou à altura da criança. Nos últimos anso, definiu-se -2 escores- $Z$ como o nível de corte mais adequado para classificar a desnutrição energético-proteíca (WORLD HEALTH ORGANIZATION 1995)

Para o diagnóstico da anemia utilizou-se a dosagem bioquímica da concentração de hemoglobina $[\mathrm{Hb}]$ com valores críticos de $11,0 \mathrm{~g} / \mathrm{dL}$ para as crianças e $11,9 \mathrm{~g} / \mathrm{dL}$ para as mães (OMS -1975). A [Hb] foi medida no HemoCue fotômetro de leitura direta (MAKAREM 1974) cujo uso vem sendo recomendado pela OMS (1975). Este aparelho utiliza uma microcuveta com reagente em forma não aquosa preparado exclusivamente para a fotometria. O sangue é retirado por punctura no dedo médio ou do calcanhar com uma lanceta descartável, após desinfecção do local. A quantidade retirada deve ser suficiente para a reação com o reagente existente na microcuveta. Nenhuma diluição é requerida. A microcuveta é colocada no fotômetro e o resultado aparece no visor após alguns segundos.

Comparou-se a $[\mathrm{Hb}]$ observada com a $[\mathrm{Hb}]$ estimada para verificar a influência do crescimento sobre a concentração da hemoglobina. Esta influência pode ser analisada através de um cálculo teórico da concentração da hemoglobina considerando-se a quantidade de ferro veiculada pelo alimento em relação a quantidade endógena existente no nascimento.

Segundo o INACG (1981) o récem-nascido tem $75 \mathrm{mg}$ de ferro/Kg de peso, $85 \%$ dos quais em forma de hemoglobina que será distribuida conforme o crescimento; no entanto, esta quantidade é constante. $O$ volume sanguíneo 
corresponde a $85 \mathrm{~mL} / \mathrm{Kg}$ de peso (BRANDALISE e MATSUDA 1981) e cada grama de hemoglobina contém 3,4mg de ferro (WHITE e col. 1976) assim tem-se a equação:

$$
\begin{aligned}
& \mathrm{Hb} \text { estimada }=\frac{\mathrm{PN} \times 75 \times 0.85 \times 100 \mathrm{~g} / \mathrm{dL}}{3,4 \times \mathrm{PA} \times 85 \mathrm{ml} / \mathrm{Kg} \text { de peso }} \\
& \mathrm{Hb}=\text { hemoglobina } \\
& \mathrm{PN}=\text { peso ao nascer em Kg } \\
& \mathrm{PA}=\text { peso atual em } \mathrm{Kg}
\end{aligned}
$$

\subsection{Variáveis do estudo}

Foram obtidas informações referentes às características da mãe relacionadas ao risco de BPN: eventos biológicos e da gestação (idade da mãe, estatura, peso pré-gestacional, peso no final da gestação, índice de massa corporal pré-gestacional e índice de massa corporal no final da gestação), fatores comportamentais da mãe (número de cigarros fumados, número de xícaras de café ingeridas), assistência no pré-natal, fatores sócio-econômicos (renda familiar, escolaridade da mãe e do pai, número de pessoas em casa, local de moradia) que afetam o peso ao nascer.

\subsection{Categorização das Variáveis}

As variáveis quantitativas foram dicotomizadas conforme os referidos na literatura sobre baixo peso ao nascer, de forma a garantir o critério de comparabilidade. Para as variáveis qualitativas com mais de duas categorias, foi definida a categoria de risco e as demais.

O ganho de peso gestacional foi calculado pela diferença entre o peso referido para o estado pré-gestacional e a medida do peso na última consulta do 
pré-natal. O valor crítico adotado de 6 consultas foi escolhido por representar o nível de assistência à saúde para as gestantes de países em desenvolvimento

O Índice de Massa Corporal (IMC) ou Índice de Quetelet é o índice obtido pela divisão do peso $(\mathrm{Kg})$ pela estatura $\left(\mathrm{m}^{2}\right)$ e foi utilizado para classificar o estado nutricional pré-gestacional da mãe, considerando-se baixo peso $\left(<19 \mathrm{Kg} / \mathrm{m}^{2}\right)$; peso ideal $\left(19-22 \mathrm{Kg} / \mathrm{m}^{2}\right)$; sobrepeso $\left(23-28 \mathrm{Kg} / \mathrm{m}^{2}\right)$ e obesas $\left(>=29 \mathrm{Kg} / \mathrm{m}^{2}\right)$. A classificação do peso adotada foi baseada nos valores propostos por GARROW (1981). As variáveis estudadas estão descritas a seguir.

\section{Quadro 1 - Descricão das variáveis de estudo}

\begin{tabular}{|c|c|c|}
\hline Variável & Nivel de Exposição & \\
\hline & Exposto & Não Exposto \\
\hline Baixo Peso ao Nascer (BPN) & $<2500 \mathrm{~g}$ & $>=2500 \mathrm{~g}$ \\
\hline Comprimento ao Nascer- Baixo & $<49 \mathrm{~cm}$ & $>=49 \mathrm{~cm}$ \\
\hline Peso Atual (escore-Z) NCHS & $<=(-2$ escore $-Z)$ & $>(-2$ escore $-Z)$ \\
\hline Altura Atual (escore- Z) NCHS & $<=(-2$ escore $-Z)$ & $>(-2$ escore $-Z)$ \\
\hline Idade da Mãe-Adolescente & $<20$ anos & $>=20$ anos \\
\hline Estatura da Mãe - Baixa & $<1,50$ metros & $>=1,50$ metros \\
\hline Estado Civil - s/companheiro & S/companheiro & Casada,c/comp. \\
\hline Peso pré-gestacional- Baixo & $<50$ Kilos & $>=50$ Kilos \\
\hline Ganho de peso na gestação - Baixo & $<=9$ Kilos & $>9$ Kilos \\
\hline ÍMC Pré-gestacional - Baixo & $<19 \mathrm{Kg} / \mathrm{m}^{2}$ & $>=19 \mathrm{Kg} / \mathrm{m}^{2}$ \\
\hline Intervalo Partal - Baixo & $<12$ meses & $>=12$ meses \\
\hline $\mathrm{N}^{0}$ de consultas de pré-natal - Baixo & $<6$ consultas & $>=6$ consultas \\
\hline Renda familiar - Baixa & $<=130$ reais & $>130$ reais \\
\hline Escolaridade da mãe- Baixa & $<=4^{\circ}$ série do $1^{\circ} \mathrm{gr}$ & $>4^{\circ}$ série do $1^{\circ} \mathrm{gr}$ \\
\hline Escolaridade do pai - Baixa & $<=4^{\circ}$ série do $1^{\circ} \mathrm{gr}$ & $>4^{\circ}$ série do $1^{\circ} \mathrm{gr}$ \\
\hline $\mathrm{N}^{\circ}$ de cigarros fumados - Alto & $>=5$ cigarros $/$ dia & $<5$ cigarros $/$ dia \\
\hline No de xícaras de café ingeridas - Alto & $>=3 \times$ xícaras $/ \mathrm{dia}$ & $<3$ xícaras/dia \\
\hline Início do Pré-Natal-Tardio & $2^{\circ}$ e $3^{\circ}$ trimestre & $1^{\circ}$ trimestre \\
\hline Intercorrências na gestação & Presentes & Ausentes \\
\hline
\end{tabular}




\section{8 - Análise Estatística}

Foi criado um banco de dados no Dbase III de todas as variáveis codificadas e posteriormente foram analisadas nos softwares Epi-info (1990) e Multlr (1989).

A descrição das variáveis de estudo foi feita por meio de porcentagens, médias, desvios-padrão e medianas.

Foram realizados os testes de diferenças das médias das variáveis maternas (idade da mãe, estatura, peso pré-gestacional, peso no final da gestação, índice de massa corporal pré-gestacional, peso ganho na gestação, hemoglobina da mãe, intervalo partal e número de consultas realizadas no pré-natal) e as variáveis sócio-econômicas e comportamentais (renda familiar, renda per capita, escolaridade da mãe, escolaridade do pai, número de cigarros fumados por dia durante a gestação, número de xícaras de café ingeridas durante a gestação) entre os dois grupos de peso ao nascer através do teste de Mann-Whitney. Os mesmos testes foram feitos para a comparação entre as áreas de risco utilizando o teste de Kruskal-Wallis.

Para a análise entre as variáves de estudo e a presença de baixo peso ao nascer, foram realizados os testes de associação pelo qui-quadrado com correção de Yates, a diferença entre 3 ou mais grupos pelo teste $F$ de Snedocor, análise ajustada de Mantel - Haenzel e a medida de de associação linear entre as variáveis quantitativas pelo teste de correlação de Pearson.

Após a realização dos testes de associação pelo qui-quadrado, procurou-se identificar o melhor modelo de regressão logistica múltipla que descrevesse o efeito conjunto das variáveis de estudo e a presença do baixo peso ao nascer. O tamanho final da amostra na análise de regressão logística foi de 575 . O processo de modelagem obedeceu a relação das variáveis maternas e posteriormente as sócio-econômicas e as comportamentais . 
Iniciou-se o processo de modelagem pela variável mais significativa do ponto de vista estatístico e, a seguir, foram acrescentadas as outras, uma a uma. A variável permanecia no modelo se era estatisticamente significativa ou melhorava o ajuste do modelo. Em todas as análises utilizou-se o nível de significância $\alpha=5 \%$.

\subsection{Questões Éticas}

O presente estudo foi aprovado pelo Comitê de Ética da Faculdade de Saúde Pública da USP. A coleta de dados das mães e crianças foi realizada através de entrevistas com a presença das mães e as dúvidas eram esclarecidas quando necessário. Durante o primeiro contato, todas as mães foram postas a par dos objetivos da pesquisa e, após a concordância da mãe, esta aceitação era formalizada mediante a assinatura no verso do formulário (Anexo 3). Para a colheita dos exames de sangue não houve dificuldades, visto que as mães ficavam muito contentes devido à realização dos exames e por ele ser gratuito. Os resultados dos exames eram entregues para as mães (Anexo 4) e os casos diagnosticados como anêmicos foram encaminhados para o controle da deficiência. 


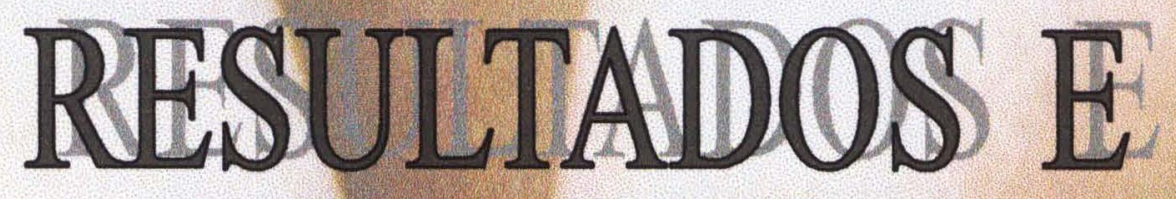
DISCUSSÃOO 


\section{4- RESULTADOS E DISCUSSÃO}

\subsection{Características da população materna}

O nível educacional desta população se apresentou adequado com $80,1 \%$ das mães com escolaridade acima da $4^{\circ}$ série do $1^{\circ}$ grau, sendo $76,7 \%$ com escolaridade entre a $5^{\circ}$ série do $1^{\circ}$ grau e $3^{\circ}$ série do $2^{\circ}$ grau e $3,4 \%$ com grau superior. Nota-se que o nível de escolaridade dos pais é similar ao das mães, salientando-se que 36 pais $(6,1 \%)$ não tinham a informação do nível de escolaridade (Figura 3). Do total das mães $117(19,9 \%)$ apresentaram de 1 a 4 anos de estudos e destas $8(6,83 \%)$ tiveram filhos BPN. Embora o estudo não tenha encontrado dados significativos, a variável escolaridade tem se mostrado potente na explicação dos diferenciais da saúde da população, além de estar fortemente associada com a renda familiar.

Segundo NOBREGA e col. (1991), quanto maior for o nível educacional da mãe menor a proporção de crianças desnutridas. Os autores destacam, ainda, que o nível de escolaridade da mãe não influencia a sua condição nutricional; no entanto, pode influenciar no cuidado do bebê que se reflete na promoção dos cuidados de higiene e alimentação. Concordando com esta assertiva, BARROS e col. (1987) observaram que as mães que nunca estudaram tinham uma probabilidade duplicada de ter filho BPN comparada àquelas que estudaram mais de 9 anos. 
Figura 3 - Distribuição (\%) de mães/pais segundo escolaridade, MaringáPR,1998.

\section{Escolaridade da Mãe}

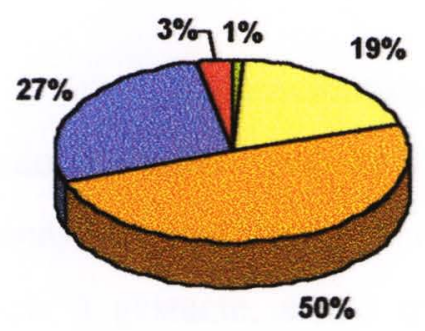

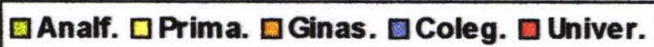

\section{Escolaridade do Pai}

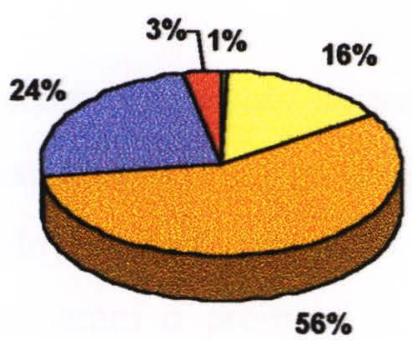

$\square$ Analf. $\square$ Prima. $\square$ Ginas. $\square$ Coleg. $\square$ Univer.

A maior parte das famílias estudadas $410(70,6 \%)$ eram compostas de 3 a 4 pessoas. Segundo o IBGE (1996), a média do número de pessoas por domicílio na área urbana para o Brasil é de 3,80, para o Paraná de 3,62 e para Maringá de 3,53. Para a zona rural estes valores são de 4,33; 3,96 e 3,86, respectivamente. Para $167(28,7 \%)$ famílias o número de pessoas na casa era superior a 4 .

As mulheres com a situação marital estável, casadas ou com companheiros, parecem exercer maior segurança no cuidado da criança, maior estabilidade no que se refere à administração da casa e assim transmitem uma estabilidade emocional para a criança, proporcionando-lhe um estado de bem estar físico e social. Do total das mães, $66,9 \%$ eram regularmente casadas, $17,1 \%$ eram solteiras e $10,2 \%$ eram solteiras com companheiros, observando-se que mais de $75,0 \%$ das mães apresentavam situação marital considerada adequada.

$\mathrm{Na}$ população de estudo encontrou-se que $54,0 \%$ das mães não trabalhavam. A maior parte daquelas que trabalhavam ou eram empregadas domésticas (17\%) ou exerciam atividade não especializada. 
O trabalho feminino se, por um lado, proporciona independência financeira à mulher e a torna mais atualizada e participativa na sociedade à qual pertence, por outro lado, pode diminuir sua disponibilidade para as atividades domésticas entre as quais destacam-se os cuidados pessoais e com os filhos.

A conscientização da necessidade de acompanhamento de saúde no período gravídico é bem nítida entre a população de gestantes de Maringá (Figura 4). Apenas 15 mulheres referiram não ter freqüentado nenhum programa de assistência à gestante, sendo que $507(86,4 \%)$ mães iniciaram o pré-natal já no primeiro trimestre da gestação.

Figura 4- Distribuição (\%) das mães segundo o início do pré-natal, Maringá-PR, 1998.

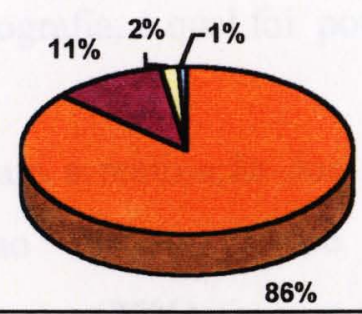

$\square 1^{\circ}$ Trim. $\square 2^{\circ}$ Trim. $\square 3^{\circ}$ Trim. $\square$ Não fez

Os procedimentos rotineiros executados na assistência pré-natal incluem o controle da pressão arterial, exames de sangue e urina, os quais foram referidos por $90 \%$ das mulheres. O exame pélvico foi realizado em $308(52,7 \%)$ delas. Salienta-se que existe muita controvérsia a respeito do exame pélvico a ser feito durante o período gestacional, pois demonstra-se que o mesmo pode causar abortos ou estar interferindo no desenvolvimento da criança; outros reforçam que, se existe uma possibidade da gestante apresentar o câncer do colo do útero, o exame deve ser realizado o mais precocemente possível, pois o câncer, sendo hormôniodependente, proporcionaria uma aceleração no desenvolvimento deste.

Durante os exames de rotina, de pré-natal podem ser diagnosticadas as intercorrências da gestação. Neste estudo, observou-se que 460 
$(78,4 \%)$ mães não apresentaram quaisquer tipos de intercorrências. Dentre aquelas que apresentaram, 64(10,9\%) tiveram síndromes hemorrágicas, 34(5,8\%) tiveram síndromes infecciosas e 29(4,9\%) síndromes hipertensivas, nenhuma delas diretamente relacionadas com o desenvolvimento fetal. Ressalta-se que entre a população amostral nenhuma mãe referiu ser diabética.

Não foi possível utilizar o índice de Kessner para verificar a adequação da assistência pela idade gestacional, uma vez que grande parte das mães não soube referir a idade gestacional em semanas como exigência para aplicação deste índice. Ele pode ser estimado pela data do último período menstrual, avaliação do ultrassom ou pelo exame clínico do RN. Acrescente-se que os prontuários das pacientes também não apresentavam esta informação, exceto quando era realizado o exame de ultrassonografia, o qual foi pouco comum nesta casuística.

Para a realização dos partos $422(71,9 \%)$ das mães utilizaram os serviços filiados ao Sistema Único de Saúde (SUS) (Figura 5). Um grande percentual de mulheres $(70 \%)$ tiveram seus filhos por parto cesáreo em desacordo com a proporção prevista como adequada de $10 \%$ a $15 \%$ referida pela WHO (1985).

Ṇos últimos anos, com o avanço das técnicas cirúrgicas, antibioticoterapia e abandono das manobras perigosas de versão externa e fórceps alto/médio pela Obstetrícia, ampliaram-se as indicações da operação cesariana como alternativa para assistência às parturientes (MAIA FILHO 1994). A operação cesareana tornou-se, atualmente, o procedimento cirúrgico mais comum dentre os atendimentos hospitalares. Esta cirurgia, apesar de ser um procedimento de fácil execução, aumenta a morbidade e a mortalidade materna e fetal quando comparada ao parto normal. As cesáreas têm sua indicação para resolver com segurança um parto que potencialmente poderia apresentar complicações colocando em risco a saúde ou a vida da gestante e/ou do feto. Segundo BOLAGI e MEEHAN (1992), as quatro maiores indicações de cesáreas são desproporção céfalo-pélvico, sofrimento fetal, cesárea prévia e apresentaçãoes fetais anômalas. No Brasil, este aumento no índice de cesárea não pode ser explicada apenas como um esforço para melhorar a 
atenção perinatal, já que as taxas são mais baixas entre entre a população pobre, justamente aquela que apresenta maiores índices de complicações e patologias obstétricas (ROUQUARYOL 1994).

Isso direciona para a necessidade de uma melhor orientação às gestantes a respeito do trabalho de parto normal, retirando suas dúvidas, crenças e os medos que muitas vezes causam problemas, angústias e até mesmo dificuldades para engravidar, com vistas a diminuir o número de cesáreas.

Figura 5 - Distribuição (\%) das mães segundo o tipo de parto, Maringá-PR, 1998.

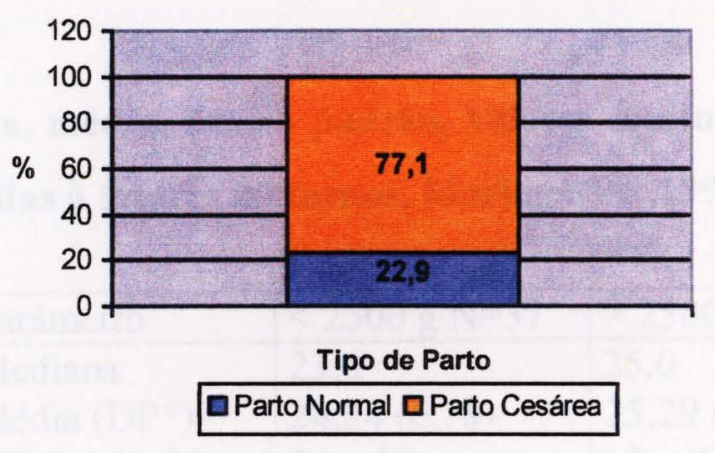

$\mathrm{Na}$ maior parte das vezes as variáveis aqui estudadas estão interrelacionadas e, freqüentemente, formando um círculo vicioso que é extremamente prejudicial ao desenvolvimento da gravidez e, na sua maioria, levando ao BPN ou outros eventos adversos e, conseqüentemente, prejudicando a saúde da criança. 
Não pode deixar de ser refletido que, embora esta amostra seja representativa da população que freqüenta a puericultura dos postos de saúde de Maringá, não está presente a parcela importante de gestações devido a perdas fetais e abortos possivelmente causados pelos mesmos determinantes do BPN e, ainda a mortalidade no $1^{\circ}$ ano de vida largamente onerada pelo BPN.

Assim, pretende-se mais do que mostrar diferenças significativas entre valores de variáveis no grupo de baixo peso e não baixo peso, verificar quais os determinantes mais comuns deste evento indesejável em uma população e refletir quais as condutas mais viáveis para controlá-las e, desta forma, minimizá-lo ao máximo. O risco de agravos à saúde é sempre maior nesse grupo, assim estudamos as variáveis relacionadas à fatores maternos (Tabelas 6 e 7).

Tabela 6 - Mediana, média, desvio padrão, valores mínimo e máximo para as variáveis relacionadas à fatores maternos, Maringá-PR,1998.

\begin{tabular}{|c|c|c|c|c|}
\hline Variável & Parâmetro & $<2500 \mathrm{~g} \mathrm{~N}=37$ & $=2500 \mathrm{~g} \mathrm{~N}=550$ & $\mathrm{P}^{* * *}$ \\
\hline $\begin{array}{l}\text { Idade da mãe } \\
\text { (anos) }\end{array}$ & $\begin{array}{l}\text { Mediana } \\
\text { Média (DP*) } \\
\text { Min-Máx** }\end{array}$ & $\begin{array}{l}23,0 \\
24,24(6,78) \\
14-36\end{array}$ & $\begin{array}{l}25,0 \\
25,29(5,96) \\
13-43\end{array}$ & 0,3036 \\
\hline $\begin{array}{l}\text { Estatura da mãe } \\
\quad(\mathrm{m})\end{array}$ & $\begin{array}{l}\text { Mediana } \\
\text { Média (DP*) } \\
\text { Min - Máx** }\end{array}$ & $\begin{array}{l}1,58 \\
1,57(0,05) \\
1,50-1,70\end{array}$ & $\begin{array}{l}1,60 \\
1,60(0,06) \\
1,40-1,80\end{array}$ & 0,0162 \\
\hline $\begin{array}{l}\text { Peso pré- } \\
\text { gestacional } \\
\quad(\mathrm{Kg})\end{array}$ & $\begin{array}{l}\text { Mediana } \\
\text { Média (DP*) } \\
\text { Min - Máx ** }\end{array}$ & $\begin{array}{l}53,0 \\
54,3(8,48) \\
39,0-72,0\end{array}$ & $\begin{array}{l}57,0 \\
57,3(9,19) \\
38,0-98,0\end{array}$ & 0,0584 \\
\hline $\begin{array}{l}\text { Peso no final da } \\
\text { gestação } \\
\quad(\mathrm{Kg})\end{array}$ & $\begin{array}{l}\text { Mediana } \\
\text { Média (DP*) } \\
\text { Min-Máx** }\end{array}$ & $\begin{array}{l}64,0 \\
66,5(14,0) \\
49,0-99,0\end{array}$ & $\begin{array}{l}69,0 \\
70,3(11,4) \\
43,0-120,0\end{array}$ & 0,0536 \\
\hline $\begin{array}{l}\text { Intervalo partal } \\
\quad \text { (meses) }\end{array}$ & $\begin{array}{l}\text { Mediana } \\
\text { Média }\left(\mathrm{DP}^{*}\right) \\
\text { Min-Máx** }\end{array}$ & $\begin{array}{l}36,0 \\
42,6(22,9) \\
12,0-96,0\end{array}$ & $\begin{array}{l}36,0 \\
40,7(21,7) \\
10,0-96,0\end{array}$ & 0,7256 \\
\hline $\begin{array}{l}\text { Peso ganho na } \\
\text { gestação } \\
\quad(\mathrm{Kg})\end{array}$ & $\begin{array}{l}\text { Mediana } \\
\text { Média (DP*) } \\
\text { Min - Máx** }\end{array}$ & $\begin{array}{l}8,0 \\
9,36(6,28) \\
(-7)-23,0\end{array}$ & $\begin{array}{l}12,0 \\
12,5(5,81) \\
(-7)-42,0\end{array}$ & 0,0032 \\
\hline
\end{tabular}




\begin{tabular}{|c|c|c|c|c|}
\hline $\begin{array}{l}\text { IMC pré- } \\
\text { gestacional } \\
\left(\mathrm{kg} / \mathrm{m}^{2}\right)\end{array}$ & $\begin{array}{l}\text { Mediana } \\
\text { Média }\left(\mathrm{DP}^{*}\right) \\
\text { Min - Max** }\end{array}$ & $\begin{array}{l}24,0 \\
24,1(4,62) \\
16,1-29,6\end{array}$ & $\begin{array}{l}21,8 \\
22,2(5,28) \\
14,7-35,1\end{array}$ & 0,5197 \\
\hline $\begin{array}{l}\text { IMC do final da } \\
\text { gestação } \\
\left(\mathrm{Kg} / \mathrm{m}^{2}\right)\end{array}$ & $\begin{array}{l}\text { Mediana } \\
\text { Média (DP*) } \\
\text { Min - Máx ** }\end{array}$ & $\begin{array}{l}27,4 \\
26,8(4,21) \\
16,8-32,0\end{array}$ & $\begin{array}{l}25,4 \\
27,1(4,33) \\
16,8-39,6\end{array}$ & 0,8100 \\
\hline $\begin{array}{l}\text { Renda Familiar } \\
\text { (reais) }\end{array}$ & $\begin{array}{l}\text { Mediana } \\
\text { Média (DP*) } \\
\text { Min - Máx ** }\end{array}$ & $\begin{array}{l}400,0 \\
493,8(342,7) \\
120,0-1900,0\end{array}$ & $\begin{array}{l}400,0 \\
506,0(347,0) \\
120,0-4000,0\end{array}$ & 0,8368 \\
\hline $\begin{array}{l}N^{\circ} \text { de pessoas } \\
\text { Em casa }\end{array}$ & $\begin{array}{l}\text { Mediana } \\
\text { Média }\left(\mathrm{DP}^{*}\right) \\
\text { Min - Máx ** }\end{array}$ & $\begin{array}{l}4,0 \\
4,5(1,51) \\
2,0-8,0\end{array}$ & $\begin{array}{l}4,0 \\
4,2(1,40) \\
2,0-11,0\end{array}$ & 0,1079 \\
\hline $\begin{array}{l}\mathrm{N}^{\circ} \text { de cigarros } \\
\text { Fumados/dia }\end{array}$ & $\begin{array}{l}\text { Mediana } \\
\text { Média (DP*) } \\
\text { Min - Máx ** }\end{array}$ & $\begin{array}{l}5,5 \\
7,1(6,0) \\
1,0-20,0\end{array}$ & $\begin{array}{l}5,0 \\
8,5(7,32) \\
1,0-20,0\end{array}$ & 0,5618 \\
\hline $\begin{array}{l}\text { No de xícaras } \\
\text { De café/dia }\end{array}$ & $\begin{array}{l}\text { Mediana } \\
\text { Média (DP*) } \\
\text { Min - Máx ** }\end{array}$ & $\begin{array}{l}2,0 \\
3,0(3,68) \\
1,0-20,0\end{array}$ & $\begin{array}{l}1,0 \\
2,2(1,93) \\
0-10,0\end{array}$ & 0,0437 \\
\hline
\end{tabular}

* DP - desvio padrão

** valores mínimo e máximo

*** $p$ : nível descritivo do teste de diferenças das médias de Mann-Whitney.

Tabela 7- Distribuição do número e porcentagens de mães, segundo as variáveis independentes e a categoria de peso ao nascer. Maringá-PR, 1998.

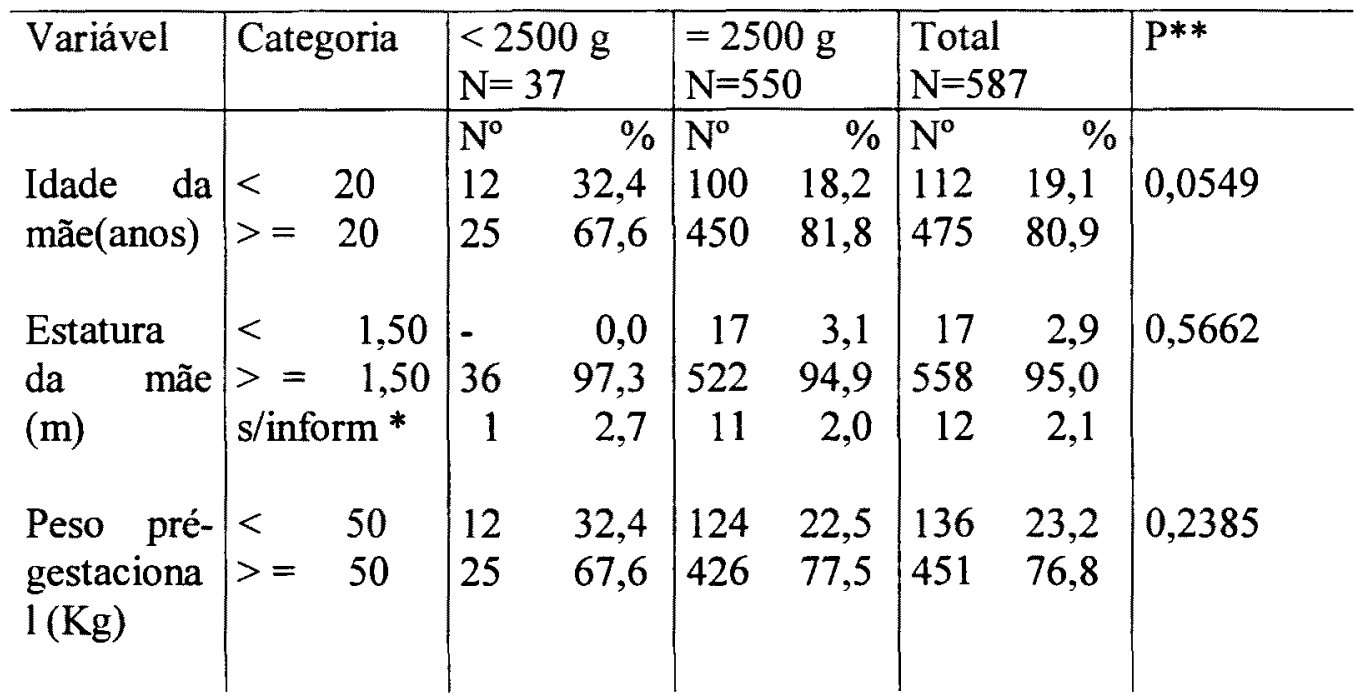




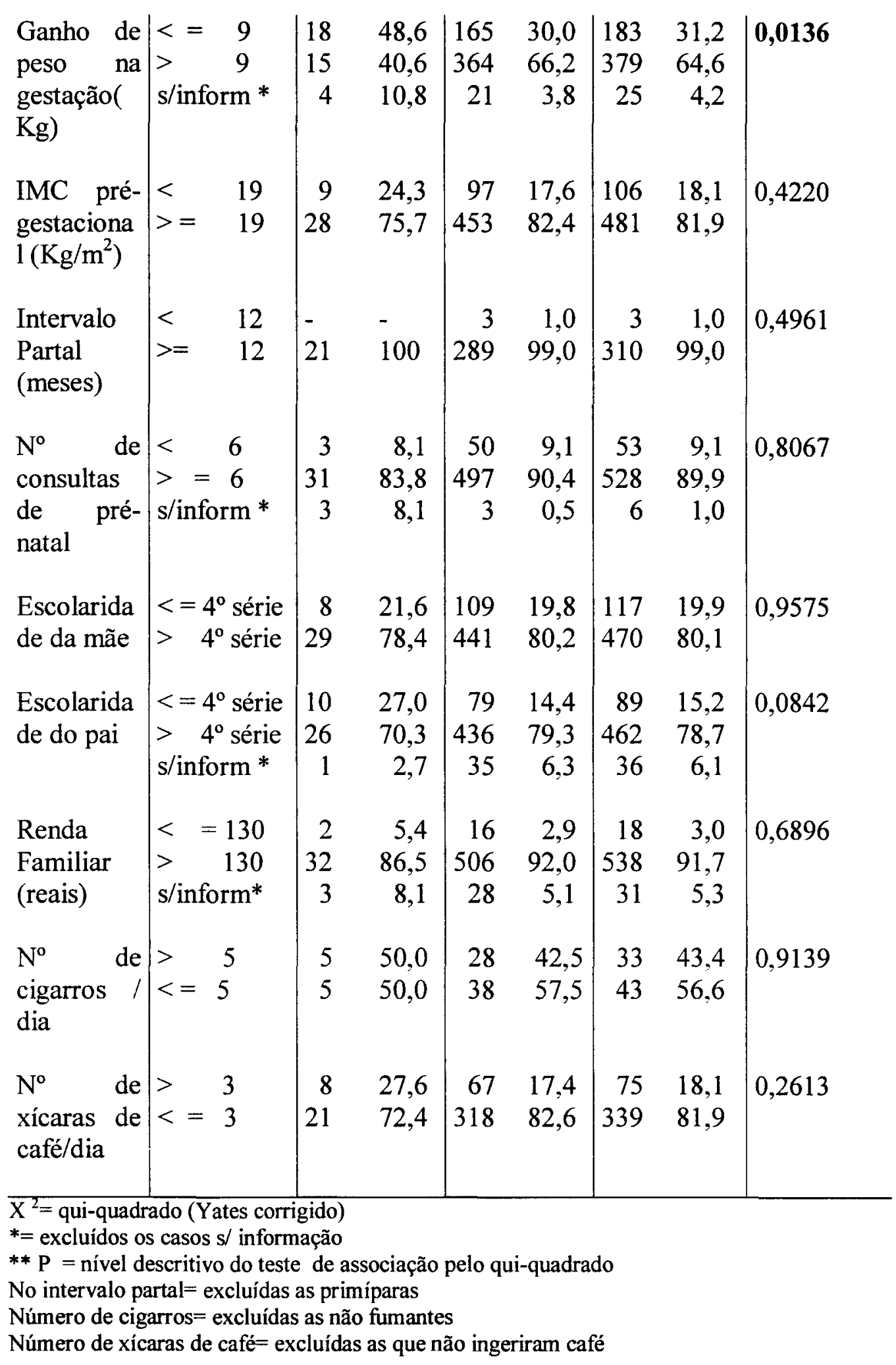

O processo de modelagem para a análise multivariada obedeceu à relação de fatores associados independentes ao baixo peso ao nascer: peso ganho durante a gestação, idade da mãe e tabagismo (Tabela 8). 
$\mathrm{Na}$ análise conjunta dos fatores associados à presença de baixo peso ao nascer procurou-se identificar o melhor modelo de regressão logística múltipla que descrevesse a associação entre o fator em estudo. Esta análise se restringiu ao total da amostra e não por área de IPTU. O tamanho final da amostra na análise de regressão logística foi de 575 mulheres.

Tabela 8 - Análise Multivariada dos Fatores de Risco do Baixo Peso ao Nascer, Maringá-PR, 1998.

\begin{tabular}{l|l|l|c}
\hline Variável & Categoria & Odds Ratio & $\mathrm{p}$ \\
\hline $\begin{array}{l}\text { Peso ganho } \\
\text { durante }\end{array}$ & $>9$ & 1,0 & $\mathbf{0 , 0 0 9 8}$ \\
gestação $(\mathrm{Kg})$ & $<=9$ & $\mathbf{2 , 7 7}$ & \\
& & & \\
Idade da mãe & $>=20$ & 1,0 & $\mathbf{0 , 0 2 6 8}$ \\
(Anos) & $<20$ & $\mathbf{2 , 4 9}$ & \\
& & 1,0 & $\mathbf{0 , 0 2 8 8}$ \\
$\mathrm{N}^{\circ}$ de cigarros & $<=5$ & $\mathbf{3 , 4 9}$ & \\
fumados/dia & $>5$ & 1,0 & \\
& & 0,9756 & 0,6535 \\
Áreas de Risco & Verde & Amarela & 0,8669 \\
do IPTU & Vermelha & 0,9082 & \\
& & &
\end{tabular}

Os resultados das gestações são geralmente menos favoráveis entre adolescentes e mulheres acima de 35 anos de idade. Entretanto, a constatação de que mulheres adultas jovens e adolescentes tendem a ter filhos com BPN tem sido referida por vários autores. BELIZAN e col. (1989) demonstraram em seu estudo que as mães com menos de 18 anos apresentararn uma associação para o nascimento de crianças pré-termos e não para o retardo de crescimento intrauterino.LIPPI e col. (1989) observaram que as mães adolescentes $(<20$ anos) apresentavam um percentual de $17,4 \%$ recém-nascidos $\mathrm{BPN}$, enquanto que para as outras este percentual foi de 15,6\%. SANTOS e col. (1992), em estudo realizado em seis maternidades da rede pública estadual de Salvador, observaram uma incidência de $14,3 \%$ de BPN entre as jovens, valores semelhantes aos descritos por BARROS e col. (1987), STEFANINI e col. (1988); FERRAZ e col. (1991). 
Dentre as 112 adolescentes encontradas na amostra, $47(8.0 \%)$ tinham entre 13 a 17 anos, idade em que a mulher se encontra ainda em desenvolvimento. A OMS (1978) aponta a idade materna menor ou igual a 16 anos como um dos fatores vitais para a qualidade do produto final e uma associação estatística importante. Este fator vem sendo utilizado como indicador preditivo de risco para o BPN.

Entre elas a incidência de BPN foi de $8(17,1 \%)$, ou seja, o dobro do número encontrado entre as adolescentes mais velhas e uma ocorrência quase 3 vezes maior do que a encontrada na amostra total, reforçando a tese de que as mulheres com idade inferior a 18 anos não estão preparadas para a reprodução.

A gestação na adolescência aumenta o risco de BPN em 2,49 vezes. Segundo SUSSER e col. (1982), a idade jovem pode ser uma causa indireta da prematuridade ou do retardo de crescimento intrauterino através do efeito estatura, peso nutricional gestacional, o cigarro e o alcool. $\mathrm{O}$ efeito das causas indiretas pode ser importante especialmente para as mulheres muito jovens, porque as intervenções visam o retardamento das gestações em adolescentes jovens, e esta iniciativa parece ser mais efetiva do que verificar a influência da sua altura, peso ou nutrição gestacional. Ainda SUSSER ressalta que, embora não tenha usado este tipo de análise para investigar estas relações, sugere que isto poderia ser de grande valia para demonstrar a extensão dos efeitos causais indiretos. YUDKIN e col. (1983); no entanto, em estudo entre a idade materna e a média de peso ao nascer, encontraram um significativo efeito independente, discordante dos achados de MLLS e col. (1984) .

A ausência de um efeito causal direto da idade da mãe não está limitada a países desenvolvidos. Embora somente poucos estudos tenham sido encontrados provenientes de países em desenvolvimento como a India (PACHAURI e MARWH 1970) e Guatemala (MATA 1978), similarmente não registraram efeito independente da idade da mãe com o peso ao nascer. Por outro lado, RODRIGUEZ e col. (1995), em estudo de registros de nascimentos de crianças nascidas na 
Espanha, observaram associação significante com o BPN com a idade da mãe $<$ de 20 anos $(\mathrm{OR}=1,63, \mathrm{IC}=1,25-2,14)$ e para as mães com mais de 34 anos $(\mathrm{OR}=$ $1,28, \mathrm{p}<0,05)$.

MILLS e col. (1984) relata que a idade está estritamente associada com a paridade, a qual deve ser controlada em estudos para isolar o impacto independente da idade. Embora adolescentes jovens (aquelas com 1 a 2 anos de menarca) não tenham completado o crescimento, provavelmente apresentam um baixo peso para a altura comparada às mulheres mais velhas, e consomem poucas calorias e poucos nutrientes, porque suas gestações não são desejadas ou não planejadas e elas freqüentemente procuram tardiamente a assistência pré-natal. $\mathrm{O}$ aumento do uso do fumo, consumo de alcool e uso de drogas entre as adolescentes podem também colocá-las em risco .

Outro indicador que pode afetar o crescimento uterino através de mecanismos genéticos ou do meio ambiente é a altura materna. Se, por um lado, parte do potencial genético pode ser passado para o feto, e um déficit na sua altura, a despeito de sua etiologia, pode impor limitações físicas no crescimento do útero, placenta e feto, por outro lado, não existe o conhecimento de qualquer mecanismo biológico por meio do qual a altura poderia afetar a idade gestacional ou a prematuridade (SCOTT e col. 1981).

Para FEDRICK e ADELSTEIN (1978) não existe uma razão primária para esperar um efeito causado pela diferença de altura entre diversos grupos populacionais. A altura materna diminuída pode ser uma das causas do aumento da taxa de BPN em muitos países em desenvolvimento, ou causado por uma verdadeira diferença no potencial genético ou pelo retardo de crescimento anterior ocasionado durante a infância da mãe. Acrescenta - se ainda que mulheres mais altas são mais pesadas e consomem mais calorias do que mulheres pequenas, e desta forma o peso pré-gestacional e a nutrição gestacional podem ou não afetar o peso ao nascer e, assim, existem muitos efeitos de confusão que poderiam ser controlados na avaliação do efeito independente da altura. 
SCOTT e col. (1981) estudaram 488 casos de crianças com retardo de crescimento uterino e 367 crianças controle com adequada idade gestacional e verificaram uma diferença entre a média de altura entre as mães controles (1,62 m)e este valor menos 1 desvio padrão $(1,55 \mathrm{~m})$ estava associando com um risco relativo de 2,03 para o retardo de crescimento intrauterino. Resultados semelhantes foram observados por BELIZAN e col.(1989); SERRANO e PUFFER (1975); SIQUEIRA e col. (1975); STEFANINI e col (1988).

No estudo de MEYER e col. (1976) as mulheres com altura inferior a 1,58 $\mathrm{m}$ apresentaram um risco relativo de 1,18 para o BPN comparadas com as mulheres de 1,58 a 1,72 m. Acrescenta, ainda, que as mulheres com altura maior que $1,73 \mathrm{~m}$ apresentaram um risco levemente aumentado para o fator. DONOSO e col. (1988) observaram uma correlação estatisticamente significativa $\left(\mathrm{r}^{2}\right.$ $=3,4$ ) entre as mães com $1,50 \mathrm{~m}$ e menos associado com o baixo peso ao nascer e neste estudo $17(2,9 \%)$ das mães apresentaram altura menor que $1,50 \mathrm{~m}$, e nenhuma delas teve filho BPN.

Assim como a altura, o peso pré-gestacional é influenciado tanto pelos fatores genéticos quanto pelos fatores do meio ambiente. Mesmo depois de corrigido para estatura, o peso corporal está em parte geneticamente determinado e os genes que controlam a adiposidade ou magreza e o índice de massa corporal poderiam teoricamente serem expressos no peso do recém - nascido. Mesmo na ausência de tal expressão, entretanto, o peso materno antes da concepção reflete o estoque nutricional potencialmente disponivel para o crescimento do feto. (SCOTT e col.(1981); MEYER e col. (1976).

KRAMER (1987) relata que as mulheres que têm peso elevado são geralmente mais altas e têm necessidades energéticas maiores do que as mulheres magras independentemente de uma situação fisiológica específica como a gravidez. Assim, o autor sugere que seja feito o controle da altura para avaliação do risco reprodutivo. KRAMER (1987), ainda, refere que o ganho de peso durante a gestação é o maior responsável tanto pelo aumento da incidência da adequação do peso ao 
nascer quanto pela diminuição do BPN por retardo de crescimento intrauterino (SHEPARD e col. 1986).

Com relação ao peso pré-gestacional SCOTT e col. (1981) em estudo de caso-controle reportaram um OR para o peso pré-gestacional de 1,84 associado com um peso pré-gestacional menor de 49,5 Kg. Quando utilizaram como ponto de corte para o peso pré-gestacional menor que $54 \mathrm{~kg}$ o OR estimado foi de 1,25 . Neste estudo $136(23,2 \%)$ das mulheres tinham peso pré-gestacional $<50 \mathrm{Kg}$ e deste total $12(8,82 \%)$ tiveram filhos BPN.

A respeito dessa variável MILLER e MERRIT (1979) verificaram que o peso ganho durante a gestação tinha um efeito positivo na idade gestacional ajustado para o peso ao nascer e que este efeito foi bastante significativo para o retardo de crescimento intrauterino. Similarmente, HORON e col. (1983) reportaram que mulheres com ganho de peso gestacional menor e igual a $9 \mathrm{Kg}$ tinham em média um bebê com o peso ao nascer de $120,0 \mathrm{~g}$ a menos que aquelas com peso ganho maior que $9 \mathrm{~kg}$. RUSH e col. (1972) mostra que esta correlação positiva entre o peso ganho e o produto da concepção ocorre tanto para países desenvolvidos quanto para aqueles em desenvolvimento. Neste estudo verificou-se que a mãe com ganho de peso menor ou igual a $9 \mathrm{Kg}$ tem o risco aumentado para gerar filhos BPN de 2,77 vezes.

ABRAMS e col. (1986) relatam que a relação entre o peso ganho durante a gestação e o resultado do pesō ao nascer independe do peso pré-gestacional da mãe. O mesmo foi observado por SINISTERRA e col. (1991), que mostraram que o risco de BPN entre mulheres que iniciam a gestação desnutridas ou não, mas que chegam nutridas ao seu final é similar. No estudo de Maringá observou-se que $183(31,2 \%)$ das mulheres apresentaram ganho de peso na gestação $<=9 \mathrm{Kg}$ e destas $18(9,83 \%)$ apresentaram filhos BPN e as diferenças entre as médias dos grupos normal e BPN foi significativa $(p=0,0136)$. Assim, estudou-se se a variável peso pré-gestacional infuenciava o ganho de peso. Observou-se que o peso pré gestacional 
não é uma variável de risco para o ganho de peso, independente do peso ao ao nascer $\left(\mathrm{RR}_{\mathrm{MH}}=1,04\right) \mathrm{IC}(0,80-1,36)$ (Tabela 9).

Tabela 9 -Distribuição do número de crianças segundo o peso ao nascer, o peso pré-gestacional e o ganho de peso materno. Maringá-PR,1998.

\begin{tabular}{|c|c|c|c|c|c|}
\hline Peso ao nascer & $\begin{array}{l}\text { Peso Pré- } \\
\text { gestacional }\end{array}$ & $\begin{array}{l}\text { Ganl } \\
<9\end{array}$ & $>=9$ & RR & IC(RR) \\
\hline $\begin{array}{c}\text { BPN } \\
(<2500 \mathrm{~g})\end{array}$ & $\begin{array}{l}<=50 \\
>\quad 50\end{array}$ & $\begin{array}{c}7 \\
11\end{array}$ & $\begin{array}{l}4 \\
11\end{array}$ & 1,27 & $0,69-2.35$ \\
\hline $\begin{array}{l}\text { Insuficiente } \\
(2500-2999 \mathrm{~g})\end{array}$ & $\begin{array}{l}<=50 \\
>\quad 50\end{array}$ & $\begin{array}{l}10 \\
32\end{array}$ & $\begin{array}{l}31 \\
44\end{array}$ & 0,58 & $0,32-1,06$ \\
\hline $\begin{array}{l}\text { Adequado } \\
(>=3000)\end{array}$ & $\begin{array}{l}<=50 \\
>\quad 50\end{array}$ & $\begin{array}{l}30 \\
93\end{array}$ & $\begin{array}{c}53 \\
236\end{array}$ & 1,28 & $0,92-1,79$ \\
\hline
\end{tabular}

O ganho de peso na gestação pode afetar o crescimento intrauterino. Segundo HITTEN e col. (1980), quatro fatores poderiam estar envolvidos: o estabelecimento de estoques de gordura, o crescimento de tecido uterino e mamário, o aumento do volume plasmático e o crescimento do feto, placenta e líquido amniótico. Refere, ainda, que somente o primeiro fator poderia servir como uma fonte de energia para o crescimento do feto.

A renda familiar se apresenta como um indicador bastante importante na ocorrência do BPN. Ela está associada primeiramente à disponibidade de recursos de saúde, ao acesso a informações, aos gastos com alimentação e, principalmente, com o nível de escolaridade o que, na maioria das vezes, está diretamente relacionado com a profissão, ocupação e, conseqüentemente, ao salário. Neste estudo encontrou-se $18(3,0 \%)$ de mães com renda inferior a 1 salário mínimo da época $(R \$ 130,00)$ e apenas $2(11,1 \%)$ destas mães apresentaram filhos BPN.

O intervalo interpartal se apresenta como um fator de relevância na incidência do BPN. O espaço entre dois partos inferior a 12 meses provavelmente 
não permite uma recuperação nutricional completa da mulher e, conseqüentemente, não poderá oferecer nutrientes em quantidade sufiente para o desenvolvimento do novo bebê. Como observou MILLER (1994), nem sempre isso ocorre com conseqüências graves. Afirma que as crianças concebidas dentro de 1 ano tinham um risco leve para a prematuridade comparadas às outras, com um percentual de $15,2 \%$ para $14,9 \%$, sugerindo que pequeno intervalo intergestacional pode estar associado com deficits na gestação. Neste estudo entre 318 mulheres não primíparas, encontrou-se $3(0,94 \%)$ com intervalo interpartal inferior a 12 meses sendo que nenhuma dessas mães apresentou uma criança BPN.

A nicotina atua como um supressor do apetite e acredita-se que ele aumenta as catecolaminas maternas e conseqüente vasoconstrição uterina. $\mathrm{O}$ tabaco também contém componentes cianídricos que interferem no mecanismo fetal oxidativo (QUIGLEY e col. 1979). Segundo PIRANI (1978), o tabagismo na gestação pode afetar o crescimento intrauterino e provavelmente a duração da gestação através de muitos mecanismos, sendo os mais prováveis a produção de monóxido de carbono e a absorção da nicotina. LONGO (1977) afirma que o monóxido de carbono pode interferir na liberação do oxigênio para o feto de duas formas: desfazendo o oxigênio da hemoglobina e pelo redirecionamento do equilíbrio da dissociação da oxihemoglobina para a esquerda. Então menos oxigênio é liberado para o tecido fetal.

ZUCKERMAN e col. (1983) não encontraram um efeito significativo do baixo peso ao nascer com o fumo. Já PAPOZ (1982) reportou resultados similares e ressalta que a falta de significância estatística se deve ao relativamente pequeno número da amostra, pois a maioria das mulheres estavam conscientizadas quanto ao dano causado pelo fumo para a criança.

Neste estudo entre as mulheres que geraram filhos BPN, 27,0\% eram fumantes e $50 \%$ destas referem ter fumado mais de 5 cigarros/dia. Para estas mulheres que fumavam acima de 5 cigarros/dia, $50,0 \%$ iniciaram o prénatal no $2^{\circ}$ trimestre e $10,0 \%$ tinham menos de 20 anos. Para as mães que tiveram filhos com 
peso insuficiente o percentual de fumantes foi de 15,8 , com 52,6\% para aquelas com mais de 5 cigarros/dia, $10,0 \%$ iniciaram o prénatal no $2^{\circ}$ trimestre e $10,0 \%$ tinham menos de 20 anos. Para as de peso adequado o percentual foi de $11,2 \%$ com $38,3 \%$ para aquelas com mais de 5 cigarros/dia, $22,2 \%$ iniciaram o pré-natal no $2^{\circ}$ trimestre e $11,1 \%$ tinham menos de 20 anos.

Embora os valores não mostrem uma relação causal entre o fumo e o peso ao nascer, estes sugerem que o tabagismo exerce uma ação sobre o crescimento fetal refletida pela maior proporção de fumantes entre as mães de crianças BPN. Assim, competiria ao Programa de Assistência à Gestante conscientizar a mulher, a cada consulta, dos possíveis problemas causados pelo cigarro na gravidez. Como informa NAEYE (1981), mulheres que pararam de fumar durante a gravidez tiveram filhos com peso ao nascer semelhantes ao das não fumantes. Neste estudo as mulheres que fumaram mais de 4 cigarros durante o período gestacional tiveram um risco de 3,49 vezes de conceber filhos BPN.

Em estudo realizado em Pelotas por BARROS e col. (1987), o baixo peso ao nascer ocorreu mais frequentemente entre os filhos de mães fumantes $(11,4 \%)$ do que entre as mães não fumantes $(6,5 \%)$ e estes resultados foram confirmados quando se controlou a paridade, assistência pré-natal e peso no final da gestação $(\mathrm{OR}=1,625, \mathrm{p}<0,0001)$.

Alguns estudos como o de RUSH (1976), aceitando a nicotina como um supressor do apetite, demonstraram baixo ganho de peso ou baixa ingesta calórica em mães fumantes; entretanto, mesmo nestes estudos o efeito causado pelo fumo tem persistido mesmo depois de controlar as diferenças nutricionais, os quais indicam um impacto acima e superior que a supressão do apetite. Assim, o efeito do fumo tem um forte e direto impacto no peso ao nascer em adição com um possível e indireto efeito de supressão do apetite.

Assim, como em muitos estudos é constatada a forte correlação entre o fumo e o consumo de álcool e como estas práticas podem levar a efeitos 
deletérios no crescimento intrauterino, para a cafeína também recomenda-se um rigoroso controle para estes efeitos de confusão, não se esquecendo da idade da mãe, peso pré-gestacional e estado sócio-econômico ou outro fator de risco correlato. Acrescentando, HINDS e col. (1996) afirmam que a cafeína pode estar interagindo com fatores genéticos e farmacocinéticos e outras drogas aumentando a probabilidade de resultados adversos na gestação.

Em Maringá do total das mulheres, $403(69,1 \%)$ mães tomavam de 1 a 8 xícaras de café por dia durante a gestação, $8(1,4 \%)$ faziam a ingestão de 10 a 20 xícaras por dia e $173(29,5 \%)$ não ingeriram café na gestação.

Embora todo o cuidado tivesse sido tomado em relação a $1^{\circ}$ quantificação do volume do líquido, a quantificação da ingestão de café é difícil devido à concentração de pó na elaboração do produto, o tipo de preparo, o tipo de filtro que interferem na concentração final da cafeína. Nesta amostra $8(22,0 \%)$ mães com filho BPN ingeriram café no período gravídico, doses não recomendáveis de café, valor que cai para $10,0 \%$ entre as outras. Ao pré-natal compete, junto com a orientação alimentar, alertar para o risco de adventos indesejáveis associados a ingestão de café, produto que faz parte da prática alimentar nacional, especialmente no desjejum, misturado ao leite.

Nos estudos de HINGSON e col. (1982) e ZUCKERMAN e col. (1983), não foram verificados efeitos no peso ao nascer e, em estudo mais detalhado, de LINN (1982), não foi observado o impacto da ingesta de café com o retardo de crescimento intrauterino. Resultados similares foram observados em nosso estudo, provavelmente devido ao pequeno número de mulheres que ingeriam grandes quantidades de café durante a gestação.

Sabe-se que existe um risco aumentado de BPN para as mulheres que ingerem cafeína FENSTER e col. (1991) demonstram que este risco se apresenta na ingestão de $300 \mathrm{mg}$ de cafeina por dia para a ocorrência de nascimentos de crianças com retardo de crescimento intrauterino. Acrescente-se que, na América 
do Norte, uma típica xícara de café contém aproximadamente $100 \mathrm{mg}$ de cafeína e para outras bebidas como o chá, $40 \mathrm{mg}$ /xícara e para as bebidas com cola, $20 \mathrm{mg}$ (NAROD e col. 1991).

RONDÓ e col. (1996), em estudo realizado com mulheres da cidade de Campinas, observaram, diferentemente do encontrado, risco significativo para mulheres que ingeriram menos de um copo de café/dia $(O R=1,88, p=0,002)$ e que a tendência em grandes consumidoras de café, para o nascimento de crianças com retardo de crescimento intrauterino permanece, mesmo controlando as variáveis de fumo e álcool.

Mesmo assim, espera-se que diminuindo o estimulante, os resultados adversos na gestação sejam diminuídos, como no estudo de FENSTER e col. (1991), que demonstraram que mulheres que reduziram sua ingestão de cafeína para $300 \mathrm{mg}$ e menos por dia já no início da gestação (6 semanas no máximo) também reduziram o risco para o nascimento de crianças BPN, comparado às mulheres que não o fizeram de forma precoce adequada. Vale, pois, um reforço do Programa de Assistência à Gestante na insistência para conscientizar a mulher dos risco advindos do café.

O número de consultas de pré-natal e, teoricamente, o grande número de contatos com o profissional de saúde que procura reduzir ou eliminar os fatores de risco ou complicações da gestação para melhorar o seu resultado se apresenta como uma solução bastante apropriada para esta população carente, pois geralmente as mulheres que dão à luz prematuramente têm um tempo reduzido para visitas e conseqüente dificuldade no controle das suas deficiências.

Como foi referido anteriormente, $86,0 \%$ das mulheres amostradas procuraram o Programa de Assistência à Gestante já no $1^{\circ}$ trimestre na gestação. DONALDSON e BILLY (1984) reportaram um significativo risco para o retardo de crescimento intrauterino nas mulheres que realizaram 5 e menos visitas de prénatal comparadas às mulheres com 6 a mais visitas. Acrescentam, ainda, que a 
participação da mulher na assistência pré-natal, através de visitas, independe do seu nível de educação, da sua idade ou paridade .

A importância do pré-natal é observada, pois o número de consultas se apresenta de forma inversamente proporcional ao risco como se observa no trabalho de LIPPI e col. (1989). As mulheres com 0 a 2 consultas apresentaram $17,8 \%$ de crianças BPN, para aquelas com 3 a 4 consultas o percentual foi de 19,1\%; para as com 5 a 6 consultas, $10,4 \%$ e para 7 a mais $8,2 \%$; acrescentando que o teste de qui-quadrado se apresentou altamente significativo $\left(x^{2}=189,54, p<0,05\right)$.

Neste estudo não foi observado associação estatísticamente significativa para as mães com menos de 6 consultas, acrescentando que $89,9 \%$ delas fizeram 6 e mais consultas de pré-natal e 9,1\% menos de 6 consultas, $6(1,0 \%)$ mães não lembravam do número de consultas realizadas.

\subsection{Indicador Sócio-econômico (IPTU)}

Como o Imposto Predial Territorial Urbano (IPTU) se apresenta como um indicador sócio-econômico, foi realizada análise separadamente nas três áreas conjuntas para verificar se havia diferença entre elas e os postos foram alocados conforme área de localização. Assim, ao distribuírmos os postos de saúde segundo as áreas de IPTU, verificamos que a área verde ficou com 7 postos, a área amarela com 9 postos e a área vermelha com 4 postos de saúde, perfazendo um total de 553 mães. Acrescente-se que 2 postos não pertencem à região geográfica de Maringá para a divisão do IPTU, mas são subdistritos do Município. Nestes 2 postos foram encontradas 34 mães e nenhum caso de BPN.

A análise do percentual de BPN segundo as áreas de moradia mostrou que a área vermelha, com menor percentual de imposto $(0,3 \%$ do valor do imóvel) e, conseqüentemente, provável menor poder aquisitivo, apresentou o maior percentual de BPN com 7,4\%, diferença essa não significativa (Figura 6). 
Figura 6 - Distribuição (\%) de mães segundo a área de atendimento e peso ao nascer da criança, Maringá-PR, 1998.

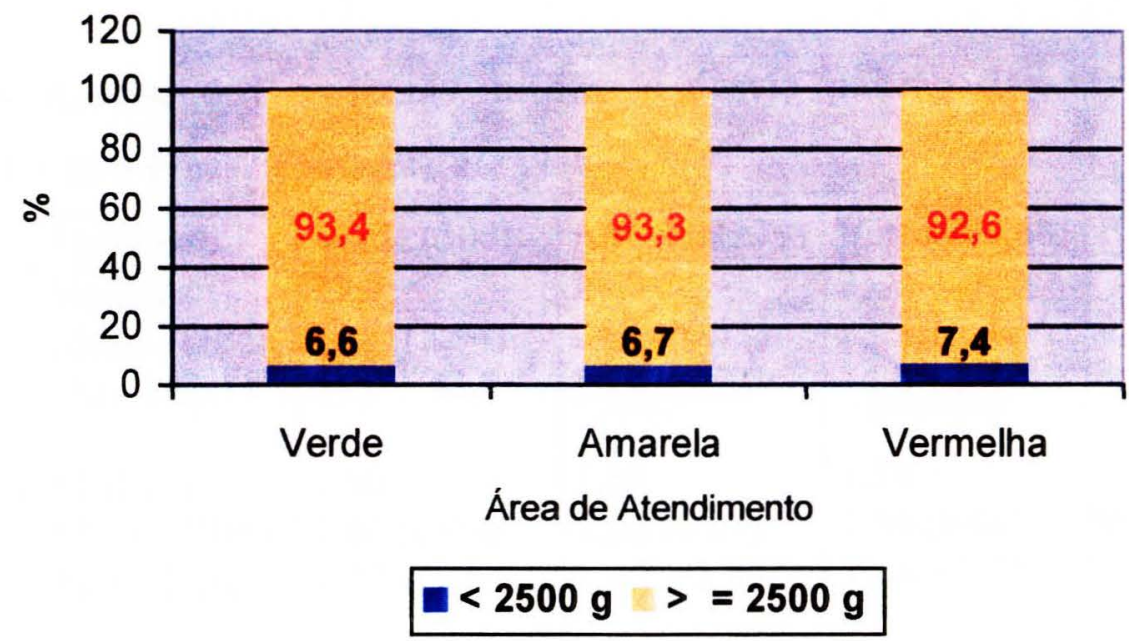

A análise das áreas foi realizada de 2 formas: inicialmente de forma conjunta e posteriormente de forma individual para verificarmos se havia diferença entre as médias das variáveis estudadas nas três áreas. Observa-se com relação à idade materna que as áreas consideradas de risco, ou seja, a área vermelha $\mathrm{e}$ a amarela, apresentam $25,0 \%$ de mães com idade $<20$ anos comparadas com a outra área com $15,0 \%$. No que se refere ao número de xícaras de café ingeridas durante a gestação, valores significativos foram observados para a área vermelha com valores medianos de ingesta, 2 vezes maior que as outras áreas, sugerindo para as áreas de risco uma orientação mais eficiente para esta população jovem sobre os fatores de risco e os efeitos adversos na gestação.

$\mathrm{O}$ índice de massa corporal pré-gestacional apresentou significativa diferença entre os grupos estudados, ressaltando aqui o percentual de $22,9 \%$ de mães com valores abaixo do recomendado para a área considerada adequada. Estas dados pressupõem que a população atendida na área verde é constituída de mulheres que trabalham na área nobre, mas moram na área considerada de risco e desta forma apresentam valores inadequados para o IMC pré-gestacional inferior a $19 \mathrm{Kg} / \mathrm{m}^{2}$ 
como limite aceitável. Confirmando o pressuposto acima, observa-se que a variável escolaridade, apesar de não apresentar diferença significativa, apresenta um percentual de $23,0 \%$ de mães com 4 anos de estudos e precentuais menores para as outras áreas (Tabela 10).

Tabela 10 - Análise das medianas, médias e desvio padrão das variáveis maternas entre as 3 áreas, Maringá-PR, 1998.

\begin{tabular}{|c|c|c|c|c|c|}
\hline Variável & Parâmetro & Verde (306) & Amarela(179) & Vermelha(68) & $\mathrm{P} * * *$ \\
\hline Idade da & Mediana & 25,0 & 24,0 & 23,0 & \multirow{3}{*}{0,0072} \\
\hline \multirow[t]{2}{*}{ Mãe (anos) } & Média (DP*) & $25,71(5,94)$ & $24,64(6,11)$ & $23,51(5,71)$ & \\
\hline & Min- Máx** & $14,0-43,0$ & $13,0-42,0$ & $14,0-39,0$ & \\
\hline \multirow{3}{*}{$\begin{array}{l}\text { Estatura da } \\
\text { Mãe }(\mathrm{m})\end{array}$} & Mediana & 1,60 & 1,60 & 1,59 & \multirow{3}{*}{0,0979} \\
\hline & Média (DP*) & $1,60(0,06)$ & $1,60(0,07)$ & $1,59(0,06)$ & \\
\hline & Min - Máx** & $1,47-1,80$ & $1,40-1,80$ & $1,44-1,75$ & \\
\hline \multirow{3}{*}{$\begin{array}{l}\text { Peso Pré- } \\
\text { gestacional } \\
(\mathrm{Kg})\end{array}$} & Mediana & 57,0 & 55,5 & 55,0 & \multirow{3}{*}{0,5489} \\
\hline & Média (DP*) & $57,28(9,61)$ & $56,38(8,44)$ & $56,48(8,46)$ & \\
\hline & Min - Máx** & $38,0-98,0$ & $40,0-86,0$ & $43,0-88,0$ & \\
\hline \multirow{3}{*}{$\begin{array}{l}\text { Peso final } \\
\text { da gestação } \\
(\mathrm{kg})\end{array}$} & Mediana & 68,0 & 68,0 & 67,0 & \multirow[t]{3}{*}{0,5276} \\
\hline & Média (DP*) & $68,90(10,31)$ & $69.08(10,11)$ & $67,32(9,16)$ & \\
\hline & Min - Máx** & $49,0-98,0$ & $45,0-98,0$ & $43,0-95,0$ & \\
\hline \multirow{3}{*}{$\begin{array}{l}\text { Peso ganho } \\
\text { na gestação } \\
(\mathrm{Kg})\end{array}$} & Mediana & 12,0 & 12.0 & 11,0 & \multirow{3}{*}{0,2160} \\
\hline & Média (DP*) & $11,96(5,86)$ & $13,01(5,68)$ & $11,84(6,05)$ & \\
\hline & Min-Máx** & $(-7)-42,0$ & $3,0-31,0$ & $(-3)-39,0$ & \\
\hline \multirow{3}{*}{$\begin{array}{l}\text { Intervalo } \\
\text { Partal } \\
\text { (mês) }\end{array}$} & Mediana & 36,0 & 36,0 & 35,0 & \multirow{3}{*}{0,5687} \\
\hline & Média (DP*) & $41,16(21,09)$ & $41,8(23,1)$ & $37,5(19,2)$ & \\
\hline & Min - Máx** & $10,0-96,0$ & $12,0-96,0$ & $12,0-96,0$ & \\
\hline \multirow{3}{*}{$\begin{array}{l}\text { IMC pré- } \\
\text { gestacional } \\
\left(\mathrm{Kg} / \mathrm{m}^{2}\right)\end{array}$} & Mediana & 20,8 & 22,4 & 24,0 & \multirow{3}{*}{0,3226} \\
\hline & Média (DP*) & $21,99(4,28)$ & $23,05(4,59)$ & $22,88(4,00)$ & \\
\hline & Min-Máx** & $14,7-35,1$ & $15,4-32,1$ & $15,8-31,2$ & \\
\hline \multirow{3}{*}{$\begin{array}{l}\text { IMC do } \\
\text { final } \\
\left(\mathrm{Kg} / \mathrm{m}^{2}\right)\end{array}$} & Mediana & 30,1 & 27,4 & 30,2 & \multirow{3}{*}{0,3546} \\
\hline & Média (DP*) & $29,00(3,81)$ & $28,09(4,22)$ & $29,14(5,36)$ & \\
\hline & Min - Máx** & $17,6-39,6$ & $21,1-38,5$ & $16,8-35,9$ & \\
\hline \multirow{3}{*}{$\begin{array}{l}\mathrm{N}^{\circ} \text { de } \\
\text { consultas } \\
\text { de pré-natal }\end{array}$} & Mediana & 9,0 & 8,0 & 8,0 & \multirow{3}{*}{0,08359} \\
\hline & Média (DP*) & $7,91(1,79)$ & $7,56(1,82)$ & $8,00(2,00)$ & \\
\hline & Min - Máx** & $1,0-15,0$ & $1,0-14,0$ & $1,0-15,0$ & \\
\hline
\end{tabular}




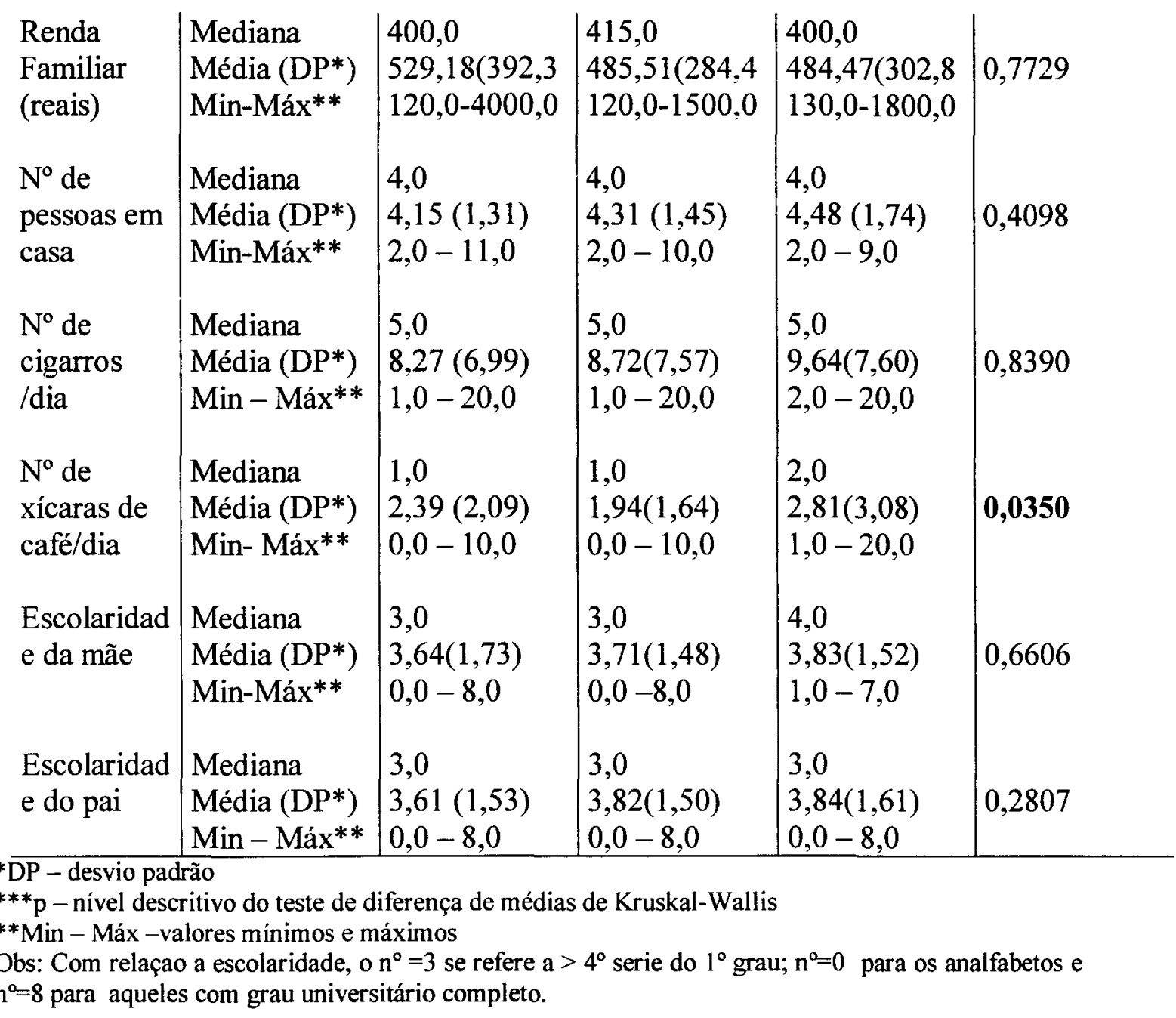

A seguir, analisou-se a distribuição das mães segundo as áreas e as variáveis dependentes para verificar se as áreas poderiam estar atuando como fator de diferenciação para a ocorrência do fator de estudo (Tabela 11).

Tabela 11 - Distribuição do número e \% de mães segundo as áreas e as variáveis independentes, Maringá-PR, 1998.

\begin{tabular}{|c|c|c|c|c|c|c|c|c|c|}
\hline \multirow[t]{2}{*}{ Variável } & \multirow[t]{2}{*}{ Categoria } & \multicolumn{2}{|c|}{$\begin{array}{l}\text { Verde } \\
\left(\mathrm{N}^{\circ} 306\right)\end{array}$} & \multicolumn{2}{|c|}{$\begin{array}{l}\text { Amarela } \\
\left(N^{\circ} 179\right)\end{array}$} & \multicolumn{2}{|c|}{$\begin{array}{l}\text { Vermelho } \\
\left(N^{\circ} 68\right)\end{array}$} & \multirow[t]{2}{*}{$\mathrm{X}^{2}$} & \multirow[t]{2}{*}{$\mathrm{P}^{* *}$} \\
\hline & & $\mathrm{N}^{\circ}$ & $\%$ & $\mathrm{~N}^{\mathrm{o}}$ & $\%$ & $\mathrm{~N}^{\circ}$ & $\%$ & & \\
\hline Peso ao & $<2500$ & 20 & 6,5 & 12 & 6,7 & 5 & 7,4 & 0,06 & 0,9706 \\
\hline nascer $(\mathrm{g})$ & $>=2500$ & 286 & 93,5 & 167 & 93,3 & 63 & 92,6 & & \\
\hline Idade da & $<20$ & 48 & 15,7 & 47 & 26,3 & 17 & 25,0 & 8,89 & 0,0117 \\
\hline mãe (anos) & $>=20$ & 258 & 84,3 & 132 & 73,7 & 51 & 75,0 & & \\
\hline
\end{tabular}




\begin{tabular}{|c|c|c|c|c|c|c|c|c|c|}
\hline $\begin{array}{l}\text { Estatura da } \\
\text { mãe }(\mathrm{m})\end{array}$ & $\begin{array}{l}<1,50 \\
>=1,50 \\
\text { S/inform* }\end{array}$ & $\begin{array}{r}5 \\
290 \\
11\end{array}$ & $\begin{array}{r}1,6 \\
94,8 \\
3,6\end{array}$ & $\begin{array}{r}9 \\
170\end{array}$ & $\begin{array}{r}5,0 \\
95,0\end{array}$ & $\begin{array}{r}3 \\
64 \\
1\end{array}$ & $\begin{array}{r}4,4 \\
94,1 \\
1,5\end{array}$ & 4,51 & 0,1046 \\
\hline $\begin{array}{l}\text { Peso Pré- } \\
\text { gestacional } \\
(\mathrm{kg})\end{array}$ & $\begin{array}{l}<50 \\
>=50\end{array}$ & $\begin{array}{r}75 \\
231\end{array}$ & $\begin{array}{l}24,5 \\
75,5\end{array}$ & $\begin{array}{r}45 \\
134\end{array}$ & $\begin{array}{l}25,1 \\
74,9\end{array}$ & $\begin{array}{l}13 \\
55\end{array}$ & $\begin{array}{l}19,1 \\
80,9\end{array}$ & 1,06 & 0,5893 \\
\hline $\begin{array}{l}\text { Ganho de } \\
\text { peso na } \\
\text { gestação } \\
(\mathrm{Kg})\end{array}$ & $\begin{array}{l}<=9 \\
>9 \\
\text { S/inform* }\end{array}$ & $\begin{array}{r}100 \\
189 \\
17\end{array}$ & $\begin{array}{r}32,5 \\
61,8 \\
5,6\end{array}$ & $\begin{array}{r}54 \\
121 \\
4\end{array}$ & $\begin{array}{r}30,2 \\
67,6 \\
2,2\end{array}$ & $\begin{array}{r}20 \\
44 \\
4\end{array}$ & $\begin{array}{r}29,5 \\
64,7 \\
5,8\end{array}$ & 3,13 & 0,6911 \\
\hline $\begin{array}{l}\text { Intervalo } \\
\text { Partal } \\
\text { (meses) }\end{array}$ & $\begin{array}{l}<\quad 12 \\
>=12 \\
\text { Primíparas }\end{array}$ & $\begin{array}{r}2 \\
156 \\
148\end{array}$ & $\begin{array}{r}0,6 \\
51,0 \\
48,4\end{array}$ & $\begin{array}{r}- \\
106 \\
73\end{array}$ & $\begin{array}{c}- \\
59,2 \\
40,8\end{array}$ & $\begin{array}{l}- \\
27 \\
41\end{array}$ & $\begin{array}{c}- \\
39,7 \\
60,3\end{array}$ & 1,70 & 0,4284 \\
\hline $\begin{array}{l}\text { IMC pré- } \\
\text { gestacional } \\
\left(\mathrm{Kg} / \mathrm{m}^{2}\right)\end{array}$ & $\begin{array}{l}<19 \\
>=19 \\
\text { S/inform* }\end{array}$ & $\begin{array}{r}70 \\
236\end{array}$ & $\begin{array}{l}22,9 \\
77,1\end{array}$ & $\begin{array}{r}1 \\
157 \\
1\end{array}$ & $\begin{array}{r}11,7 \\
87,7 \\
0,6\end{array}$ & $\begin{array}{r}8 \\
59 \\
1\end{array}$ & $\begin{array}{r}11,8 \\
86,8 \\
1,4\end{array}$ & 9,79 & 0,0074 \\
\hline $\begin{array}{l}\text { Renda } \\
\text { Familiar } \\
\text { (reais) }\end{array}$ & $\begin{array}{l}<=130 \\
>130 \\
\text { S/inform* }\end{array}$ & $\begin{array}{r}8 \\
283 \\
15\end{array}$ & $\begin{array}{r}2,6 \\
92,5 \\
4,9\end{array}$ & $\begin{array}{r}9 \\
161 \\
9\end{array}$ & $\begin{array}{r}5,0 \\
90,0 \\
5,0\end{array}$ & $\begin{array}{r}1 \\
65 \\
2\end{array}$ & $\begin{array}{r}1,5 \\
95,6 \\
2,9\end{array}$ & 2,93 & 0,2307 \\
\hline $\begin{array}{l}\text { Escolaridade } \\
\text { da mãe }\end{array}$ & $\begin{array}{l}<=4^{\mathrm{a}} \text { série } \\
>4^{\mathrm{a}} \text { série }\end{array}$ & $\begin{array}{r}70 \\
236\end{array}$ & $\begin{array}{l}22,9 \\
77,1\end{array}$ & $\begin{array}{r}25 \\
154\end{array}$ & $\begin{array}{l}14,0 \\
86,0\end{array}$ & $\begin{array}{l}12 \\
56\end{array}$ & $\begin{array}{l}17,6 \\
82,4\end{array}$ & 5,89 & 0,0526 \\
\hline $\begin{array}{l}\text { Escolaridade } \\
\text { do Pai }\end{array}$ & $\begin{array}{l}<=4^{a} \text { série } \\
>4^{a} \text { série } \\
\text { S/inform* }\end{array}$ & $\begin{array}{r}52 \\
231 \\
23\end{array}$ & $\begin{array}{r}17,0 \\
75,5 \\
7,5\end{array}$ & $\begin{array}{r}21 \\
152 \\
6\end{array}$ & $\begin{array}{r}11,7 \\
84,9 \\
3,4\end{array}$ & $\begin{array}{r}9 \\
54 \\
5\end{array}$ & $\begin{array}{r}13,2 \\
79,4 \\
7,4\end{array}$ & 3,26 & 0,1957 \\
\hline $\begin{array}{l}\mathrm{N}^{o} \text { de } \\
\text { consultas de } \\
\text { pré-natal }\end{array}$ & $\begin{array}{l}<6 \\
>=6 \\
\text { S/inform* }\end{array}$ & $\begin{array}{r}16 \\
289 \\
1\end{array}$ & $\begin{array}{r}5,3 \\
94,4 \\
0,3\end{array}$ & $\begin{array}{r}8 \\
167 \\
4\end{array}$ & $\begin{array}{r}4,5 \\
93,3 \\
2,2\end{array}$ & $\begin{array}{r}5 \\
62 \\
1\end{array}$ & $\begin{array}{r}7,3 \\
91,2 \\
1,5\end{array}$ & 2,51 & 0,2845 \\
\hline $\begin{array}{l}\mathrm{N}^{\circ} \text { de } \\
\text { cigarros / dia }\end{array}$ & $\begin{array}{l}>\quad 5 \\
<=5 \\
\tilde{N} \text { fumantes }\end{array}$ & $\begin{array}{r}17 \\
19 \\
270\end{array}$ & $\begin{array}{r}5,6 \\
6,2 \\
88,2\end{array}$ & $\begin{array}{r}9 \\
13 \\
157\end{array}$ & $\begin{array}{r}5,0 \\
7,3 \\
87,7\end{array}$ & $\begin{array}{r}7 \\
7 \\
54\end{array}$ & $\begin{array}{l}10,3 \\
10,3 \\
79,4\end{array}$ & 0,34 & 0,8433 \\
\hline $\begin{array}{l}N^{\circ} \text { de } \\
\text { xicaras de } \\
\text { café/dia }\end{array}$ & $\begin{array}{l}<=3 \\
>\quad 3 \\
\text { s/café }\end{array}$ & $\begin{array}{r}43 \\
164 \\
99\end{array}$ & $\begin{array}{l}14,1 \\
53,6 \\
32,4\end{array}$ & $\begin{array}{c}17 \\
120 \\
42\end{array}$ & $\begin{array}{r}9,5 \\
67,0 \\
23,5\end{array}$ & $\begin{array}{l}11 \\
38 \\
19\end{array}$ & $\begin{array}{l}16,2 \\
55,9 \\
27,9\end{array}$ & 4,62 & 0,0991 \\
\hline
\end{tabular}


Foi realizada análise das variáveis de risco por área de IPTU; no entanto as variáveis não se apresentaram com significância estatística e desta forma o estudo individualizado por área ficou alocado nos anexos 06, 07 e 08 (área verde, amarela e vermelha respectivamente).

Dois aspectos chamam a atenção em relação aos serviços públicos de saúde e a situação sócio-econômica da população. O primeiro diz respeito à homogeneidade de características sociais e econômicas da população de gestantes que freqüentaram o Programa de Assistência à Gestante de Maringá, no ano de 1997 mas que se diferencia pelo valor imobiliário de suas residências. Embora isso ocorra, não é possível distinguir a população de estudo pela renda familiar que apresenta médias e medianas bastante próximas. Ressalta-se que a população da área com menor valor de IPTU é a que se apresenta com melhor nível de escolaridade e com zero casos de analfabetismo (Tabela 11).

Outro aspecto interessante é que, diferentemente do que ocorre em serviços públicos de saúde, é na região de maior poder aquisitivo que se concentra a maior demanda pelo Programa de Assistência à Gestante e a maior proporção de filhos nascidos com baixo peso e com peso inadequado. Uma hipótese para explicar tal distribuição seria que as mulheres que trabalham o fazem na área verde e, por isso, utilizam os serviços desta área. 


\subsection{O peso ao nascer}

O peso ao nascer é o retrato da qualidade nutricional espelhando a atenção e cuidados praticados no periodo gravídico. Em Maringá foram estudadas 587 mães biológicas e suas respectivas crianças menores de 1 ano de idade. Encontrou-se $37(6,3 \%)$ crianças com baixo peso ao nascer $(<2500 \mathrm{~g}), 122(20,8 \%)$ com peso insuficiente $(2500-2999 \mathrm{~g})$ e $428(72,9 \%)$ com peso adequado $(>=3000 \mathrm{~g})$.

Cotejando estes resultados com aqueles encontrados para o Brasil no estudo "Aleitamento Materno, dieta de desmame e anemia no primeiro ano de vida em crianças atendidas na rede pública de saúde" *, verifica-se que a proporção de crianças BPN é maior do que o encontrado em Maringá $(9,0 \%)$ e o peso insuficiente também ocorreu em maior proporção. Essa diferença entre os valores encontrados em postos de saúde do Brasil e em Maringá sugere, ao mesmo tempo, que o Programa de Assistência à Gestante é melhor conduzido nesta última localidade, mas também e principalmente, que resultados similares aos encontrados em paises desenvolvidos podem ser reproduzidos em serviços públicos de saúde de paises em desenvolvimento.

O menor e o maior valor do peso ao nascer foram $855 \mathrm{~g}$ e $4850 \mathrm{~g}$. Os pesos médios e medianos foram respectivamente $3213 \mathrm{~g}$ (desvio padrão 503,22) e $3200 \mathrm{~g}$, valores estes semelhantes aos encontrados por COSTA e col. (1996) no município de São Paulo.

Das crianças identificadas como BPN, 17(45,9\%) nasceram a termo, ou seja, tiveram retardo de crescimento intrauterino e $20(54,1 \%)$ antes da $37^{\circ}$ semana,ou seja, prétemo. A Figura 7 mostra a distribuição de peso das crianças entre a população que freqüenta a rede básica de saúde de Maringá, segundo sexo. 
Figura 7- Distribuição (\%) de crianças segundo o peso ao nascer e sexo, Maringá-PR,1998

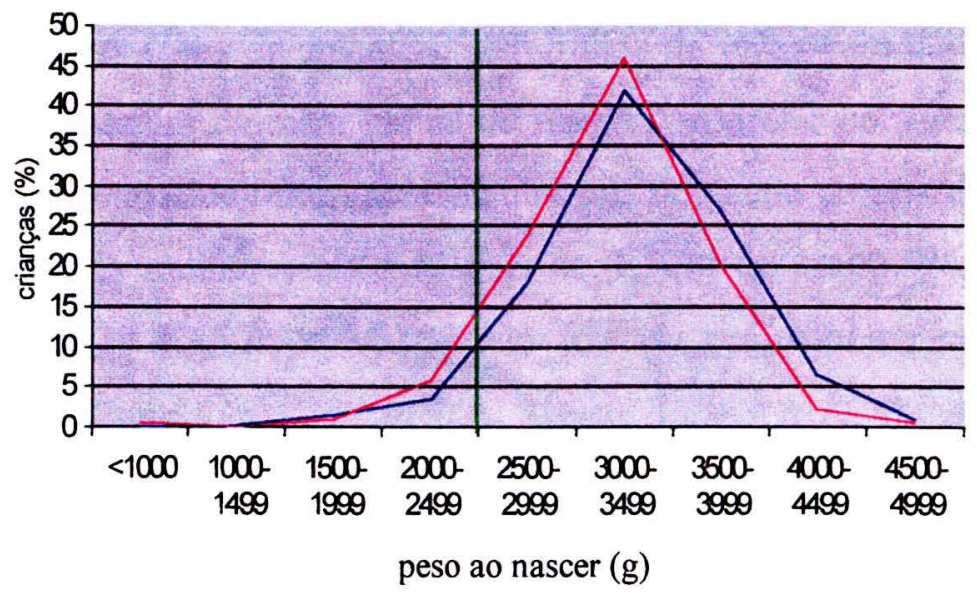

- Masc - Fem

Do total das crianças $315(53,6 \%)$ eram do sexo masculino e as meninas apresentaram um percentual maior de baixo peso ao nascer comparado com os meninos com 7,4\% e 5,4\%, respectivamente. Ressalte-se que não houve associação estatisticamente significativa entre o sexo e a incidência de baixo peso ao nascer $(\mathrm{p}=0,4224)$.

Das 37 crianças identificadas como BPN, observou-se que 17(45,9\%) eram crianças do sexo masculino e não foi observada proporcionalidade entre BPN e a idade da criança e $57,0 \%$ estavam no $1^{\circ}$ semestre de vida, para o qual basicamente a alimentação é láctea.

Para o grupo com retardo de crescimento intrauterino

(RCIU) observou-se que 70,6\% eram do sexo feminino, 76,5\% das crianças eram anêmicas, e 45,8\% eram filhos de mães casadas. Os fatores de risco não se apresentaram significativos e, na maioria das vezes, eram bastante diferentes do referido na literatura com pequena proporção de mães adolescentes $(11,8 \%) ; 25,0 \%$ apresentaram índice de massa corporal menor que $19,0 \mathrm{Kg} / \mathrm{m}^{2}$ e $5,9 \%$ das mães fizeram menos de 6 consultas de pré-natal. Acrescente-se que 100\% das mães deste 
grupo tinham altura maior ou igual a $1,50 \mathrm{~m}$, ou seja, baixa estatura, não foi um fator do risco presente.

Encontrou-se um percentual de $54,05 \%$ de crianças prematuras, com 55,2\% de crianças anêmicas, $65,0 \%$ filhos de mães casadas, e, para os outros fatores como estatura da mãe, índice de massa corporal e consultas de pré-natal os percentuais encontrados foram semelhantes aos do grupo de retardo de crescimento, ou seja, todas as mulheres tinham mais de $1,50 \mathrm{~m}$ de altura, 25,0\% apresentaram IMC $<$ do que $19 \mathrm{Kg} / \mathrm{m}^{2}$ e $6,0 \%$ não fizeram pré-natal na quantidade mínima adequada de consultas.

$\mathrm{Na}$ análise conjunta dos casos de RCIU e prematuridade encontrouse $37(6,3 \%)$ casos de BPN, com pesos médios e medianos de $2077,02 \mathrm{~g}$ e $2200 \mathrm{~g}$. VICTORA e col. (1989) observaram médias de $2454 \mathrm{~g}$ e $2297 \mathrm{~g}$ para as crianças prematuras e crianças com baixo peso para a idade gestacional, respectivamente, acrescentando que a mortalidade foi cerca de 2,5 vezes superior entre as crianças prematuras. SANTOS e col. (1992) encontraram na cidade de Salvador- BA uma incidência de $12 \%$ de BPN, com um peso médio de $2130 \mathrm{~g}$. Não se observaram grandes variações regionais para a incidência de BPN com o estudo de STEFANINI e col. (1988) em sete municípios de São Paulo o percentual foi de 7,3\% e em Recife, FERRAZ e col. (1991) encontraram 9,6\%.

A prevalência de baixo peso ao nascer para a região Sul, segundo a Pesquisa Nacional sobre Saúde e Nutrição (INAN/PNSN - 1989), foi de 9,7\% e, para os Estados Unidos, foi de 6,9\% (HUTCHINS e col. 1984), percentual semelhante ao encontrado em nosso estudo e para 1997, segundo a Secretaria de Saúde do Município de Maringá, foi de 7,0\%, valores estes referenciados para os paises desenvolvidos. Ainda SCHWARCZ e col. (1984), em estudo em 59 maternidades de 11 países latino-americanos, observaram um total de 9,2\% de recém-nascidos de baixo peso, com mortalidade precoce neonatal (até 7 dias) de $78 \%$. 
A análise das médias de ganho de peso diários nos mostra que o ganho de peso diário da criança BPN não se diferencia daquele da amostra total, significando que a criança que nasce com baixo peso tende a crescer com maior velocidade relativa do que as outras na tentativa de alcançar a normalidade de peso (Tabela 12). Isto se confirma, pois na análise das curvas segundo a categoria de peso, o ganho de peso por dia por idade foi bastante similar e esta não se apresentou significativa pelo teste de Snedocor $(F=0,0938, p=0,9597)$.

Tabela 12 - Distribuição do ganho diário de peso (g), segundo a idade e categoria de peso ao nascer. Maringá-PR,1998.

\begin{tabular}{lllll}
\hline $\begin{array}{l}\text { Idade } \\
\text { (trimestre) }\end{array}$ & $\begin{array}{l}\text { BPN } \\
(<2500 \mathrm{~g})\end{array}$ & $\begin{array}{l}\text { PIN } \\
(2500-2999 \mathrm{~g})\end{array}$ & $\begin{array}{l}\text { PAD } \\
(>=3000 \mathrm{~g})\end{array}$ & Total \\
\hline $1^{\circ}$ & $25(10)$ & $36(33)$ & $20(132)$ & $22(175)$ \\
$2^{\circ}$ & $26(12)$ & $27(33)$ & $26(103)$ & $26(148)$ \\
$3^{\circ}$ & $20(12)$ & $37(26)$ & $21(101)$ & $24(139)$ \\
$4^{\circ}$ & $17(3)$ & $19(30)$ & $19(92)$ & $19(125)$ \\
\hline Total & $23(37)$ & $27(122)$ & $21(428)$ & $23(587)$
\end{tabular}

BPN = baixo peso ao nascer

$\mathrm{PIN}=$ peso insuficiente

$\mathrm{PAD}=$ peso adequado

( ) $\mathrm{n}^{\circ}$ de crianças por trimestre de idade

\section{4. Índice de Rohrer}

$\mathrm{Na}$ análise do Índice de Rohrer (IR) para o total da população observou-se que das 587 crianças, 12 não apresentaram o comprimento ao nascer na sua ficha cadastral., ficando para o total da amostra 575 crianças. Na Tabela 13 observa-se que $30,0 \%$ das crianças são desproporcionadas não havendo associação estatisticamente significante entre o sexo e o índice de Rohrer; ARENO (1984) encontrou $14,9 \%$ de crianças desproporcionadas em seu estudo em São Paulo. . 
Tabela 13 - Distribuição do $\mathrm{n}^{\circ} \mathrm{e} \%$ de crianças seguundo o sexo e o índice de Rohrer. Maringá-PR,1998

\begin{tabular}{llll}
\hline Sexo & IR $(<2,51)$ & IR $(>=2,51)$ & Total \\
\hline Masculino & $92(54,8)$ & $215(52,8)$ & $307(53,4)$ \\
Feminino & $76(45,2)$ & $192(47,2)$ & $268(46,6)$ \\
\hline Total & $168(29,2)$ & $407(70,8)$ & $575(100)$ \\
\hline
\end{tabular}

$\mathrm{X}^{2}=0,11 \quad \mathrm{p}=0,7403 \quad \mathrm{OR}=1,08 \quad \mathrm{IC}(0,74-1,58)$

$\mathrm{Na}$ análise por grupos de crianças categorizadas pelo peso ao nascer, observa-se como o esperado, um maior percentual de crianças desproporcionadas para o grupo de crianças BPN, seguidas pelas crianças com peso insuficiente e as com peso adequado com 76,5\%, 53,7\% e 18,3\%, respectivamente. Chama a atenção o maior percentual de crianças desproporcionadas do sexo feminino para os grupos de BPN e peso insuficiente, ocorrendo o inverso para as crianças de peso adequado. Acrescente-se que não houve associação estatisticamente significativa em todos os casos estudados. (Tabela 14, 15 e 16).

Tabela 14 - Distribuição do $n^{\circ}$ e \% de crianças BPN segundo o sexo e o índice de Rohrer. Maringá-PR, 1998.

\begin{tabular}{llll}
\hline Sexo & IR $(<2,51)$ & IR $(>=2,51)$ & Total \\
\hline Masculino & $11(42,3)$ & $4(50,0)$ & $15(44,1)$ \\
Feminino & $15(57,7)$ & $4(50,0)$ & $19(55,9)$ \\
\hline Total & $26(76,5)$ & $8(23,5)$ & $34(100)$ \\
\hline
\end{tabular}

$\mathrm{X}^{2}=0,02 \quad \mathrm{p}=0,5058 \quad \mathrm{OR}=0,73 \quad \mathrm{IC}(0,11-4,63)$

Tabela 15 - Distribuição do $\mathrm{n}^{\circ}$ e \% de crianças com peso insuficiente segundo o sexo e o índice de Rohrer. Maringá-PR, 1998.

\begin{tabular}{llll}
\hline Sexo & IR $(<2,51)$ & IR $(>=2,51)$ & Total \\
\hline Masculino & $32(49,2)$ & $24(42,8)$ & $56(46,3)$ \\
Feminino & $33(50,8)$ & $32(57,2)$ & $65(53,7)$ \\
\hline Total & $65(53,7)$ & $56(46,3)$ & $121(100)$ \\
\hline
\end{tabular}

$\mathrm{X}^{2}=0,27 \mathrm{p}=0,6042 \quad \mathrm{OR}=1,29 \quad \mathrm{IC}(0,59-2,83)$ 
Tabela 16 - Distribuição do $\mathrm{n}^{\circ}$ e \% de crianças com peso adequado segundo o sexo e o índice de Rohrer. Maringá-PR, 1998.

\begin{tabular}{llll}
\hline Sexo & IR $(<2,51)$ & IR $(>=2,51)$ & Total \\
\hline Masculino & $49(63,6)$ & $187(54,5)$ & $236(56,2)$ \\
Feminino & $28(36,4)$ & $156(45,5)$ & $184(43,8)$ \\
\hline Total & $77(18,3)$ & $343(81,7)$ & $420(100)$ \\
\hline $\mathrm{X}^{2}=1,77 \mathrm{p}=0,1834$ & $\mathrm{OR}=1,46 \quad$ IC $(0,85-2,51)$ & &
\end{tabular}

Segundo MILLER e col. (1972) crianças com o comprimento ao nascimento $<47 \mathrm{~cm}$ e baixo IR apresentam um risco aumentado para o óbito fetal. Neste estudo, entre as 56 crianças que apresentaram comprimento $<47 \mathrm{~cm}, 13$ apresentaram IR $<2,51$, o que significa que $23,2 \%$ apresentaram um elevado risco de óbito. Para o grupo das crianças BPN 21 ( 56,7\%) apresentaram comprimento menor $47 \mathrm{~cm}$, sendo $13 \mathrm{com} \mathrm{IR}<2,51$. Para os outros grupos, de peso insuficiente e peso adequado apresentaram comprimento $<47 \mathrm{~cm}, 24(19,7 \%)$ e $11 \quad(2,8 \%)$ respectivamente, sendo que nenhuma destas crianças apresentou $\mathrm{IR}<2,51$.

Analisou-se também a sensibilidade e a especificidade do Índice de Rohrer considerando como padrão a classificação da OMS (1995) de Baixo Peso ao Nascer ( $<2500 \mathrm{~g})$ e Normal $(>=2500 \mathrm{~g})$. Observa-se na Tabela 17 que para o Índice de Rohrer, 26 das 575 crianças eram realmente desproporcionadas com uma sensibilidade de $70 \%$, por outro lado das 541 crianças consideradas sadias, 399 destas eram realmente sadias, uma especificidade de $73 \%$.. O valor preditivo positivo do IR foi de $15 \%$ e o valor preditivo negativo foi de $98 \%$. Para o IR o valor preditivo negativo se apresentou mais adequado, ou seja, dos 407 pacientes com IR adequado, 399 se apresentaram proporcionadas. 
Tabela 17 - Distribuição do $n^{\circ}$ de crianças segundo o IR e o peso ao nascer. Maringá-PR,1998.

\begin{tabular}{llll}
\hline IR & PN $(<2500 \mathrm{~g})$ & PN $(>=2500 \mathrm{~g})$ & Total \\
\hline$<2,51$ & 26 & 142 & 168 \\
$>=2,51$ & 8 & 399 & 407 \\
\hline Total & 37 & 541 & 575 \\
\hline
\end{tabular}

Com o objetivo de verificar a importância do peso ao nascer ao longo do $1^{\circ}$ ano de vida, estudou-se o estado nutricional atual da criança através de seus índices antropométricos e os níveis de concentração da hemoglobina .

\subsection{Peso ao nascer e estado nutricional}

As conseqüências deletérias decorrentes do BPN para a sobrevida e desenvolvimento da criança têm sido sobejamente descritas. Se compete ao pré-natal minimizar os riscos de incidência desse evento, compete à puericultura dar um atendimento especial a essa criança de forma a recuperá-la colocando-a em condições de igualdade com crianças nascidas com peso adequado e de termo. A identificação do estado nutricional dessas crianças permitirá conhecer sua evolução no primeiro ano de vida, levando em consideração o peso ao nascer.

Desta forma avaliou-se o estado nutricional dos filhos das mães amostradas no que se refere aos dois problemas nutricionais de maior relevância entre nós: a desnutrição, avaliada através das medidas antropométricas de peso e comprimento e a anemia, diagnosticada pela $[\mathrm{Hb}]$. Há que se destacar que a criança BPN tende a perpetuar alguns determinantes do evento, como a baixa estatura. Quando ocorre um crescimento mais acelerado a anemia se instala. Em estudos populacionais o BPN e a anemia estão sempre relacionados, pois o peso ao nascer é um fator muito importante na determinação da anemia. 
Entre os fatores que interferem na qualidade da gravidez e, conseqüentemente, no peso ao nascer, destacam-se as deficiências nutricionais (RODRIGUES e col. 1995). A anemia é, ao lado da desnutrição, uma deficiência de suma importância durante a gravidez pela elevada prevalência com que ocorre e, especialmente, pelos efeitos prejudiciais a ela associados (OMS 1975; INACG 1981).

\subsubsection{O Crescimento}

A figura 8 apresenta a distribuição das crianças segundo o peso atual e destaca as nascidas com baixo peso. Verifica-se, com poucas exceções, que estas crianças, independente do tempo transcorrido desde o nascimento, mantém-se com pesos abaixo do peso médio para a idade. Esta ocorrência expõe a dificuldade de recuperação da criança que, no entanto, apresenta um perfil de evolução de crescimento, como já foi constatado, similar ao encontrado na população como um todo.

Figura 8 - Distribuição do peso médio atual e o peso médio atual das crianças BPN segundo a idade em dias. Maringá-PR,1998.

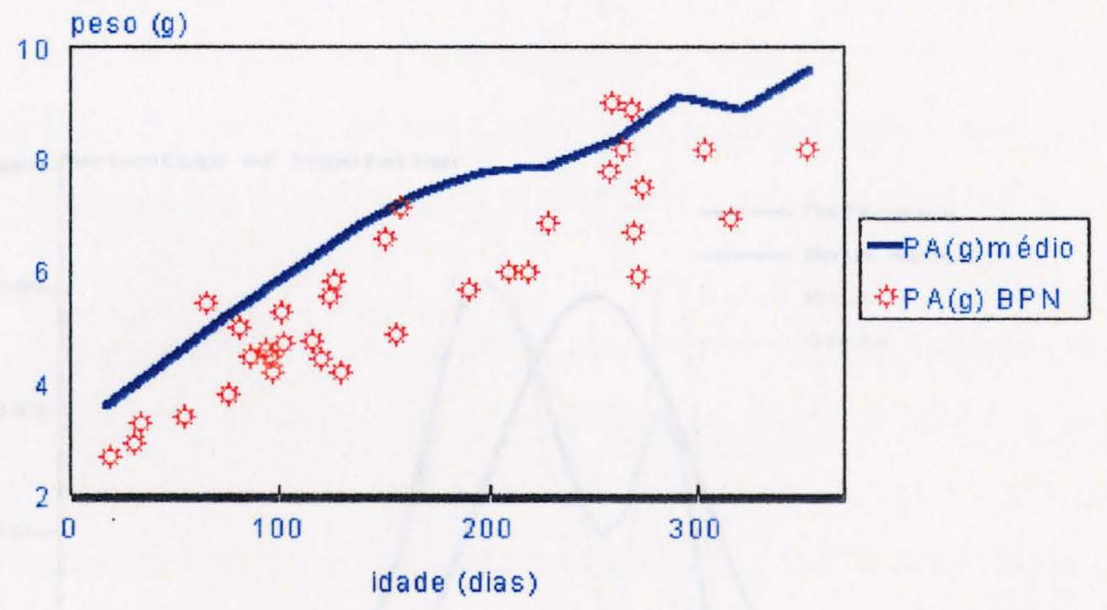


A avaliação do estado nutricional das crianças se apresentou diferenciada. Os grupos foram analisados segundo o peso ao nascer e os indicadores nutricionais de altura para a idade $(\mathrm{A} / \mathrm{I})$ e peso para a idade $(\mathrm{P} / \mathrm{I})$.

As Figuras 9, 10 e 11 apresentam a distribuição (escore-Z) da altura/idade segundo a categoria de peso ao nascer.

Figura 9 - Distribuição \% das crianças BPN segundo o índice escore-Z (Altura /Idade). Maringá-PR, 1998.

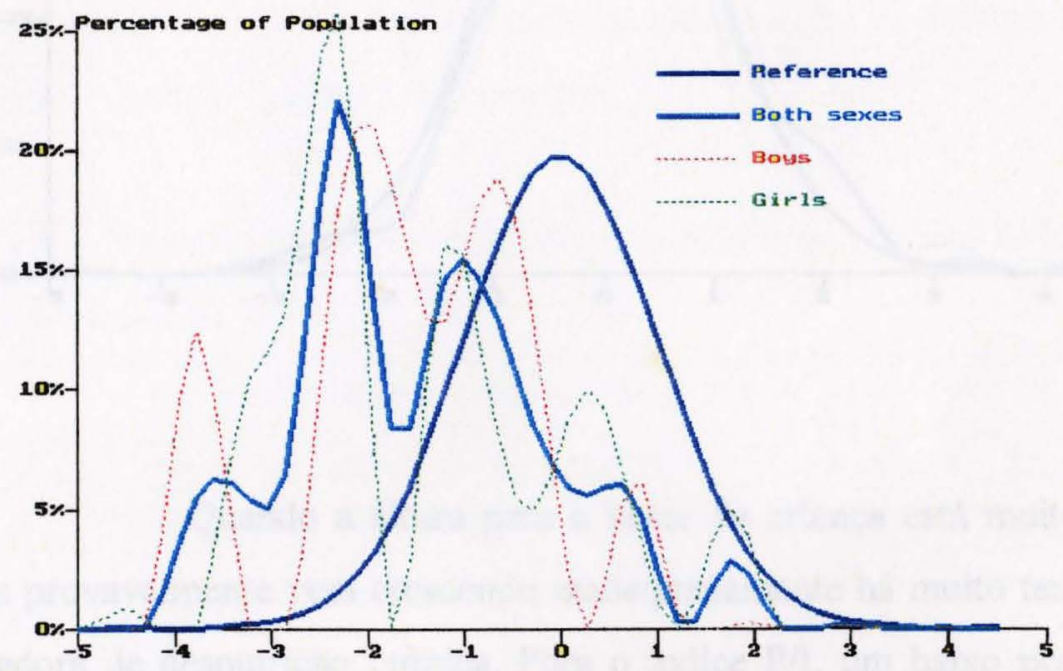

Figura 10 - Distribuição \% das crianças com peso insuficiente segundo o índice escore-Z (Altura /Idade). Maringá-PR, 1998.

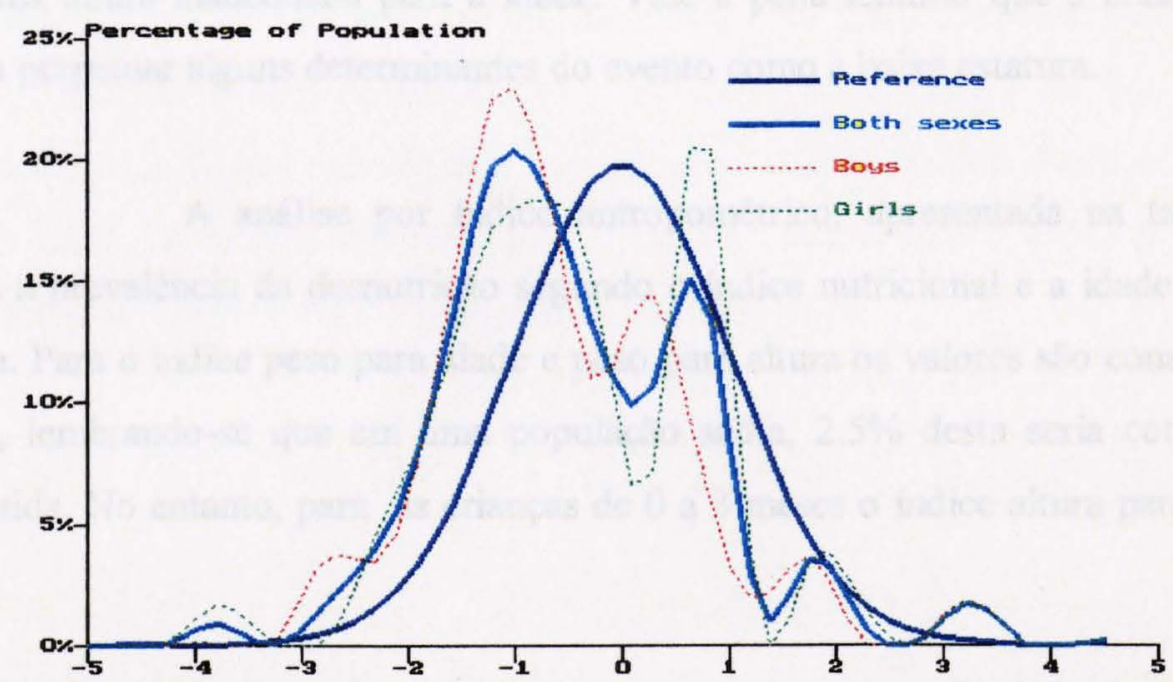


Figura 11 - Distribuição \% das crianças com peso adequado segundo o índice escore-Z (Altura /Idade). Maringá-PR, 1998.

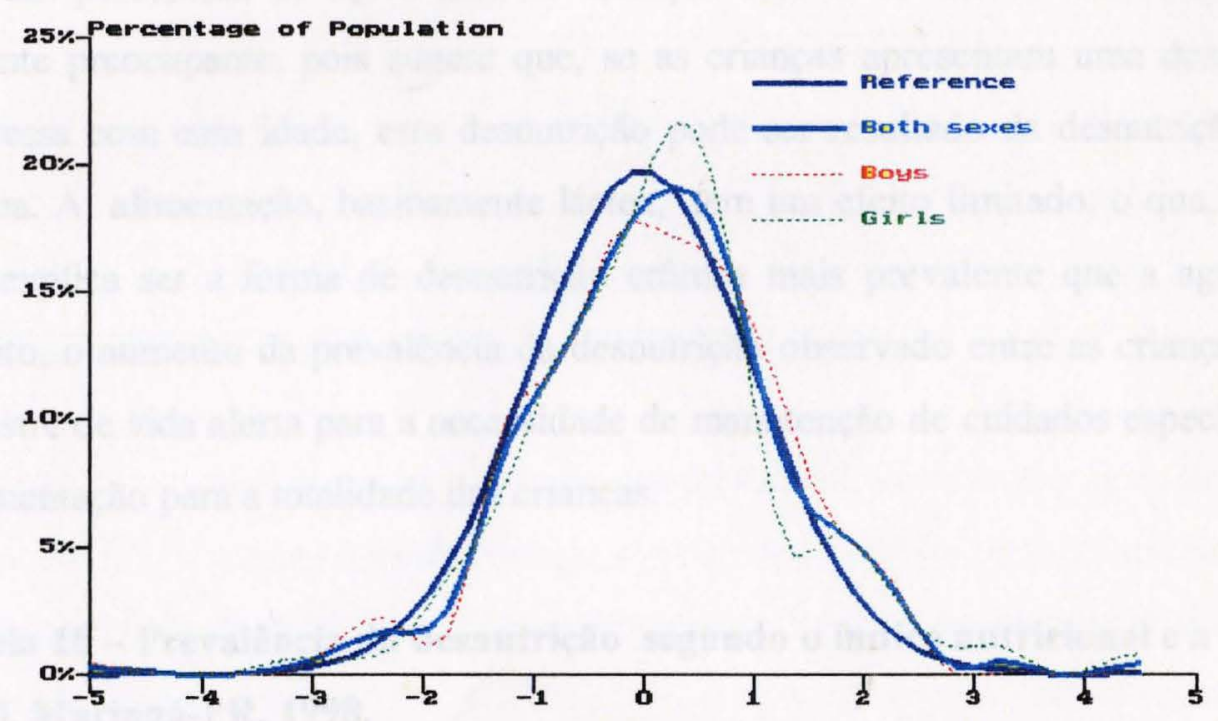

Quando a altura para a idade da criança está muito baixa indica que ela provavelmente vem crescendo inadequadamente há muito tempo, isto é, que é portadora de desnutrição crônica. Para o índice P/I, um baixo peso para a idade pode resultar tanto num processo crônico ( a criança vem ganhando peso de maneira insuficiente há bastante tempo) ou de um processo agudo (a criança vinha crescendo bem mas perdeu peso recentemente). As figuras permitem observar que as crianças nascidas BPN, diferentemente daquelas nascidas com peso insuficiente, mantém-se com uma altura inadequada para a idade. Vale a pena lembrar que a criança BPN tende a perpetuar alguns determinantes do evento como a baixa estatura.

A análise por índice antropométrico, apresentada na tabela 18, mostra a prevalência da desnutrição segundo o índice nutricional e a idade atual da criança. Para o índice peso para idade e peso para altura os valores são considerados baixos, lembrando-se que em uma população sadia, 2,5\% desta seria considerada desnutrida. No entanto, para as crianças de 0 a 3 meses o índice altura para a idade 
se apresentou com um percentual de $14,8 \%$, chamando a atenção para uma desnutrição crônica e não aguda.

O mesmo resultado foi observado por VICTORA e col. (1989) com um percentual de 5,3\% para as crianças de 9 a 12 meses. Este resultado é bastante preocupante, pois sugere que, se as crianças apresentam uma desnutrição pregressa com essa idade, esta desnutrição pode ser resultado da desnutrição intrauterina. A alimentação, basicamente láctea, tem um efeito limitado, o que, por sua vez, explica ser a forma de desnutrição crônica mais prevalente que a aguda. No entanto, o aumento da prevalência da desnutrição observado entre as crianças no $2^{\circ}$ semestre de vida alerta para a necessidade de manutenção de cuidados especiais com a alimentação para a totalidade das crianças.

Tabela 18 - Prevalência da desnutrição segundo o índice nutricional e a idade atual. Maringá-PR, 1998.

Índice $\quad$ Percentual de crianças desnutridas * segundo a idade

\begin{tabular}{lllll} 
& $0-3$ meses & $4-6$ meses & $7-9$ meses & $10-12$ meses \\
\hline Altura/Idade & 14,8 & 8,9 & 10,1 & 11,2 \\
Peso/Idade & 0,9 & 2,0 & 7,0 & 3,4 \\
Peso/Altura & 2,3 & 4,1 & 5,5 & 3,4 \\
\hline$N^{\circ}$ de crianças & $217(37,4)$ & $146(25,2)$ & $128(22,1)$ & $89(15,3)$ \\
\hline
\end{tabular}

* abaixo da média menos 2 desvios padrão do escore-Z (NCHS)

A tabela 19 mostra resultados esperados uma vez que o tamanho da criança é resultado do peso em que nasceu e este resultado demonstrou que a criança BPN não conseguiu recuperar o seu peso atual para a idade, e o mais preocupante é que esta desnutrição se apresenta como crônica. Para o total das crianças observou-se uma desnutrição de $2,9 \%$ de crianças para o índice peso/idade, $3,3 \%$ para peso/altura e 10,9\% para o índice altura/idade. 
Tabela 19 - Prevalência da desnutrição segundo os grupos de peso ao nascer e o índice nutricional atual. Maringá-PR, 1998.

\begin{tabular}{lllll}
\hline Peso ao nascer & \multicolumn{3}{c}{ Percentual de crianças desnutridas * } \\
& Altura/Idade & Peso/Idade & Peso/Altura & Total de \\
& & & & crianças \\
\hline BPN & 41,7 & 11,1 & 2,7 & 36 \\
PIN & 18,0 & 4,1 & 7,4 & 122 \\
PAD & 6,1 & 1,4 & 2,1 & 422 \\
\hline Total & $63(10,9 \%)$ & $15(2,9 \%)$ & $19(3,3 \%)$ & 580 \\
\hline
\end{tabular}

* abaixo da média menos 2 desvios padrão do escore-Z (NCHS)

Analisando o grupo de crianças BPN, observou-se que, tanto para as crianças RCIU quanto para as crianças prematuras, $o$ índice de desnutrição crônica é alto, sendo $52,9 \%$ e $50,0 \%$, respectivamente. Para as prematuras encontramos $25,0 \%$ de desnutrição aguda e 5,0\%, de desnutrição pelo índice peso/altura, resultados similares ao estudo de VICTORA e col. (1989), diferenciando, no entanto, para os casos de desnutrição aguda (Tabela 20). No estudo de Maringá, os percentuais menores para as crianças prematuras fazem sentido em termos biológicos, pois a criança prematura nasceu com um baixo peso pelo nascimento precoce enquanto que as RCIU já estavam com o crescimento inadequado intrautero. No entanto, os percentuais encontrados das crianças prematuras, apesar de serem menores que o outro grupo, sugere que o alimento recebido não esta sendo suficiente para um aumento de peso adequado.

Tabela 20 - Prevalência da desnutrição das crianças BPN e índice nutricional atual. Maringá- PR, 1998.

\begin{tabular}{lcccccc}
\hline Peso ao nascer & \multicolumn{5}{c}{ Percentual de crianças desnutridas ${ }^{*}$} \\
\hline & $\begin{array}{c}\text { Altura / } \\
\text { Idade }\end{array}$ & Peso/Idade & Peso/Altura & Normal & $\begin{array}{c}\text { Total de } \\
\text { crianças }\end{array}$ \\
\hline RCIU & $9(52,9)$ & $2(11,8)$ & - & $6(35,3)$ & $17(45,9)$ \\
Prematuras & $10(30,0)$ & 5 & $(25,0)$ & $1(5,0)$ & $4(20,0)$ & $20(54,1)$ \\
\hline Total & $19(51,3)$ & $7(18,9)$ & $1(2,7)$ & $10(27,1)$ & $37(54,1)$
\end{tabular}




\subsubsection{Concentração de Hemoglobina}

Alguns estudos entre os quais INACG (1977), DALLMAN e REEVES (1984) apontam a anemia por deficiência de ferro como a doença carencial de maior prevalência na população infantil em todo o mundo. A concentração do nível de hemoglobina para o diagnóstico de anemia ferropriva, mesmo na ausência de outros exames bioquímicos, é considerada adequada em populações onde a deficiência de ferro apresenta alta prevalência. BRUNKEN (1999), em estudo realizado no município de São Paulo, relata um aumento desta prevalência principalmente em crianças menores de 1 ano.

Nos dois primeiros meses de vida ocorre a transformação da concentração da hemoglobina fetal para a adulta, é a chamada impropriamente de "anemia fisiológica", que independe dos fatores nutricionais e é causada pela diminuição da eritropoiese em resposta à saída de $\mathrm{O}_{2}$ para os tecidos. Aos 6 meses ela alcança um platô que é mantido até o final da infância (OSKI e NAIMAN 1984). Segundo DeMAYER e col. (1989), durante o primeiro semestre o lactente utiliza as reservas de ferro acumuladas na vida intrauterina para suprir suas necessidades e devido ao rápido crescimento no primeiro ano de vida, estas reservas de ferro se esgotam aos 4 meses. Este declínio referido nos dois meses de vida foi observado neste estudo (Figura 13), acrescentando-se que, aos 4 meses, quando as reservas de ferro já se esgotaram, a reposição do mineral se apresenta adequada, pois o aleitamento materno, apesar de pobre em ferro, se apresenta com alta biodisponibilidade e é o alimento mais adequado para a criança nesta faixa etária (STEKEL 1984).

A suplementação férrica pode ser feita experimentalmente durante a gestação e tentativas randomizadas provaram que o melhor método seria minimizar no estudo a confusão deste fator. Por causa da queda dos níveis de hemoglobina durante a gestação, este deveria ser medido mais precocemente na gravidez; caso contrário o efeito poderia ser confundido com a expansão do volume plasmático (McLAUGHLIN e KEVANY 1982). 
Há que se chamar a atenção para a inexistência de valores padronizados para identificação desta deficiência nutricional no $1^{\circ}$ semestre de vida. Os valores usualmente utilizados, descritos por BRAULT- DUBUK (1983), referemse a crianças selecionadas e cuja dieta, a maior parte das vezes, incluia alimentos fortificados com o ferro, prática alimentar pouco comum entre as crianças atendidas em serviços públicos de saúde. Assim adotou-se, também para o grupo de crianças de 0 a 6 meses inclusive, o valor de $11,0 \mathrm{~g} / \mathrm{dL}$ a exemplo do feito por outros autores (MONTEIRO e SZARFARC 1987).

Entre as variáveis estudadas em Maringá, a anemia se apresentou com elevada prevalência; entre as mães $87(14,6 \%)$ apresentaram-se anêmicas, não havendo, no entanto, relação desta com o BPN (Tabela 21).

Tabela 21 - Distribuição do $n^{\circ}$ e \% de mães segundo o peso ao nascer da criança e a concentração de hemoglobina da mãe. Maringá-PR,1998.

\begin{tabular}{|c|c|c|c|}
\hline Peso ao nascer & {$[\mathrm{Hb}]$} & Da mãe & Total das crianças \\
\hline & Anêmica & Não Anêmica & \\
\hline$<2500 \mathrm{~g}$ & $7(18,9)$ & $30 \quad(81,1)$ & $37(6,3)$ \\
\hline$>=2500 \mathrm{~g}$ & $79(14,4)$ & $471(85,6)$ & $550(93,7)$ \\
\hline Total & $86(14,6)$ & $501(85,4)$ & $587(100)$ \\
\hline
\end{tabular}

Na Figura 12 a mãe recupera-se da gestação e puerpério muito rapidamente. Já há dois meses do parto, a $[\mathrm{Hb}]$ média é similar à de mulheres não gestantes. Diferentemente do que ocorre com a mãe, as crianças diagnosticadas como anêmicas $338(58,0 \%)$ apresentaram $\mathrm{OR}=3,03(\mathrm{p}=0,0170)$ para o $\mathrm{BPN}$, permitindo supor que a criança que nasce com peso menor que $2500 \mathrm{~g}$ tem uma probabilidade triplicada em ser anêmica comparada àquela com peso superior a $2500 \mathrm{~g}$. 
Figura 12 - Evolução (tendência) da [Hb] da criança e da [Hb] da mãe. Maringá - Pr, 1998.

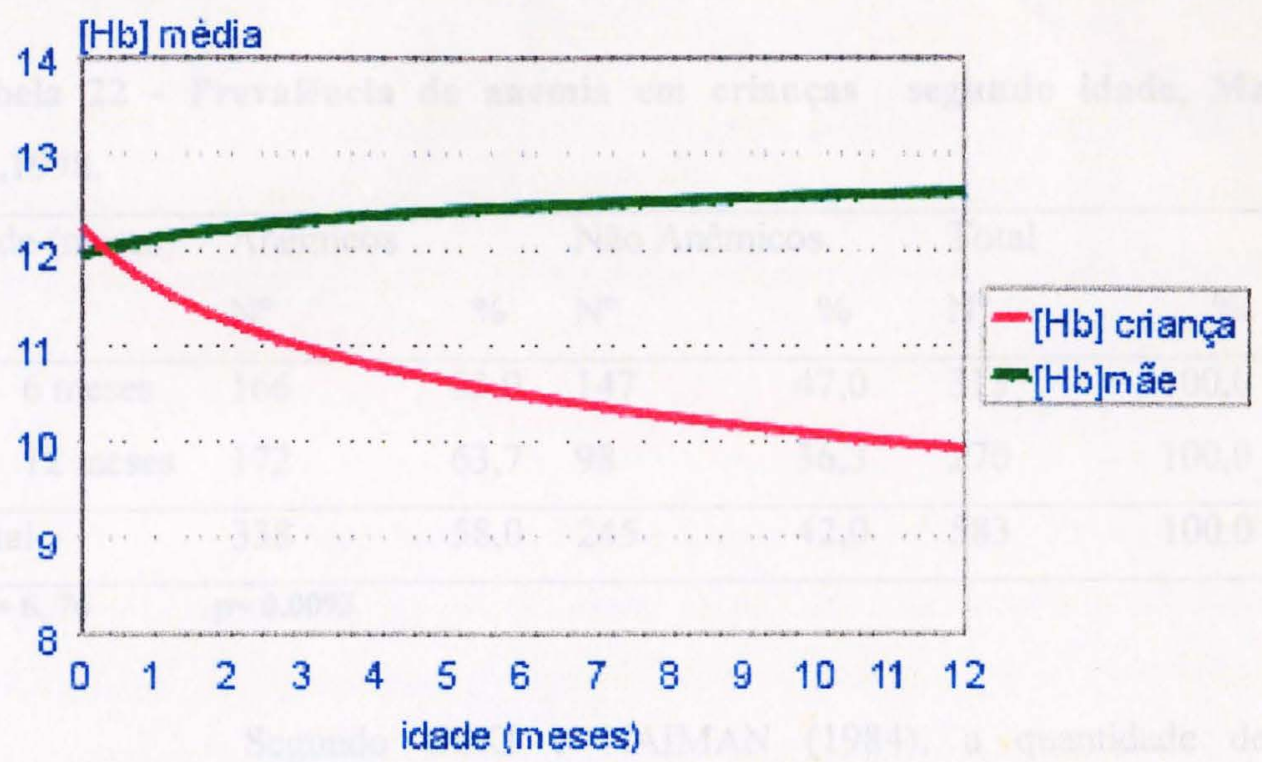

Em pesquisa realizada com mulheres australianas de baixa renda a média de concentração de hemoglobina foi de $12,7 \mathrm{~g} / \mathrm{dL}$. Poucas destas mulheres foram anêmicas e os achados são de pequena relevância para países em desenvolvimento onde a prevalência de anemia ferropriva é alta (KITAY \& HARBORT 1975)

Outros estudos (HINGSON e col. 1982); (GANGULY e col. 1972); (METCOFF e col. 1981) foram realizados em países desenvolvidos e nenhum deles relatou um efeito significativo no estado hematológico ou ingesta de ferro, ajustado para a idade gestacional e peso ao nascer. Também não houve referência relacionada deste efeito na prematuridade e RCIU.

Segundo KRAMER (1987), estudos que têm uma relação do impacto do ferro ou anemia no crescimento intrauterino apresentam falhas na sua metodologia; no entanto, não pode ser tomado como regra que a suplementação férrica não é importante em países com altas prevalências de anemia ferropriva. Verificou-se uma prevalência de anemia de $58 \%$ e, em relação à idade, ela é mais 
prevalente no segundo semestre de vida, sendo esta diferença estatisticamente significativa $(p=0,0093)$ (Tabela 22).

Tabela 22 - Prevalência de anemia em crianças segundo idade, MaringáPR,1998.

\begin{tabular}{llclccc}
\hline Idade (meses) & Anêmicos & \multicolumn{4}{l}{ Não Anêmicos } & \multicolumn{2}{l}{ Total } \\
& No & $\%$ & $\mathrm{~N}^{\circ}$ & $\%$ & $\mathrm{~N}^{\circ}$ & $\%$ \\
\hline $0-6$ meses & 166 & 53,0 & 147 & 47,0 & 313 & 100,0 \\
$6-12$ meses & 172 & 63,7 & 98 & 36,3 & 270 & 100,0 \\
\hline Total & 338 & 58,0 & 245 & 42,0 & 583 & 100,0 \\
\hline $\mathbf{X}^{2}=\mathbf{6 , 7 6}$ & $\mathbf{p = 0 , 0 0 9 3}$ & & & & &
\end{tabular}

Segundo OSKI e NAIMAN (1984), a quantidade de ferro acumulada pelo feto na fase intrauterina é proporcional ao seu aumento de peso. Assim, quanto menor o peso de nascimento mais baixa é a quantidade de ferro orgânico. Este fato é confirmado neste estudo, pois, dentre as crianças BPN, $29(78,4 \%)$ eram anêmicas, e especificamente para o grupo de RCIU, 76,5\% apresentavam a deficiência.

A anemia é uma deficiência nutricional especialmente importante na infância. As consequências de sua presença mantém-se mesmo após o controle da deficiência de ferro. Assim, é necessário identificar precocemente o risco, evitá-lo e/ou corrigi-lo o mais precocemente possivel. A criança nasce com uma quantidade de ferro proporcional ao peso ao nascer e, entre as crianças nascidas com BPN cuja velocidade de crescimento é relativamente maior do que as outras, a deficiência se manifesta muito precocemente e com maior severidade.

Associada ao crescimento, a introdução precoce da dieta de desmame à base de legumes, cereais e leite de vaca podem levar ao desenvolvimento da anemia por volta do $6^{\circ}$ mês, uma vez que o leite, além de ser pobre em ferro, inibe a absorção deste mineral (DALLMAN e REEVES 1984). Com este objetivo realizou-se o cálculo teórico de concentração de hemoglobina (hemoglobina 
estimada) com base no peso ao nascer e o peso no momento da coleta de dados, para verificar a influência do crescimento sobre a concentração da hemoglobina como no trabalho de SICHIERI (1987) em estudo com crianças no Município de São Paulo.

Observou-se que as médias de concentração de hemoglobina para os grupos estudados foram de 9,7g/dL para as crianças BPN, 10,6 g/dL para as de peso insuficiente e $10,6 \mathrm{~g} / \mathrm{dL}$ para aquelas de peso adequado e para o total do estudo o valor encontrado foi de $11,0 \mathrm{~g} / \mathrm{dL}$.

Como mostra a Figura 13, até o $4^{\circ}$ mês de vida a $[\mathrm{Hb}]$ estimada é superior à observada. A partir desta idade, as concentrações de hemoglobina observadas se apresentaram mais elevadas que as outras possivelmente em decorrência da ingestão de ferro exógeno veiculado pelos alimentos de desmame. Mesmo assim os valores de [Hb] são inferiores aos propostos pela OMS (1975. SICHIERI (1987) encontrou um modelo diferente em função dos alimentos.

Figura 13 - Hemoglobina (Hb g/dL) média e das crianças BPN segundo a idade. Maringá-PR, 1998.

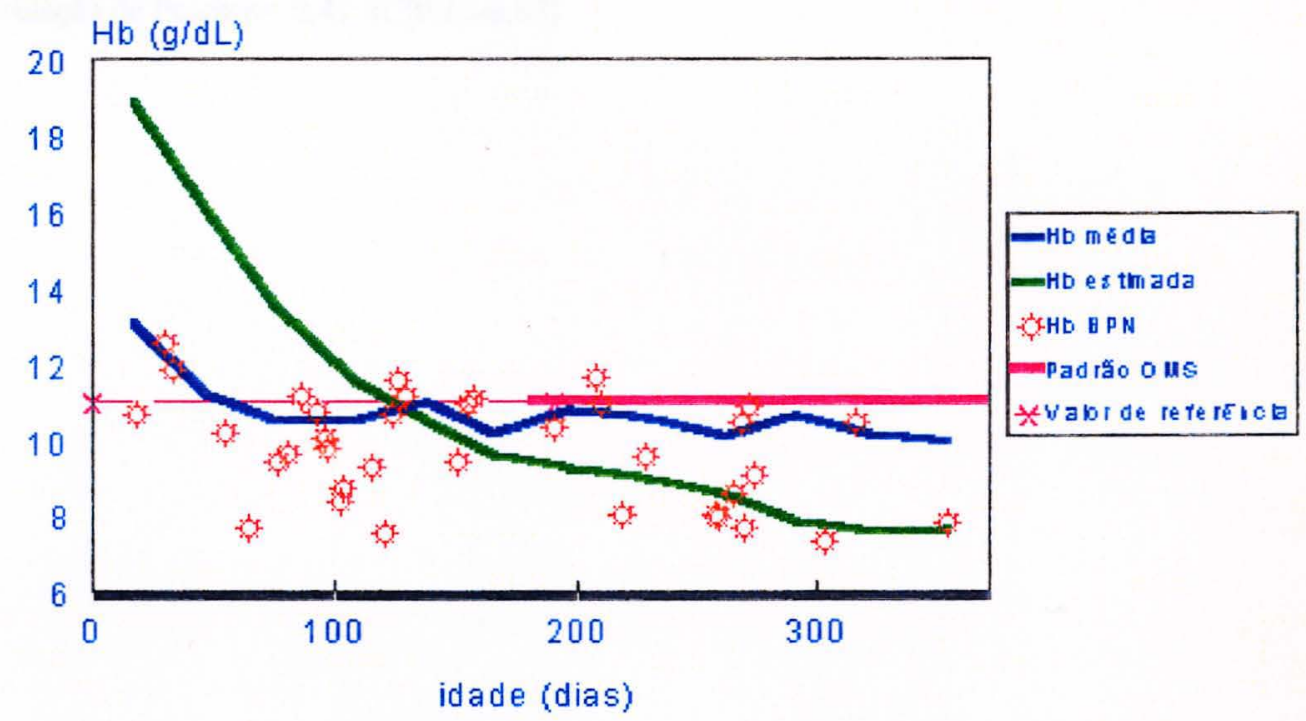

Considerando que durante a vida intra-uterina o feto acumula ferro em quantidade proporcional a seu aumento de peso (WOODRUF 1977); (OSKI e NAIMAN 1984) realizou-se a análise de correlação entre os níveis de hemoglobina 
observada e estimada para o grupo de crianças segundo o peso ao nascer, como uma tentativa de se verificar se esta correlação é mantida ao longo do $1^{\circ}$ ano de vida. (Figuras 14, 15 e 16). Em todos os três grupos estudados observou-se uma baixa correlação entre estas variáveis, contrariando o referido na literarura.

Figura 14 - Distribuição (\%) das médias de concentração de hemoglobina esperada e observada das crianças BPN segundo a idade. Maringá- PR, 1998.

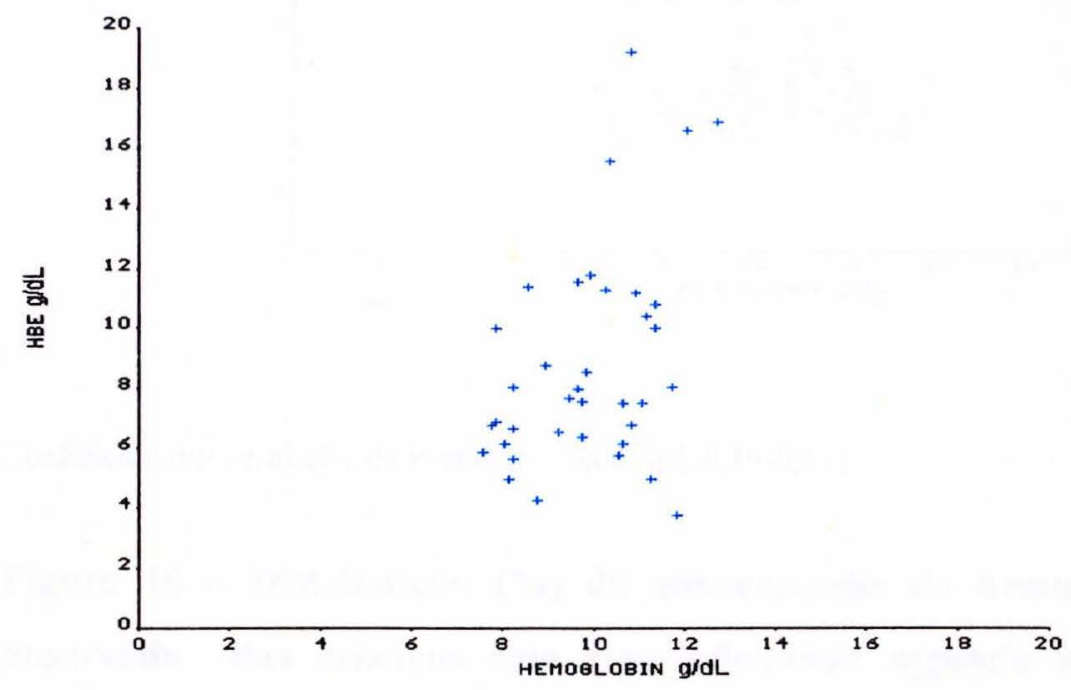

Coeficiente de correlação de Pearson=0,41 IC $[0,10-0,65]$ 
Figura 15 - Distribuição (\%) das médias de concentração de hemoglobina esperada e observada das crianças com peso insuficiente segundo a idade. Maringá,PR,1998.

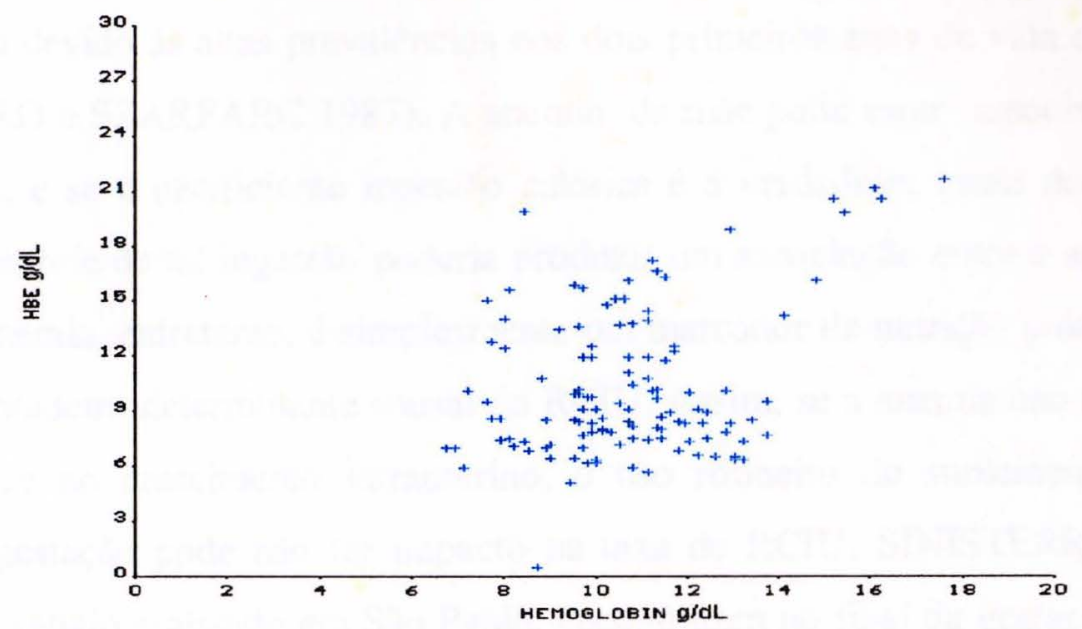

Coeficiente de correlação de Pearson= - 0,01 IC[-0,19-0,17]

Figura 16 - Distribuição (\%) da concentração de hemoglobina esperada e observada das crianças com peso adequado segundo a idade. MaringáPR,1998.

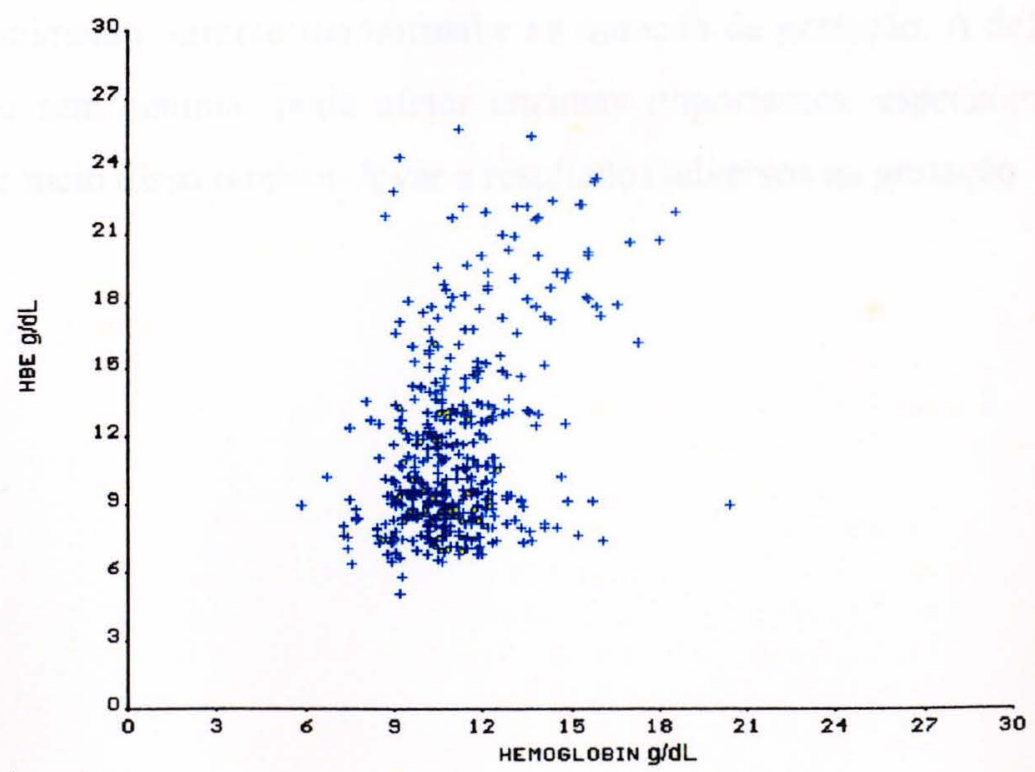

Coeficiente de correlação de Pearson= 0,18 IC $[0,09-0,27]$ 
Embora não se verifique uma correlação entre as hemoglobinas observadas e a estimadas, sabe-se que a anemia esta associada ao peso da criança e o conhecimento da etiologia da anemia no primeiro ano de vida é de fundamental importância devido às altas prevalências nos dois primeiros anos de vida da criança (MONTEIRO e SZARFARC 1987). A anemia da mãe pode estar associada com a desnutrição, e se a insuficiente ingestão calórica é a verdadeira causa do RCIU, a falha no controle de tal ingestão poderia produzir um associação entre a anemia e o RCIU. A anemia, entretanto, é simplesmente um marcador de nutrição pobre da mãe e não o verdadeiro determinante causal do RCIU. Assim, se a anemia não tem efeito independente no crescimento intrauterino, o uso rotineiro de suplemento férrico durante a gestação pode não ter impacto na taxa de RCIU. SINISTERRA e col. (1991), em estudo realizado em São Paulo, encontraram no final da gestação, 29,2\% de gestantes anêmicas e $17,2 \%$ de desnutridas , não tendo sido verificada associação entre essas duas deficiências nutricionais.

Segundo KITAY e HARBORT (1975), a despeito da eritropoiese durante a gestação, a concentração de hemoglobina falha progressivamente até cerca da $32^{\circ}$ semana de gestação, mesmo com grandes aumentos do volume plasmático. A anemia, se grave, pode prejudicar a liberação do oxigênio para o feto e, assim, interferir no crescimento intrauterino normal e na duração da gestação. A deficiência de ferro, mesmo sem anemia, pode afetar enzimas importantes, especialmente os citocromos e por meio disso também levar a resultados adversos na gestação. 


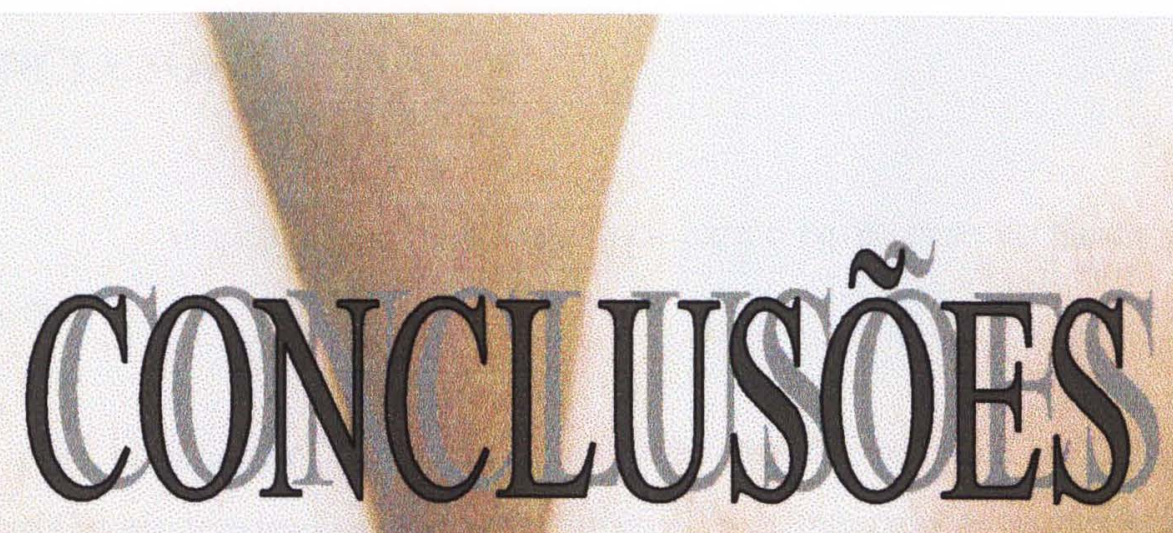




\section{CONCLUSÕES}

O estudo dos fatores de risco para o baixo peso ao nascer permitiu concluir que:

- a mãe com ganho de peso na gestação menor ou igual a $9 \mathrm{Kg}$ tem a probabilidade triplicada de ter um filho BPN comparada às outras com maior ganho de peso .

- a mãe com a idade menor de 20 anos tem 2,49 vezes a chance de ter um filho BPN comparada com as mães mais velhas.

- a mãe que fuma mais de 5 cigarros por dia durante a gestação tem 3,49 vezes mais a probabilidade de ter um filho BPN comparada com aquelas que fumam menos.

- o peso pré-gestacional não é risco para o ganho de peso independente do peso ao nascer $(\mathrm{RRMH}=1,04)(\mathrm{IC}=0,80-1,36)$;

- as áreas de risco para o IPTU (vermelha e amarela) apresentaram 25,0\% de mães com idade $<20$ anos comparada à outra área com $15,0 \%$;

- as mães atendidas na área vermelha apresentaram valores 2 vezes maior de ingesta de café comparadas às outras mães;

- o ganho de peso diário da criança BPN não se diferencia da amostra total, ou seja, a criança BPN tende a crescer com maior velocidade relativa do que as outras; 
- Na análise do IR, para o total da população, 30,0\% das crianças foram classificadas como desproporcionadas;

- Nos grupos BPN, Peso Insuficiente e Peso Adequado o percentual de desproporcionados foi de $76,5 \%, 53,7 \%$ e $18,3 \%$;

- Do total da população dentre as 56 crianças que apresentaram comprimento ao nascer $<47 \mathrm{~cm}, 13$ apresentaram IR $<2,51$, significando que 23,2\% apresentaram elevado risco de óbito;

- A sensibilidade e a especificidade do IR, tendo o peso ao nascer $<2500 \mathrm{~g} \mathrm{e}$ $>=2500 \mathrm{~g}$ como padrão, foi de $70,0 \%$ e $73,0 \%$ respectivamente;

- O valor preditivo positivo do IR foi de $15,0 \%$ e o valor preditivo negativo de $98,0 \%$

- $\quad \mathrm{Na}$ população das crianças, 58\% eram anêmicas e estas apresentaram $\mathrm{OR}=3,03, \mathrm{p}=0,0170$ para o $\mathrm{BPN}$, ou seja, as crianças com baixo peso ao nascer apresentam apresentam uma probabilidade 3 vezes maior em ser anêmica do que as outras;

- Entre as crianças BPN, a [Hb] observada se apresenta mais elevada do que as estimadas para todas as idades, permitindo supor que as crianças nascidas de baixo peso aproveitam o ferro dietético melhor e mais eficientemente do que as outras e que a reciclagem de ferro circulante é mais eficiente;

- A desnutrição manteve-se praticamente na totalidade das crianças BPN, sugerindo que o período transcorrido entre o nascimento e o momento da avaliação foi insuficiente para permitir a inclusão entre as crianças eutróficas. Essa desnutrição é especialmente notável em relação à estatura, mostrando uma desnutrição crônica particularmente grave nos 3 primeiros meses de vida. 


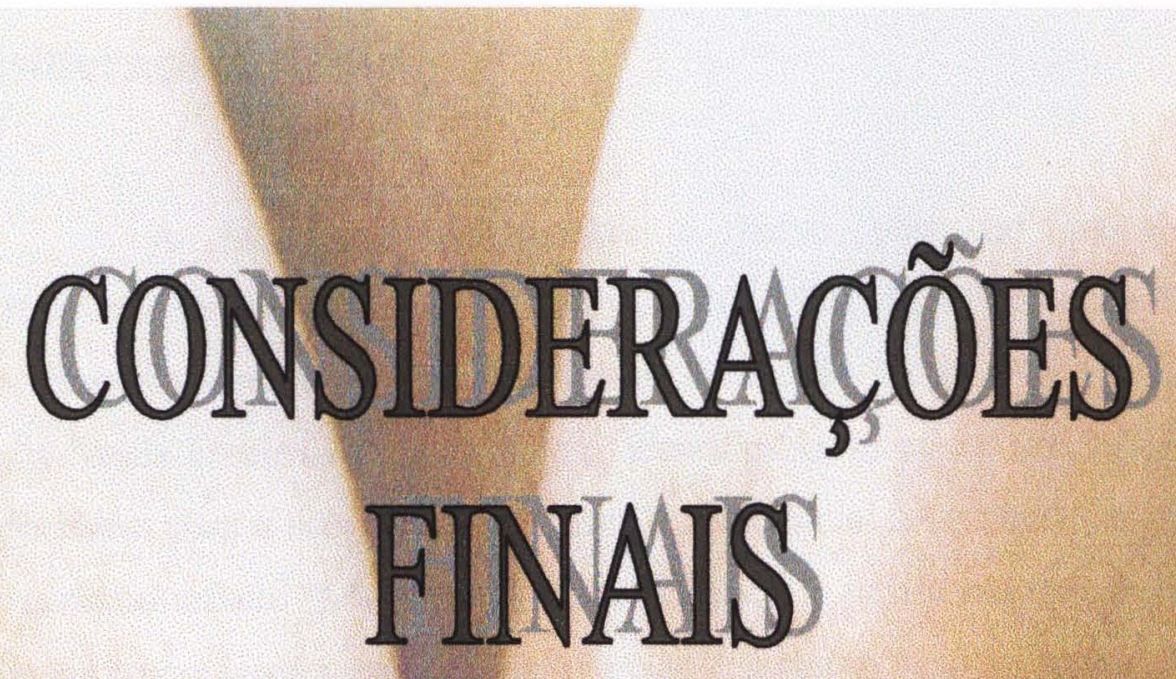




\section{Considerações Finais}

A forte associação entre o baixo peso ao nascer e a morbimortalidade neonatal e infantil (MONTEIRO 1980; PUFFER e SERRANO 1988) se apresenta como um problema grave de Saúde Pública. A Organização Mundial da Saúde confirma esta evidência, identificando-o como um indicador de suma importância para a sobrevivência infantil, e essencial à vigilância e avaliação da saúde materno-infantil (OMS 1980). Esta evidência é verificada tanto em países desenvolvidos como aqueles em desenvolvimento e assim, o peso ao nascer tem sido por muito tempo objeto de investigações clínicas e epidemiológicas em todo o mundo (LECHTING 1988).

Existem muitas controvérsias acerca dos fatores que determinam o $\mathrm{BPN}$, assim como quanto à importância quantitativa destes efeitos, dificultando a distinção entre o retardo de crescimento intrauterino (RCIU) e a prematuridade. Desta forma, se o determinante causal difere do RCIU e da prematuridade o resultado do estudo do determinante etiológico do BPN em um país onde muitos casos nascem com RCIU provavelmente seria diferente daquele onde mais casos de BPN são prematuros (KRAMER 1987). Acrescente-se ainda, a importância de se verificar se este aumento do índice de nascidos com peso abaixo de $3000 \mathrm{~g}$ está associado com a mortalidade infantil.

Embora algumas intervenções não resolvam o problema básico, podem ter um impacto na qualidade de vida do indivíduo, ações tais como o planejamento familiar, a assistência de pré-natal e programas de reabilitação nutricional identificando as crianças ou mulheres de risco.

Um programa de assistência pré-natal adequado daria ênfase à monitorização do ganho de peso durante a gravidez, à educação antifumo, à vacinação antitetânica, aspectos que parecem ser pouco valorizados atualmente. Este programa teria que ser descentralizado, levando através de serviços de saúde o atendimento às populações de risco. No Brasil, segundo o IBGE (1984), 25\% das 
mães não receberam assistência pré-natal, proporção que aumentou para $47 \% \mathrm{em}$ segmentos mais pobres da população e para $41 \%$ em similares segmentos da população rural mais concentrada no nordeste do país.

Esta dificuldade em distinguir corretamente os fatores determinantes com precisão reside na questão que muitos dos determinantes são altamente associados e seus efeitos são mutuamente confundidos, por isso, o não controle das variáveis de confusão pode levar a erros na associação entre o RCIU e a prematuridade. A interação de dois ou mais índices de avaliação do estado nutricional com o objetivo de minimizar os riscos da criança BPN são importantes pois assegura um aumento no percentual de sobrevida desta.

Neste estudo o processo de coleta de dados não apresentou dificuldades, pois a população estava bem informada e, na grande maioria as solicitações eram feitas para que os exames pudessem ser realizados para os outros membros da família, pois era muito prático e com resultados rápidos. Foram perdidos somente 12 casos para o final da análise de regressão, visto que estes casos não apresentavam todos os dados das variáveis que se apresentaram mais significativas.

Com relação ao estudo das áreas geográficas, a coleta de endereço verdadeiro da mãe seria interessante; no entanto, isto não acontece, pois as mães, ao referirem o seu verdadeiro local de moradia, não poderiam ser atendidas nos postos da zona central, pois as mães são orientadas para procurarem o posto mais próximo de suas casas.

A importância de se estudar os fatores de risco maternos é relevante, pois, apesar da existência de muitos estudos sobre a desnutrição na infância, o BPN é um fator de risco importante para a mortalidade infantil, acrescentando-se que para a cidade de Maringá este estudo se apresenta como um dos pioneiros. 
Assim sugerimos que esforços conjuntos para melhorar esta assistência pré-natal se apresentam como ações necessárias e urgentes para reduzir os índices de BPN e os efeitos adversos no concepto. 


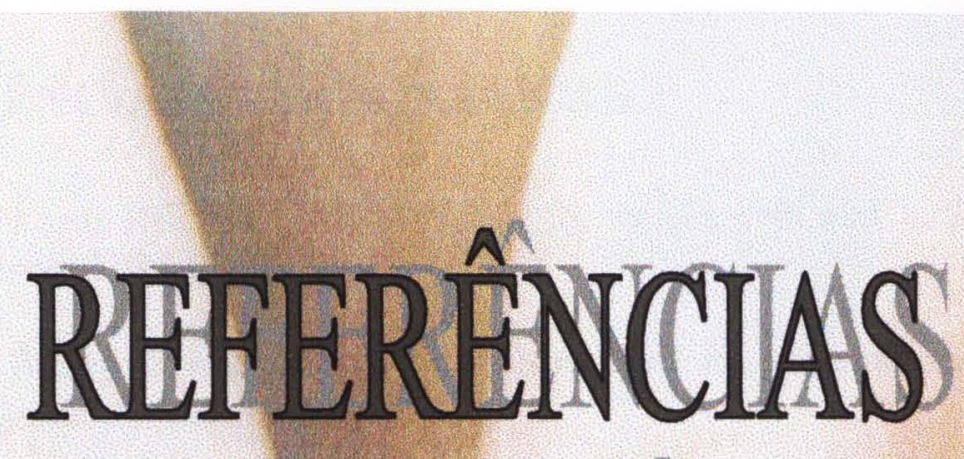

BIBLIOGRÁHICAS 


\section{REFERÊNCIAS BIBLIOGRÁFICAS}

Abrams BF, Laros RK. Pre-pregnancy weigth, weigth gain and birth weigth. Am $J$ Obstetr Gynecol 1986;154: 503-9.

Aldrige A, Bailey J,Neims AH. The disposition of caffeine during and after pregnancy. Semin Perinatol 1981; 5: 310 - 4 .

Anderson JD, Blinder IN, McClemont S, Sinclair JC. Determinants of size at birth in a Canadian population. Am J Obstet Gynecol 1984; 150: 236 - 44.

Areno FB. Contribuição ao Estudo da Antropometria do Recém-Nascido.São Paulo; 1984. [Tese mestrado - Faculdade de Saúde Pública da USP].

Bakewell JM, Stockbauer JN, Schramm WF. Factors associated with repetition of low birth weigth, Missouri longitudinal study. Paediatr Perinat Epidemiol 1997;11 supll 1: 119-29.

Barros FC, Victora CG, Granzoto JA, Vaughan JP, Lemos Jr AV. Saúde perinatal, em Pelotas, RS - Brasil: fatores sociais e biológicos. Rev Saúde Pública 1984; 18 : 301-12.

Barros FC, Victora CG, Vaughan JP, Estanislau HJ. Bajo peso al nacer en el Município de Pelotas, Brasil: factores de riesgo. Bol Oficina Sanit Panam $1987 ; 102: 541-53$.

Barros $\mathrm{H}$, Tavares M, Rodrigues $\mathrm{T}$. Role of prenatal care in preterm birth and low birth weigth in Portugal. J Public Health Med 1996; 18 :321 - 8.

Belizan JM, Nardin JC, Carroli G, Campodónico L. Factores de riesgo de bajo peso al nacer en un grupo de embarazadas de Rosário, Argentina. Bol Oficina Sanit Panam. 1989; 106 : 380- 8.

Bener A, Abdulrazzaq YM, Dawodu A. Sociodemographic risk factors associated with low birth weigth in United Arab Emirates $\boldsymbol{J}$ Biosoc Sci $1996 ; 28$ : 339 - 46.

Benício MH. Fatores de risco do baixo peso ao nascer em recém- nascidos vivosMunícipio de São Paulo, 1978. São Paulo; 1983. [Tese doutorado. - Faculdade de Medicina da USP].

Benício MHD'A, Monteiro CA, Souza JMP, Castilho EA, Lamonica IMR. Análise multivariada de fatores de risco para o baixo peso ao nascer em nascidos vivos do Município de São Paulo - SP (Brasil ). Rev Saúde Pública 1985; 19: 311 20. 
Bolaji II, Meehan FP. Caesarean section survey in Galway 1973- throught 1987. Europen Journal of Obstetrics \& Gynecology and Reprodutive Biology, 48 (1): 1$8,1993$.

Brandalise SR, Matsuda E. Anemias carenciais. In: Nobrega F, editor. Desnutrição intrauterina e pós-natal. São Paulo. Panamed; 1981. P.395-405.

Bratton SL, Shoultz DA, Williams MA. Recurrence risk of low birthweigth deliveries among women with a prior very low birth weigth delivery. Am $J$ Perinatol 1996; $13: 147$ - 50.

Brault-Dubuc M, Nadeau M, Dickie J. Iron status of french-canadian children: a three year follow-up study. Hum Nutr Appl Nutr 1983; 37A.

Bross DS, Shapiro S. Direct and indirect associations of five factors with infant mortality. Am J Epidemiol 1982; 115 : 78 - 91.

Brown HL, Watkins K, Hiett AK. The impact of the women, infants and children food, supllement programe on birth outcome. Am $J$ Obstet Gynecol 1996; 174 ;1279-83.

Brunken AL. Avaliação da Eficácia da Suplementação semanal no Controle da Anemia em pré-escolares $\neg$ São Paulo; 1999. [Tese doutorado - Curso de Pósgraduação Interunidades de Nutrição Humana Aplicada - USP].

Campos- Filho N, Franco EL. A microcomputer program for multiple logistic regression by unconditional and conditional maximum likelihood methods. $A \boldsymbol{m} \boldsymbol{J}$ Epidemiol 1989; $129: 439$ - 44.

Castilho EA, Siqueira EA, Ciari Jr C, Almeida PAM, Alvarenga AT. Altura materna e peso da criança ao nascer. Rev Saúde Pública 1976; 10: 233 - 7.

Centers for Disease Control and Prevention. Epi - Info. Epidemiologia em microcomputadores, um sistema de processamento de texto, banco de dados $e$ estatísticas. [Programa de computador] Versão 5.01. Atlanta: OPAS/WHO; 1990.

CEPI - Centro de Epidemiologia do Paraná. Instituto de Saúde do Paraná, Curitiba, 1996.

Ciari Jr C, Almeida PAM, Siqueira AAF. Relação entre peso da criança ao nascer, altura materna, idade gestacional e restrição alimentar em gestantes normais. Rev Saúde Pública 1975; 9:33-42.

Cobas JA, Balcazar H, Benin MB, Keith VM, Chong Y. Acculturation and low birth weigth infants among latino women : a reanalysis of NHANES data with strutural equation models. Am J Public Health 1996; 86 : 394 - 6. 
Conlisk E. The heterogenety of low birth weigth as its relates to the black-white gap in birthweigth specific neonatal mortality. 1993 [Dissertation - Ithaca NY CornellUniversity].

Copper RL, DuBard MB, Goldenberg RL, Oweis AI. The relationship of maternal altitude toward weigth gain to weigth gain during pregnancy and low birth weigth. Obstet Gynecol 1995; $85: 590-5$.

Coria-Soto IL, Bobadilha, J, Notzon, F. The effectiveness of antenatal care in preventing intrauterine growth retardation and low birth weigth due to preterm delivery. Int J Qual Health Care 1996; 8 :13-20.

Costa JSD e col. Assistência médica em duas coortes de base populacional no sul do Brasil: tendências e diferenciais. Cadernos de Saúde Pública 1996;12 : 59-66.

Dallman PR, Reeves JD. Laboratory diagnosis of iron deficiency. In : Stekel A. Iron nutrition in infancy and childhood. New York: Nestlé/ Raven Press; 1984; p.11--44.

DeMaeyer E, Dallman P, Gurney JM, Hallberg L, Sood SK, Srikantia SG. Preventing and controlling iron deficiency anaemia througth primary health care: a guide for health administrators and programme managers. Geneva: World Health Organization; 1989.

Dinh PH, To TH, Vuong TH, Hojer B, Person LA. Maternal factors influencing the ocurrence of low birth weigth in northen Vietnam. Ann Trop Paediatric 1996; 16: $327-33$.

Donaldson PJ, Billy JOG. The impact of prenatal care on birth weigth: evidence from an international data set. Med Care 1984; 22: 177-88.

Donoso-Sina E, Espinoza-Gonzales R. Effect of some maternal nutritional variables on term newborns weigth. Rev Latinoam Perinatol 1988; 8, 90-4.

Edwards LE, Alton IR, Barrada MI, Hakanson EY. Pregnancy in the under weigth woman: Course outcome and growth patterns of the infant. Am J Obstet Gynecol 1979; 135: $297-302$.

Fedrick J, Adelstein P. Factors associated with low birth weigth infants delivered at term. Br J Obstetr Gynaecol 1978; 85: 1-7.

Fenster L, Eskenazi B, Windham GC, Swan SH. Cafeine consumption during pregnancy and fetal growth. Am J Public Health 1991; 81: 458 - 61.

Ferraz IC, Araujo CB, Rodrigues DL, Pereira DS, Cunha EVB, Silva Jr HM et al. Estudo do peso ao nascer em maternidades do Recife. Rev Ins Infant Pernambuco $1991 ; 5: 7-12$. 
Ferreira $\mathrm{CE}$ de $\mathrm{C}$. Peso ao nascer e mortalidade infantil no Município de Mogi das Cruzes. Inf Demogr 1982; 8: 203- 23.

FUNDAÇÃO INSTITUTO BRASILEIRO DE GEOGRAFIA E ESTATISTICA FIBGE. Contagem da população, Rio de Janeiro, 1984.

FUNDAÇÃO INSTITUTO BRASILEIRO DE GEOGRAFIA E ESTATISTICAFIBGE. Censo demográfico- Paraná: Rio de Janeiro; 1991.

FUNDAÇÃO INSTITUTO BRASILEIRO DE GEOGRAFIA E ESTATÍSTICA FIBGE. Contagem da população, Rio de Janeiro, 1996.

FUNDAÇÃO INSTITUTO BRASILEIRO DE GEOGRAFIA E ESTATÍSTICA FIBGE. Anuário Estatístico - Indicadores Demográficos, Rio de Janeiro, 1998.

Ganguly M, Elwood JH, Mackenzie G. Factors associated with low and higth birth weigth. Am J Epidemiol 1972; 96: 161 - 7.

Garrow J. Treat obesity seriously. London: Churchill Livingstone;1981.

Goldenberg RL, Clíver SP, Mulvihill FX, Hickey CA, Hoffman HJ, Klerman LV. Medical, psychosocial and behavioral risk factors do not explain the increased risk for low birth weigth among black women. Am J Obstet Gynecol 1996; 175 : 1317 24.

Habitcht C. Relationship of birth weigth maternal nutrition and infant mortality. Nutr Rep 1973; 7: 533-46.

Hinds TS, West WL, Knight EM, Harland BF. The effect of caffeine on pregnancy outcome variables. Nutr Rev 1996; $54: 203-7$.

Hingson R, Alpert JJ, Day N, Dooling E, Kayne H, Morelock S et al. Effects of maternal drinking and marijuana use on fetal growth and development. Pediatrics $1982 ; 70: 539$ - 546 .

Hitten F, Chamberlain G. Clinical physiology in obstetrics. Oxford: Blackwell Scientifics Publications 1980; p. 226- 7.

Horon IL, Strobino DM, Mac Donald HM. Birth weigths among infants born to adolescent and young adult women. Am J Obstet Gynecol 1983; 146: 444-9.

Horta BL, Victora CG, Barros FC, Santos IS, Menezes AMB. Tabagismo em gestantes de área urbana da região Sul do Brasil, 1982 - 1993. Rev Saúde Pública 1997; 31: $247-53$.

Hutchins V, Kessel SS, Placek PJ. Trends in maternal and infant health factors associated with low infant birth weight, United States, 1972 and 1980. Public Health $\operatorname{Rep~1984;~99,~162-72.~}$ 
[INACG]. International Nutritional Anemia Consultative Group. Guidelines for irradication of iron deficiency. Washington (DC); 1977.

[INACG]. International Nutritional Anemia Consultative Group. Iron deficiency in infancy and childhood. Washington (DC), 1981.

INAN, PNSN -1989. Arquivo de dados de Pesquisa. Instituto Nacional de Alimentação e Nutrição, Brasília, Abril, 1990.

Joyce T, Corman H, Grossmann M. A cost effectiveness analysis of strategies to reduce infant mortality. Med Care 1988;26: $348-60$.

Kessner DM, Singer J, Kalk CW, Schlesinger ER. Infant death: an analysis of maternal risk and heath care. In: Contrasts in Heath Status. Washington (DC): Institute of Medicine/ National Academy of Sciences; 1973. vol 1: 1 - 203

Khan AA, Gupta BM. Social and economic factors in malnourished children around Luzaka, Zambia. Trop Geogr Med 1977; 29: 283 - 7.

Kirkinen P, Jouppila P, Koivula A, Vuori J, Puukka M. The effect of caffeine on placental and fetal blood flow in human pregnancy. Am $J$ Obstetr Gynecol 1983; 147: 939-942.

Kitay D, Harbort RA. Iron and folic acid deficiency in pregnancy. Clin Perinatol $1975 ; 2: 255-73$.

Knutti R, Rothweiler H, Schlatter C. The effect of pregnancy on the pharmacokinetics of caffeine. Arch Toxicol 1982; 5 suppl :187-92.

Korenbrot C, Simpson MB, Phibbs CS. Prenatal care needs assessment comparing service use and outcomes in Fresno CA. Public Health Rep 1994; 109 : 68 - 76.

Kramer MS. Determinants of low birth weigth : methodological assessment and meta-analysis. Bull World Health Organ 1987; 65: 663 -737.

Leader A, Wong KH, Deitez M. Maternal nutrition in pregnancy. Part 1: a review: Can Med Assoc J 1981; 15: 544-9.

Lechtig A, Delegado H, Yarbrough C, Habicht JP, Martorell R, Klein RE. A simple assessment of the risk of low birth weigth to select women for nutritional intervention . Am J Obstet Gynecol 1976; 125:25-34.

Lechtig A. Predicting risk of delivering low birthweigth babies: which indicator is better? J Trop Pediatr 1988; 34: 34-41. 
Linn S, Schoenbaum SC, Monson RR, Rosner B, Stubblefield PG, Ryan KJ. No association between coffee consumption and adverse outcomes of pregnancy, $\boldsymbol{N} \boldsymbol{E n g l}$ J Med 1982; 306:141- 5 .

Lippi UG, Andrade AS, Bertagnon Jr D, Melo E. Fatores obstétricos associados ao baixo peso ao nascer. Rev Saúde Pública 1989; 23: 382-7

Longo LD. The biological effects of carbon monoxide on the pregnant woman, fetus and newborn infant. Am $\boldsymbol{J}$ Obstetr Gynecol 1977; 129: 69-103.

Maia Filho NL e col. Operação cesariana - a proposito de suas indicações. $J$. Bras Ginecologia 1994; 104 (11/12): 423- 26.

Makarem A. Blood Hemoglobin Photometer. In: Henry RJ, Cannon DC, Winkelman JW, editores. Clinical Chemistry: Principles and Techincs, $2^{\circ}$ ed. Hagerstown Md; 1974.p.1125-1147.

Martorell R, Gonzalez-Cossio T. Maternal nutrition and birth weigth. Yb Psys Anthrop 1987; 30: 195-220.

Mata LJ. The children of Santa Maria Cauqué: a prospective field study of health and growth. Cambridge MIT Press ;1978.

McCormick MC. The contribution of low birth weight to infant mortality and childhood morbility. $N$ Engl $J$ Med 1985; 312:82-90.

McLaughlin B, Kevany J. Haemoglobin concentration in pregnancy: relationships with maternal age and birth weigth. Irish $\boldsymbol{J}$ Med Sci 1982: 151: 71 -4.

Metcoff J, Costiloe JP, Crosby W, Sandstead HH, McClain P, Bodwell CE et al. Maternal nutrition and fetal outcome. Am J Clin Nutr 1981; 34: 708 - 21.

Meyer MB, Jonas BS, Tonascia JA. Perinatal events associated with maternal smoking during pregnancy. Am $\boldsymbol{J}$ Epidemiol 1976; 103: 464-76.

Miller HC, Merrit TA. Fetal growth in humans Chicago Year Book Medical Publishers, 1979.

Miller JE, Birth order, interpregnancy interval and birth outcomes amongfilipino infants. J Biosoc Sci 1994, 26:243-259.

Mills J, Graubard BI, Harley EE, Rhoads GG, Berendes HW. Maternal alcohol consumption and birth weigth. How much drinking during pregnancy is safe? $A \boldsymbol{m} J$ Med Ass 1984: 252:1875-9.

Mills JL, Holmes LB, Aarons JH, Simpson JL, Brown ZA, Jovanovic-Peterson LG et al. Moderate caffeine use and the risk of spontaneous abortion and intrauterine growth retardation. $\boldsymbol{J A} \boldsymbol{M A}$ 1993; 269: $593-7$. 
Monteiro CA. Peso ao nascer e excesso de mortalidade infantil em São Paulo (Brasil). Rev Saúde Pública 1980; 14: 1-8.

Monteiro CA. Estimativa dos coeficientes específicos de mortalidade infantil segundo peso ao nascer no Município de São Paulo (Brasil). Rev Saúde Pública $1981 ; 15: 603-10$.

Monteiro CA, Szarfarc SC. Estudo das condições de saúde das crianças no Município de São Paulo, SP(Brasil) 1984 - 1985. V. Anemia. Rev Saúde Pública $1987 ; 21: 255-60$.

Naeye RL. Influence of maternal cigarette smoking during pregnancy on fetal and childhood growth. Obstet Gynecol 1981; $57: 18-21$.

Narod SA, Sanjose S, Victora C. Coffee during pregnancy: A reproductive hazard ? Am J Obstet Gynecol 1991; $164: 1109-14$

[NCHS] National Center for Health Statistics- Growth curves for children, birth - 18 years, United. States. Vital Health Sta. 1977; 11: 1-74.

Nobrega FJ. Antropometria, patologias e malformações congênitas do recémnascido brasileiro. Estudo de associações com algumas variáveis maternas. $J$ Pediatr 1985; 59 supl 1: 1 - 114 .

Nobrega FJ, Vitolo J, Brasil MR, Dias AL, Lopez FA. Condição nutricional de mães e filhos: relação com o peso de nascimento, variaveis maternas e sócio-econômicas. J Pediatr 1991; 67 (9/10): 288 - 96.

Oliveira LA de. Comparação de dois indicadores da desnutrição materna usando regressão e classificação por árvore e logística multinomial São Paulo; 1996. [ Tese de Doutorado - Faculdade de Saúde Pública da USP].

[OMS]. Organizacion Mundial de la Salud. Lucha contra la anemia nutricional especialmente contra la carencia de hierro. Ginebra; 1975. (OMS - Serie Informes Técnicos, 580).

[OMS]. Organização Mundial da Saúde. Risk approach for maternal and child health care. Geneva. 1978. [WHO offset Publ, 39]

[OMS]. Organización Mundial de la Salud. Divisón de la Salud de la Família. The incidence of low birth weight. A critical review of available information. World Health Stat $Q$ 1980; 33: 197-224.

[OMS]. Organização Mundial da Saúde. Classificação internacional das doenças $10^{\circ}$ revisão II-5: definições, regulamentações, regras, normas para mortalidade e morbidade. São Paulo: Cbcd; 1993. [dados inéditos]

Oski FA, Naiman JL. Hematologia do recém-nascido. $3^{\circ}$ ed. São Paulo: Mondé. 1984. 
Pachauri S, Marwah SM. A study of the effect of certain maternal factors on birth weigth. Indian $\boldsymbol{J}$ Med Sci 1970; 24: 650-9.

Paneth NS. The problem of low birth weigth. Future Child 1995; 5: 19- 34.

Papoz L, Eschwege E, Pequignot G, Barrat J, Schwartz D. Maternal smoking and birth weigth in relation to dietary habits. Am $J$ Obstet Gynecol 1982; 142:870-6.

Petersen S, Larsen T, Greisen G. Judging fetal growth from body proportions at birth. Early human development 1992; 30:139-46.

Pirani BBK. Smoking during pregnancy. Obstetr Gynecol Survey 1978; 33:1-13.

Puffer RR, Serrano CN. Patterns of mortality in childhood: Washington (DC). Pan American Health Organization; 1973. (PAHO - Scientific Publication, 262).

Puffer RR, Serrano CN. Características del peso ao nascer. Washington. (DC) Organizacion Panamericana de la Salud; 1988.p.89 -95 (OPAS - Publicacion Cientifica, $\mathrm{n}^{\circ}$ 504).

Quigley ME, Sheehan KL, Wilkes MM, Yen SSC. Effects of maternal smoking on circulation catecholamine levels and fetal heart rates. Am J Obstet Gynecol 1979; 133: $685-90$.

Rodrigues C, Regidor E, Gutierrez Fisac JL. Low birth weigth in Spain associated with sociodemographic factors. J Epidemiol Community Health 1995; 49: 38 - 42.

Rondo PHC, Rodrigues LC, Tomkins AM. Coffee consumption and intrauterine growth retardation in Brazil. Eur J Clin Nutr 1996;50: 705 - 9.

Roselli CAM, Segre CAM. Classificação do RN.In: Segre CAM et al . RN. $4^{\circ}$ ed. São Paulo: Sarvier; 1995; p. 24- 9

Rosemberg J. Tabagismo sério problema de saúde pública. São Paulo: Almed/ EDUSP, 1981 .

Rosso P, Winick M. Intrauterine growth retardation. A new systematics approach based on the clinical and biochemical characteristics of this condition. J. Perinat. Med 1974;2:147-160.

Rouquaryol MZ . Epidemiologia e Saúde. São Paulo: Medsi. 1994.

Rush D, Davis H, Susser M. Antecedents of low birthweigth in Harlen. New York City Int J Epidemiol 1972; 1: 375 - 7. 
Rush D. Examination on the relationship between birth weigth, cigarette smoking during pregnancy and maternal weigth gain. J Obstet Gynaecol Brit Comm 1974; $81: 716-52$.

Rush D. Cigarette smoking during pregnancy: the relationship with depressed weigth gain and birthweigth. An update report In: Kelly S, Hook EB, Janerich D, Porter IH editores. Birth defects: risks and consequences. New York: Academic Press; 1976. p. $161-72$.

Russel C S, Smoking in pregnancy maternal blood pressure, pregnancy outcome, body weigth and growth and other related factors. Br J Prev Soc Med 1968; 22: 119 $-26$.

Santos SMC, Silva RCR, Costa SFS, Silveira TMO. Peso ao nascer nas seis maternidades da rede pública estadual de Salvador. Rev Baiana Saúde Pública $1992 ; 19: 29-36$.

Schramm WF. Weighing costs and benefits of adequate prenatal care for 12.023 births in Missouri's Medicaid Program, 1988. Public Health Rep 1992; 107: 647 52.

Schuler D, Klinger A. Causes of low birth weight in Hungary. Acta Paediatr Hung 1984; $25: 173$.

Schwarcz R. e col. Bajo peso al nacer y mortalidade perinatal em maternidades da America Latina. In: Organización Panamericana de la Salud. Salud materna-infantil $y$ atencion primária de las Américas. México (DF); 1984. p : 105-17 (OPAS Publicacion científica 461).

Scott A, Moar V, Ounsted M. The relative contributions of different maternal factors in small for gestational-age pregnancies. Eur J Obstetr Gynecol Reprodutive Biol 1981; 12: 157-65.

Secretaria de Saúde de Maringá. Código Tributário - Prefeitura Municipal de Maringá, 1989.

Secretaria de Saúde de Maringá. Seção de Epidemiologia. SINASC - Sistema de nascidos vivos . Maringá; 1997 [dados preliminares].

Secretaria de Saúde de Maringá. SIM - Sistema de informação de mortalidade ; 1996.

Serrano $\mathrm{CN}$, Puffer $\mathrm{PR}$. El peso ao nacer, la edad materna y el orden de nacimiento, tres importantes determinantes de la mortalidade infantil. Washington (DC): Organizacion Panamericana de la Salud; 1975.(OPAS - Publicacion Cientifica, 294). 
Shepard MJ, Hellenebrand KG, Bracken MB. Proportional weigth gain and complications of pregnancy, labor and delivery in health women of normal prepregnant estature Am J Obstetr Gynecol 1986; 155:947-54.

Showstack JA, Budetti PP, Minkler D. Factors associated with birthweight: an exploration of the roles of prenatal care and length of gestation. Am J Public Health 1984; 74: $1003-8$.

Sichieri R. Anemia nutricional em crianças de 5 anos do Município de São Paulo: papel da dieta na determinação de sua prevalência. São Paulo; 1987 [ Tese de doutorado - Faculdade de Saúde Pública da USP].

Sinisterra ROT, Szarfarc SC, Benicio MHD’A. Anemia e desnutrição maternas e sua relação com peso ao nascer. Rev Saúde Pública 1991; 25 :193-7.

Siqueira AAF, Ciari Jr C, Almeida PAM, Tanaka ACD'A, Monteleone PPR, Arruda JJR. Influência da altura e ganho de peso maternos e de idade gestacional sobre o peso do recém-nascido: estudo de 3 grupos de gestantes normais. Rev Saúde Pública 1975; 9:331-42.

Soyka LS. Effects of methylxantines on the fetus. Clin Perinatol 1979; 6:37 - 51 .

Souza RKT. Mortalidade infantil e sub registro de nascidos vivos no Município de Maringá-PR. São Paulo; 1989 [Tese de Mestrado -Faculdade de Saúde Pública da USP].

Srisuphan W, Bracken MB. Caffeine, consumption during pregnancy and association with late spontaneous abortion. Am J Obstet Gynecol 1986; 154: 14 - 20.

Stefanini MLR, Martini DL, Lerner BR, Chaves SP, Mondini L. Avaliação do programa de nutrição em saúde no grupo de gestantes de sete municípios de São Paulo (Brasil) Rev Nutr Puccamp 1988; 1: 153-62.

Stekel A. Necessidades de hierro en el lactante y el niño. In: Resumo do IV Seminário Nestlé Nutrition (El hierro en la alimentacion del lactante y del niño) Manila. New York: Raven Press; 1984; p. 7 -10.

Susser M, Stein Z. Third variable analysis: application to causal sequences among nutrient intakes, maternal weigth, birthweigth, placental weigth and gestation. Stat Med 1982; 1: 105-20.

Szarfarc SC, Böell CP, Andrade J, Ciari Jr C. Características vitais como indicadores do risco gravídico. Rev Saúde Pública 1980 ;14: 310- 9.

Tanner JM. Fetus into man physical growth from conception to maturity Cambridge: Harvard University Press; 1978;p.40 - 3 . 
Trindade CEP, Nobrega FJ, Rudge MCV, Zuliani A, Suguihara CY, Pinho SZ. Estudo do peso e a idade gestacional de recém-nascidos e suas relações com patologias maternas. $J$ Pediatr 1981; $50: 69-74$.

Uchimura TT, Uchimura NS. Szarfarc SC, Santana RG. Amamentação, dieta e baixo peso ao nascer. In : Anais do V Encontro Nacional de Aleitamento Materno; 1997 set 17 - 20; Londrina, Brasil. Londrina: Universidade Estadual de Londrina; 1997. P 25.

UNICEF. Fundo das Nações Unidas para a Infância- Situação Mundial na Infância Brasília;1984 .

UNICEF._Fundo das Nações Unidas para a Infầncia. Situação Mundial na Infância. Brasília; 1995.

Victora CG, Barros FC, Vaughan JP, Lombardi C, Béria J, Victora MFB, Martines JC. Epidemiologia da desigualdade. $2^{\circ}$ ed. São Paulo; Hucitec; 1989.

Villar J, Belizán JM. The relative contribution of prematurity and fetal growth retardation to low birth weigth in developing and developed societies. Am J Obstet Gynecol 1982; 143: 793-8.

Villar J, Belizan JM. Crecimiento y desarrollo de niños con retardo del crecimiento intrauterino. Arch Argent Pediatr 1986; 84: 77-91.

Watkinson B, Fried PA. Maternal caffeine use before, during and after pregnancy and effects upon offspring. Neurobehav. Toxicol Teratol 1985; 7:9-17.

Wessel H, Cnattingius S, Bergstrom S, Dupret A, Reitmaier P. Maternal risk factors for preterm birth and low birth weigth in Cape Verde. Acta Obstet Gynecol Scand $1996 ; 75: 360-6$.

White A, Dandler P, Smith EL. Hemoproteínas e porfirinas. In: White A, Handler P. Smith EL, editores. Princípios de Bioquímica. $5^{\circ}$ ed. Rio de Janeiro, GuanabaraKoogan, 1976. P.139-50.

[WHO]. World Health Organization. International classification of diseases: manual of the international statistical classification of diseases, injuries and causes of death. Ninth revision. Geneva; 1977; 210-21.

[WHO] World Health Organization. Appropriate technology for birth. Lancet 1985; 436- 7 .

[WHO] World Health Organization. Physical status: the use and interpretation of anthropometry. Report of a Expert Commitee. WHO 1995. (Technical Report

Series 854).

Woodruff CW. Iron deficiency and childhood. In: Symposium on Nutrition in Pediatrics. Pediatr Chin North America 1977; 24: 85- 94. 
Yudkin PL, Harlap S, Baras M.Higth birth weigth in an ethinic group of low socioeconomic status. Br J Obstetr Gynaecol 1983; 90: 291- 6 .

Zuckerman B, Alpert JJ, Dooling E, Hingston H, Morelock S, Oppenheimer E. Neonatal outcome: is adolescenmt pregnant a risk factor? Pediatr 1983; 71: $489-$ 93. 


\section{ANEXO 01}

Fatores de Risco para o Baixo Peso ao Nascer

1- Identificação da Mãe

01 . Nome

02. Data de nascimento

03. Estado Civil

04. Estatura $(\mathrm{m}) \_$2.Solteira_ 3.Solteira com companheiro ___ 4.Outro

05. Início do Pré-natal data

06. DUM $1^{\circ}$ trim

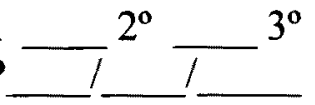

08. Peso pré-gravídico

09. Peso no final da gestação

10. Tipo de gravidez

11. Tem filho BPN (Peso 07. DPP $3^{\circ}$

\section{Não 2.Sim}

12. Intervalo Partal (meses)

13. Fumou durante a gestação

14. $\overline{\mathrm{N}^{\circ}}$ de cigarros/ dia
2. Sim

15. Bebeu (bebida alcoólica) durante a gestação 1. Não 2. Sim

16. $\mathrm{N}^{\circ}$ de copos / dia

17. Tomou café durante a gestação
1. Não
2. Sim

18. $\mathrm{N}^{\circ}$ de xícaras / dia

19. $\mathrm{N}^{\circ}$ de visitas pré-natal

20. Realizado controle de $\overline{\mathrm{PA} \text { (Pressão Arterial) }}$
1. Não
2. Sim

21. Realizou exames de sangue

1. Não

2. Sim

22. Realizou exames de urina
1.Não
2. Sim

23. Realizou exame pélvico no pré-natal

$$
\text { 1. Não 2 2. Sim }
$$

24. Intercorrências na gestação

$$
\text { Quais }
$$

1.Não 1.Sim

25. Trabalhou fora durante a gestação

$$
\text { Por quê }
$$
1.Não 2. $\operatorname{Sim}$

26. Renda familiar (R\$)

27. $\mathrm{N}^{\circ}$ de pessoas na casa

28. Qual o convênio utilizado quando do parto. 1.SUS 2.Particular_3.Outros- especificar 


\section{ANEXO 02}

Prezada Mamãe

O Departamento de Enfermagem da Universidade de Maringá está realizando uma pesquisa para avaliar a assistência prestada a saúde da criança e da mãe. Para isso necessitamos de sua presença no posto de saúde no período para coletarmos alguns dados a respeito da gestação e do nascimento de

Sabemos que o seu tempo é precioso, mas sua contribuição será também muito valiosa para que possamos propor medidas mais eficazes para o atendimento de nossas crianças. Obrigada pela sua colaboração.

Favor procurar a Enfermeira do Posto.

Prof Taqueco Uchimura e ou Prof Luciana Bercini 


\section{ANEXO 03}

UNIVERSIDADE ESTADUAL DE MARINGÁ DEPARTAMENTO DE ENFERMAGEM

Av Colombo 5790 - Zona 7

CEP : 87020 - 900

Tel : (044) $261-4318$

Fax: (044) $261-4385$

\section{AUTORIZAÇÃO}

EU AUTORIZO meu filho (a), a participar da pesquisa para verificar a presença de anemia, em menores de 1 ano de idade, e sua associação com a alimentação, bem como com o crescimento e o desenvolvimento. Esta pesquisa está sendo realizada em diferentes cidades brasileiras e em Maringá estará sendo coordenada pelas professoras Taqueco T. Uchimura e Luciana Olga Bercini, da Universidade Estadual de Maringá - Departamento de Enfermagem. Para participar da pesquisa é necessário colher uma pequena amostra de sangue da criança, por punctura do pé, feita com material descartável. O resultado é obtido imediatamente após a coleta do sangue. Concordo também em responder às questões sobre alimentação, crescimento e desenvolvimento que fazem parte da pesquisa.

OBS: A mãe ou o responsável, concordando com o exposto, dará sua autorização assinando o verso do formulário da criança. 


\section{ANEXO 04}

\section{Resultado do Exame de Sangue (HB)}

Método : Punctura Digital

Leitura : Fotômetro HemoCue

Nome da Criança:

Data:

Resultado:

Nome da Mãe:

Data:

Resultado:

\section{Resultado do Exame de Sangue (HB)}

Método : Punctura Digital

Leitura : Fotômetro HemoCue

Nome da Criança:

Data:

Resultado:

Nome da Mãe:

Data:

Resultado: 


\section{ANEXO 05 \\ Manual de uso do formulário}

- NOME

Colocar o nome completo da mãe.

- DATA DE NASCIMENTO

Preencher com o dia, mês e ano.

- ESTADO CIVIL

Preencher: 1- Casada

3- Solteira com companheiro
2- Solteira

4- Outro

- ALTURA (m)

É a estatura referida pela mãe. Caso ela não saiba, fazer a medida.

- ÍNICIO DO PRÉ- NATAL

$1^{\circ}$ trim - ( de --- até --- sem )

$2^{\circ}$ trim - ( de --- até --- semanas)

$3^{\circ}$ trim - ( de --- até --- sem)

- DUM ( data da última mestruação)

Colocar o dia, mês e ano.

- DPP ( data provável do parto)

Colocar o dia, mês e ano.

- PESO PRÉ- GRÁVIDICO

Colocar qual foi o último peso antes de engravidar.

- PESO NO FINAL DA GESTAÇÃO

Colocar qual foi o último peso na gestação.

- TIPO DE GRAVIDEZ

Preencher: 1- Única

2- Dupla

3- Tripla

- TEVE FILHO BPN

Preencher sim ou não e colocar o peso da criança em gramas.

- INTERVALO PARTAL ( meses )

Colocar o tempo ( meses ) entre a gestação anterior e a última.

- FUMOU DURANTE A GESTAÇÃO

Verificar se fumou ou não independente do tempo. 
- No DE CIGARROS / DIA

Preencher com o $n^{\circ}$ de cigarros fumados por dia.

- BEBEU DURANTE A GESTAÇÃO

Verificar se bebeu bebida alcoólica independente do tempo, se souber o trimestre colocar.

- $\mathrm{N}^{\circ}$ DE COPOS / DIA

Preencher com o $\mathrm{n}^{\circ}$ de copos por dia.

- TOMOU CAFÉ DURANTE A GESTAÇÃO?

Verificar se tomou café/ chá/ refrigerantes durante a gestação

- $\mathrm{N}^{\circ}$ COPOS / DIA

Preencher com o ${ }^{0}$ de copos / dia.

- No VISITAS PRÉ- NATAL

Verificar o $\mathrm{n}^{\circ}$ de visitas de pré - natal.

- FEITO CONTROLE DE PA (Pressão Arterial)

Verificar se foi realizado controle de PA.

- REALIZOU EXAMES DE SANGUE

Verificar se foi feito exames de sangue. ( rotina de pré-natal)

- REALIZOU EXAMES DE URINA

Verificar se foi realizado exames de urina para detectar infecções ou intercorrências. (rotina de pré-natal).

- INTERCORRÊNCIAS NA GESTAÇÃO

Verificar se apresentou intercorrências na gestação e caso a resposta for afirmativa, citar quais.

- TRABALHOU FORA DURANTE A GESTAÇÃO

Verificar se trabalhou fora e se a resposta for sim, colocar o motivo.

- RENDA FAMILIAR

Colocar o total da renda liquida de todas as pessoas que trabalham na casa.

- NÚMERO DE PESSOAS DA CASA

Colocar o número de pessoas que moram na casa.

- CONVÊNIO UTILIZADO QUANDO DO PARTO

Preencher: 1-SUS

2- Particular

3- Outros - especificar 


\section{ANEXO 06}

\section{1. Área Verde}

A área verde com alíquota de $1,0 \%$ do valor venal, ficou com 306 $(55,3 \%)$ de mães do total da amostra, distribuídas em 7 postos, apresentando $6,6 \%$ de crianças com BPN, para o total da amostra, e na figura 17 são apresentados os percentuais por posto segundo o número de atendimento de crianças menores de um ano.

Figura 17 - Distribuição (\%) de crianças com baixo peso ao nascer da Área Verde segundo posto de saúde, Maringá-PR,1998.

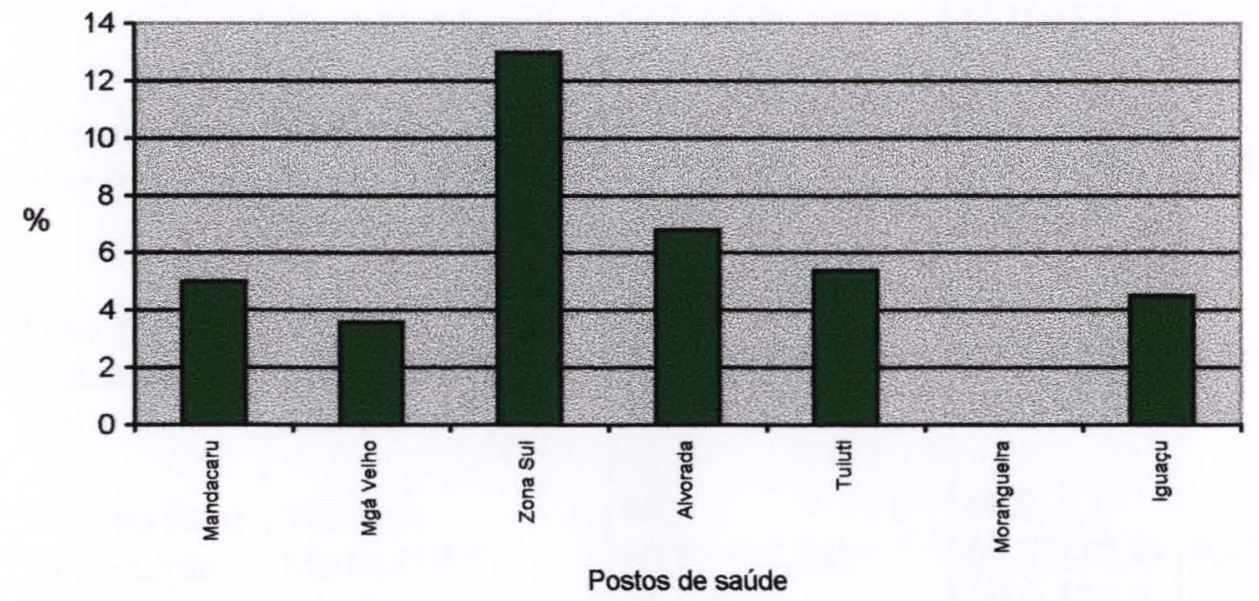

Observou-se que as diferenças das médias das variáveis hemoglobina da criança $(\mathrm{p}=0,0155)$, peso no final da gestação $(\mathrm{p}=0,0101)$, estatura da mãe $(\mathrm{p}=0,0146)$ e comprimento ao nascer $(\mathrm{p}<0,0001)$ foram estatisticamente significativas; no entanto o mesmo não se verificou para as outras variáveis (Tabela 23) A variável comprimento ao nascer se apresentou também significativa ( $p=<$ $0,0001)$ no teste de associação pelo qui-quadrado (Tabela ).

As variáveis biodemográficas (idade da mãe) e as comportamentais $\left(\mathrm{n}^{\circ}\right.$ de cigarros fumados $\mathrm{e} \mathrm{n}^{\circ}$ de xícaras de café ingeridas durante o período da 
gestação) e as sócio-econômicas (renda e escolaridade) não se apresentaram significativas.

Dentro desta área, os postos da Zona Sul e Alvorada apresentaram o maior percentual de BPN com $30,0 \%$ e $40,0 \%$ do total de BPN da área.

Tabela 23 - Mediana, média e desvio padrão das variáveis da Área Verde segundo o peso ao nascer. Maringá-Pr, 1998.

\begin{tabular}{|c|c|c|c|c|}
\hline Variável & Parâmetro & $\begin{array}{l}<2500 \mathrm{~g} \\
\mathrm{~N}=20\end{array}$ & $\begin{array}{l}>=2500 \mathrm{~g} \\
\mathrm{~N}=286\end{array}$ & $\mathrm{p}^{* * *}$ \\
\hline Idade da Mãe & $\begin{array}{l}\text { Mediana } \\
\text { Média (DP*) } \\
\text { Min-Máx** }\end{array}$ & $\begin{array}{l}24,5 \\
24,6(6,84) \\
14,0-36,0\end{array}$ & $\begin{array}{l}25,0 \\
25,7(5,88) \\
15,0-43,0\end{array}$ & 0,5882 \\
\hline $\begin{array}{l}\text { Estatura da } \\
\text { Mãe }(\mathrm{m})\end{array}$ & $\begin{array}{l}\text { Mediana } \\
\text { Média (DP*) } \\
\text { Min-Máx** }\end{array}$ & $\begin{array}{l}1,57 \\
1,57(0,04) \\
1,50-1,70\end{array}$ & $\begin{array}{l}1,61 \\
1,61(0,06) \\
1,44-1,80\end{array}$ & 0,0146 \\
\hline $\begin{array}{l}\text { Peso Pre- } \\
\text { gestacional } \\
(\mathrm{Kg})\end{array}$ & $\begin{array}{l}\text { Mediana } \\
\text { Média (DP*) } \\
\text { Min-Máx** }\end{array}$ & $\begin{array}{l}52,0 \\
53,72(9,44) \\
39,0-72,0\end{array}$ & $\begin{array}{l}57,0 \\
57,36(9,30) \\
38,0-92,0\end{array}$ & 0,1047 \\
\hline $\begin{array}{l}\text { Peso no final } \\
\text { da gestação } \\
(\mathrm{Kg})\end{array}$ & $\begin{array}{l}\text { Mediana } \\
\text { Média (DP*) } \\
\text { Min-Máx** }\end{array}$ & $\begin{array}{l}60,5 \\
62,83(11,84) \\
49,0-90,0\end{array}$ & $\begin{array}{l}69,0 \\
69,75(10,9) \\
50,0-120,0\end{array}$ & 0,0101 \\
\hline $\begin{array}{l}\text { Ganho de } \\
\text { peso na } \\
\text { gestação } \\
(\mathrm{Kg})\end{array}$ & $\begin{array}{l}\text { Mediana } \\
\text { Média (DP*) } \\
\text { Min-Máx** }\end{array}$ & $\begin{array}{l}10,0 \\
8,92(7,56) \\
(-7)-22\end{array}$ & $\begin{array}{l}9,0 \\
10,35(5,86) \\
(-7)-32\end{array}$ & 0,5894 \\
\hline $\begin{array}{l}\text { IMC pré- } \\
\text { gestacional } \\
\left(\mathrm{Kg} / \mathrm{m}^{2}\right)\end{array}$ & $\begin{array}{l}\text { Mediana } \\
\text { Média (DP*) } \\
\text { Min-Máx** }\end{array}$ & $\begin{array}{l}26,0 \\
24,52(4,07) \\
19,10-29,60\end{array}$ & $\begin{array}{l}22,0 \\
22,22(3,76) \\
14,7-35,10\end{array}$ & 0,1819 \\
\hline $\begin{array}{l}\text { IMC no final } \\
\text { da gestação } \\
\left(\mathrm{Kg} / \mathrm{m}^{2}\right)\end{array}$ & $\begin{array}{l}\text { Mediana } \\
\text { Média (DP*) } \\
\text { Min-Máx** }\end{array}$ & $\begin{array}{l}25,10 \\
26,42(4,09) \\
21,9-32,0\end{array}$ & $\begin{array}{l}27,30 \\
27,58(3,98) \\
17,6-39,6\end{array}$ & 0,5577 \\
\hline $\begin{array}{l}\text { Intervalo } \\
\text { partal } \\
\text { (meses) } \\
\end{array}$ & $\begin{array}{l}\text { Mediana } \\
\text { Média (DP*) } \\
\text { Min-Máx** }\end{array}$ & $\begin{array}{l}60,0 \\
51,0(31,55) \\
12,0-96,0 \\
\end{array}$ & $\begin{array}{l}48,0 \\
51,2(28,9) \\
10,0-96,0 \\
\end{array}$ & 0,9800 \\
\hline
\end{tabular}




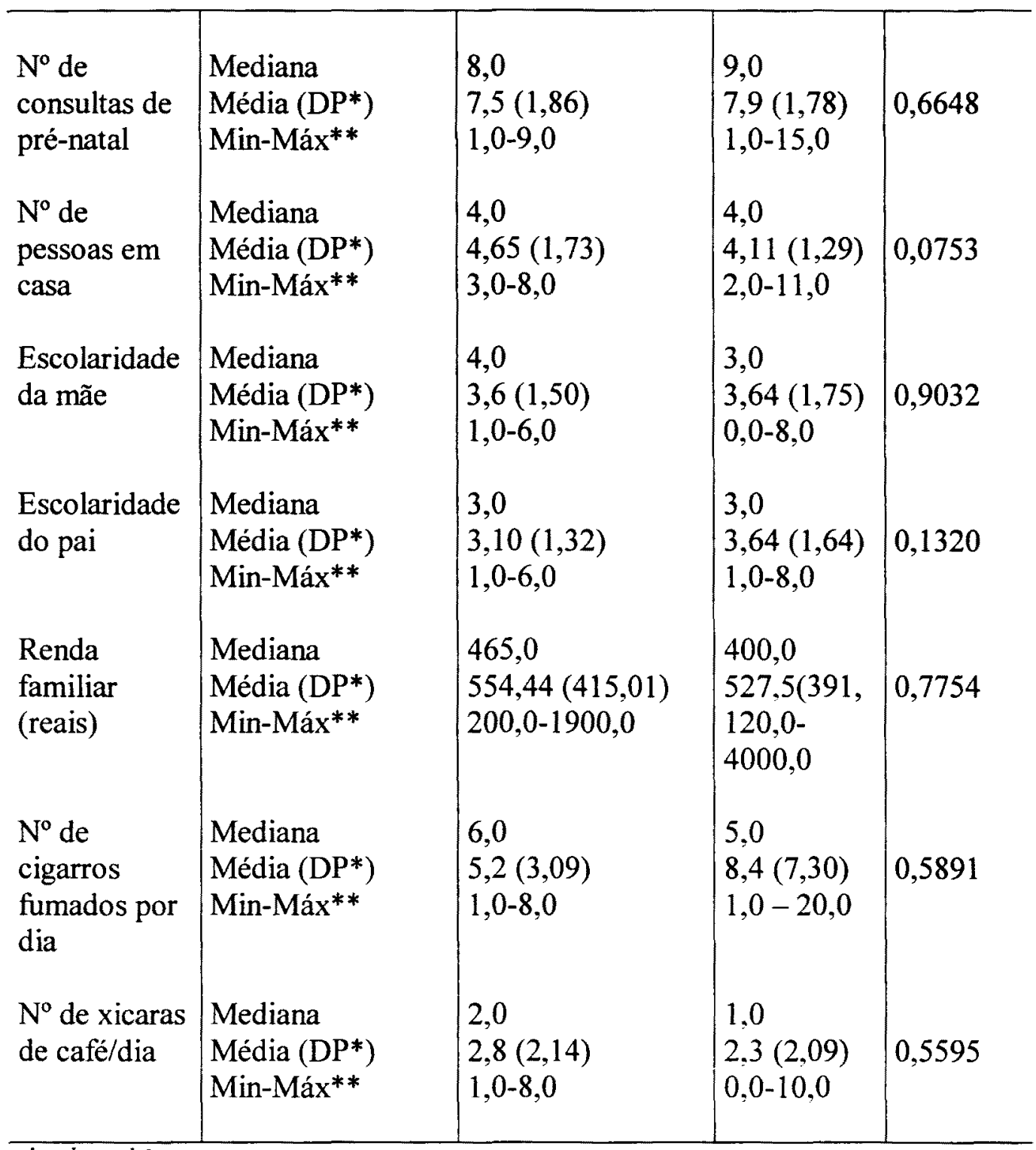

* $\mathrm{DP}=$ desvio padrão

** Min-Máx = valores minimo e máximo

*** $\mathrm{p}=$ nível descritivo do teste de diferença das médias de Mann-Whitney

Tabela 24 - Distribuição do número e porcentagem de mães, segundo Área Verde e o peso ao nascer, Maringá - PR, 1998

\begin{tabular}{|c|c|c|c|c|c|c|c|c|c|}
\hline Variável & Categoria & $\begin{array}{l}<2 \\
\mathrm{~N}=\end{array}$ & & $\begin{array}{l}>=2 \\
N=2\end{array}$ & & $\begin{array}{l}\text { Total } \\
\mathrm{N}=30\end{array}$ & & $\mathrm{X}^{2}$ & $\mathrm{P}^{* *}$ \\
\hline & & $\mathrm{N}^{\circ}$ & $\%$ & $\mathrm{~N}^{\circ}$ & $\%$ & $\mathrm{~N}^{\circ}$ & $\%$ & & \\
\hline Idade da mãe & $<20$ & 6 & 30,0 & 42 & 14,7 & 48 & 15,7 & 2,26 & 0,1329 \\
\hline (anos) & $>=20$ & 14 & 70,0 & 244 & 85,3 & 258 & 84,3 & & \\
\hline Estatura da & $<1,50$ & - & - & 5 & 1,7 & 5 & 1,6 & 0,11 & 0,7436 \\
\hline mãe (m) & $>=1,50$ & 19 & 95,0 & 271 & 94,8 & 290 & 94,8 & & \\
\hline & S/inform* & 1 & 5,0 & 10 & 3,5 & 11 & 3,6 & & \\
\hline
\end{tabular}




\begin{tabular}{|c|c|c|c|c|c|c|c|c|c|}
\hline $\begin{array}{l}\text { Peso pré- } \\
\text { gestacional } \\
(\mathrm{Kg})\end{array}$ & $\begin{array}{l}<50 \\
>=50\end{array}$ & $\begin{array}{r}8 \\
12\end{array}$ & $\begin{array}{l}40,0 \\
60,0\end{array}$ & $\begin{array}{r}67 \\
219\end{array}$ & $\begin{array}{l}23,4 \\
76,6\end{array}$ & $\begin{array}{r}75 \\
231\end{array}$ & $\begin{array}{l}24,5 \\
75,5\end{array}$ & 1,95 & 0,1624 \\
\hline $\begin{array}{l}\text { Ganho de } \\
\text { peso na } \\
\text { gestação } \\
(\mathrm{Kg})\end{array}$ & $\begin{array}{l}<=9 \\
>9 \\
\text { S/inform* }\end{array}$ & $\begin{array}{l}9 \\
8 \\
3\end{array}$ & $\begin{array}{l}45,0 \\
40,0 \\
15,0\end{array}$ & $\begin{array}{r}91 \\
181 \\
14\end{array}$ & $\begin{array}{r}31,8 \\
63,3 \\
4,9\end{array}$ & $\begin{array}{r}100 \\
189 \\
17\end{array}$ & $\begin{array}{r}32,7 \\
61,8 \\
5,5\end{array}$ & 3,31 & 0,1653 \\
\hline $\begin{array}{l}\text { Intervalo } \\
\text { partal } \\
\text { (meses) }\end{array}$ & $\begin{array}{l}<12 \\
>=12 \\
\text { S/inform* }\end{array}$ & $\begin{array}{r}- \\
11 \\
9\end{array}$ & $\begin{array}{c}- \\
55,0 \\
45,0\end{array}$ & $\begin{array}{r}2 \\
145 \\
139\end{array}$ & $\begin{array}{r}0,7 \\
50,7 \\
48,6\end{array}$ & $\begin{array}{r}2 \\
156 \\
148\end{array}$ & $\begin{array}{r}0,6 \\
51,0 \\
48,4\end{array}$ & 1,02 & 0,3131 \\
\hline $\begin{array}{l}\text { IMC pré- } \\
\text { gestacional } \\
\left(\mathrm{Kg} / \mathrm{m}^{2}\right)\end{array}$ & $\begin{array}{l}<19 \\
>=19\end{array}$ & $\begin{array}{r}7 \\
13\end{array}$ & $\begin{array}{l}35,0 \\
65,0\end{array}$ & $\begin{array}{r}63 \\
223\end{array}$ & $\begin{array}{l}22,0 \\
78,0\end{array}$ & $\begin{array}{r}70 \\
236\end{array}$ & $\begin{array}{l}22,9 \\
77,1\end{array}$ & 1,12 & 0,2891 \\
\hline $\begin{array}{l}\text { Renda } \\
\text { familiar } \\
\text { (reais) }\end{array}$ & $\begin{array}{l}<=130 \\
>130 \\
\text { S/inform* }\end{array}$ & $\begin{array}{r}18 \\
2\end{array}$ & $\begin{array}{c}90,0 \\
10,0\end{array}$ & $\begin{array}{r}8 \\
265 \\
13\end{array}$ & $\begin{array}{r}2,8 \\
95,6 \\
4,6\end{array}$ & $\begin{array}{r}8 \\
283 \\
15\end{array}$ & $\begin{array}{r}2,6 \\
92,5 \\
4,9\end{array}$ & 0,00 & 0,9938 \\
\hline $\begin{array}{l}\text { Escolaridade } \\
\text { da mãe }\end{array}$ & $\begin{array}{l}<=4^{\mathrm{a}} \text { série } \\
>4^{\mathrm{a}} \text { série }\end{array}$ & $\begin{array}{l}5 \\
15\end{array}$ & $\begin{array}{r}25,0 \\
75,0\end{array}$ & $\begin{array}{c}65 \\
221\end{array}$ & $\begin{array}{r}22,7 \\
77,3\end{array}$ & $\begin{array}{l}70 \\
236\end{array}$ & $\begin{array}{l}22,9 \\
77,1\end{array}$ & 0,00 & 0,9669 \\
\hline $\begin{array}{l}\text { Escolaridade } \\
\text { do pai }\end{array}$ & $\begin{array}{l}<=4^{\mathrm{a}} \text { série } \\
>4^{\mathrm{a}} \text { série } \\
\text { S/inform* }\end{array}$ & \begin{tabular}{|l|}
6 \\
13 \\
1
\end{tabular} & $\begin{array}{r}30,0 \\
65,0 \\
5,0\end{array}$ & $\begin{array}{l}46 \\
218 \\
22\end{array}$ & $\begin{array}{r}16,1 \\
76,2 \\
7,7\end{array}$ & $\begin{array}{l}52 \\
231 \\
23\end{array}$ & $\begin{array}{c}17,0 \\
75,5 \\
7,5\end{array}$ & 1,52 & 0,2179 \\
\hline $\begin{array}{l}\mathrm{N}^{\circ} \text { de } \\
\text { consultas de } \\
\text { pré-natal }\end{array}$ & $\begin{array}{l}<=6 \\
>6 \\
\text { S/inform* }\end{array}$ & \begin{tabular}{|l|}
1 \\
18 \\
1
\end{tabular} & $\begin{array}{l}5,0 \\
9,0 \\
5,0\end{array}$ & $\begin{array}{l}15 \\
271\end{array}$ & $\begin{array}{c}5,2 \\
94,8\end{array}$ & $\begin{array}{l}16 \\
289 \\
1\end{array}$ & $\begin{array}{r}5,3 \\
94,4 \\
0,3\end{array}$ & 0,28 & 0,5976 \\
\hline $\begin{array}{l}\mathrm{N}^{\circ} \text { de } \\
\text { cigarros } \\
\text { fumados /dia }\end{array}$ & $\begin{array}{l}>5 \\
<=5 \\
\text { S/inform* }\end{array}$ & $\begin{array}{l}2 \\
3 \\
15\end{array}$ & $\begin{array}{c}10,0 \\
15,0 \\
75,0\end{array}$ & $\begin{array}{l}17 \\
14 \\
255\end{array}$ & $\begin{array}{r}5,9 \\
4,9 \\
89,2\end{array}$ & $\begin{array}{l}19 \\
17 \\
270\end{array}$ & $\begin{array}{r}6,2 \\
5,6 \\
88,2\end{array}$ & 0,02 & 0,8933 \\
\hline $\begin{array}{l}N^{\circ} \text { de xicaras } \\
\text { de café por } \\
\text { dia }\end{array}$ & $\begin{array}{l}>3 \\
<=3 \\
\text { S/inform* }\end{array}$ & $\begin{array}{l}5 \\
10 \\
5\end{array}$ & $\begin{array}{l}25,0 \\
50,0 \\
25,0\end{array}$ & $\begin{array}{l}38 \\
154 \\
94\end{array}$ & $\begin{array}{l}13,3 \\
53,8 \\
32,9\end{array}$ & \begin{tabular}{|l|}
43 \\
164 \\
99
\end{tabular} & $\begin{array}{c}14,0 \\
53,6 \\
32,4\end{array}$ & 0,84 & 0,3603 \\
\hline
\end{tabular}




\section{ANEXO 07}

\section{2. Área Amarela}

A área amarela ficou constituída de 9 postos, com 179 de mães (32,3\% do total da amostra) e $12(6,7 \%$ de crianças com BPN). Na (Figura 18) são apresentados os percentuais de crianças BPN de acordo com o número de atendimento de crianças. As variáveis que apresentaram diferenças das médias estatisticamente significativas foram a hemoglobina da criança $(p=0,0161)$, comprimento ao nascer ( $\mathrm{p}<0,0001)$ e IMC no final da gestação $(\mathrm{p}=0,0481)$ (Tabela 25). A variável comprimento ao nascer se apresentou também significativa $(\mathrm{p}=<0,0001)$ no teste de associação pelo qui-quadrado (Tabela 26).

Para esta área 6 postos apresentaram um percentual maior do que o total de crianças BPN, destes, referenciamos o Posto Vila Esperança e Internorte com $16,7 \%$ e $10,0 \%$ respectivamente.

Figura 18 - Distribuição (\%) de crianças com baixo peso ao nascer da Área Amarela segundo posto de saúde, Maringá-PR,1998.

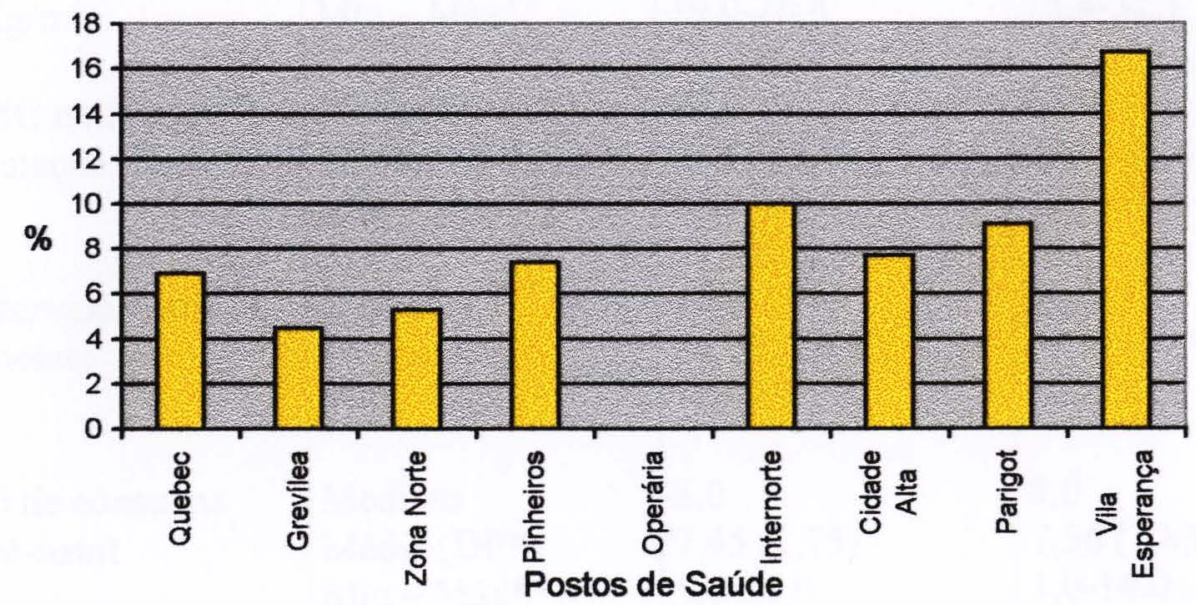


Tabela 25- Mediana, média e desvio padrão das variáveis da Área Amarela segundo o peso ao nascer. Maringá-Pr,1998.

\begin{tabular}{|c|c|c|c|c|}
\hline Variável & Parâmetro & $\begin{array}{r}<2500 \mathrm{~g} \\
\mathrm{~N}=12\end{array}$ & $\begin{array}{r}>=2500 g \\
N=167\end{array}$ & $\mathrm{P}^{* * *}$ \\
\hline $\begin{array}{l}\text { Idade da mãe } \\
\text { (anos) }\end{array}$ & $\begin{array}{l}\text { Mediana } \\
\text { Média (DP*) } \\
\text { Min-Máx** }\end{array}$ & $\begin{array}{l}23,5 \\
24,91(7,07) \\
16,0-34,0\end{array}$ & $\begin{array}{l}24,0 \\
24,62(6,06) \\
13,0-42,0\end{array}$ & 0,8671 \\
\hline $\begin{array}{l}\text { Estatura da mãe } \\
\text { (m) }\end{array}$ & $\begin{array}{l}\text { Mediana } \\
\text { Média (DP*) } \\
\text { Min-Máx** }\end{array}$ & $\begin{array}{l}1,61 \\
1,58(0,05) \\
1,50-1,65\end{array}$ & $\begin{array}{l}1,60 \\
1,60(0,07) \\
1,40-1,80\end{array}$ & 0,5906 \\
\hline $\begin{array}{l}\text { Peso pré- } \\
\text { gestacional }(\mathrm{Kg})\end{array}$ & $\begin{array}{l}\text { Mediana } \\
\text { Média (DP*) } \\
\text { Min-Máx** }\end{array}$ & $\begin{array}{l}54,0 \\
55,25(7,87) \\
43,0-72,0\end{array}$ & $\begin{array}{l}56,0 \\
56,47(8,50) \\
40,0-86,0\end{array}$ & 0,6356 \\
\hline $\begin{array}{l}\text { Peso no final da } \\
\text { gestação }(\mathrm{Kg})\end{array}$ & $\begin{array}{l}\text { Mediana } \\
\text { Média (DP*) } \\
\text { Min - Máx** }\end{array}$ & $\begin{array}{l}65,5 \\
66,41(8,54) \\
54,0-79,0\end{array}$ & $\begin{array}{l}69,0 \\
69,72(10,92 \\
45,0-108,0\end{array}$ & 0,3070 \\
\hline $\begin{array}{l}\text { Ganho de peso na } \\
\text { gestação }(\mathrm{Kg})\end{array}$ & $\begin{array}{l}\text { Mediana } \\
\text { Média (DP*) } \\
\text { Min-Máx** }\end{array}$ & $\begin{array}{l}9,5 \\
11,16(5,98) \\
4,0-23,0\end{array}$ & $\begin{array}{l}12,0 \\
13,15(5,66) \\
3,0-31,0\end{array}$ & 0,1921 \\
\hline $\begin{array}{l}\text { IMC pré- } \\
\text { gestacional } \\
\left(\mathrm{Kg} / \mathrm{m}^{2}\right)\end{array}$ & $\begin{array}{l}\text { Mediana } \\
\text { Média (DP*) } \\
\text { Min-Máx** }\end{array}$ & $\begin{array}{l}21,5 \\
21,95(2,77) \\
19,0-28,8\end{array}$ & $\begin{array}{l}21,6 \\
21,96(2,95) \\
15,4-32,1\end{array}$ & 0,9903 \\
\hline $\begin{array}{l}\text { IMC no final da } \\
\text { gestação }\left(\mathrm{Kg} / \mathrm{m}^{2}\right)\end{array}$ & $\begin{array}{l}\text { Mediana } \\
\text { Média (DP*) } \\
\text { Min-Máx** }\end{array}$ & $\begin{array}{l}27,5 \\
27,41(3,13) \\
22,8-30,9\end{array}$ & $\begin{array}{l}29,9 \\
29,64(2,86) \\
22,8-37,5\end{array}$ & 0,0481 \\
\hline $\begin{array}{l}\text { Intervalo Partal } \\
\text { (meses) }\end{array}$ & $\begin{array}{l}\text { Mediana } \\
\text { Média (DP*) } \\
\text { Min-Máx** }\end{array}$ & $\begin{array}{l}48,0 \\
54,75(26,72) \\
18,0-96,0\end{array}$ & $\begin{array}{l}36,0 \\
47,31(27,95 \\
12,0-96,0\end{array}$ & 0,3830 \\
\hline $\begin{array}{l}\mathrm{N}^{\circ} \text { de consultas } \\
\text { pré-natal }\end{array}$ & $\begin{array}{l}\text { Mediana } \\
\text { Média (DP*) } \\
\text { Min-Máx** }\end{array}$ & $\begin{array}{l}8,0 \\
7,45(1,75) \\
5,0-10,0\end{array}$ & $\begin{array}{l}8,0 \\
7,56(1,83) \\
1,0-14,0\end{array}$ & 0,8377 \\
\hline $\begin{array}{l}\text { Escolaridade da } \\
\text { mãe }\end{array}$ & $\begin{array}{l}\text { Mediana } \\
\text { Média (DP*) } \\
\text { Min - Máx** }\end{array}$ & $\begin{array}{l}3,0 \\
3,0(1,20) \\
1,0-3,0\end{array}$ & $\begin{array}{l}3,0 \\
3,7(1,49) \\
0,0-6,0\end{array}$ & 0,0803 \\
\hline
\end{tabular}




\begin{tabular}{l|l|l|l|l}
\hline $\begin{array}{l}\text { Escolaridade do } \\
\text { pai }\end{array}$ & Mediana & 3,0 & 3,0 & \\
& $\begin{array}{l}\text { Média (DP*) } \\
\text { Min - Máx** }\end{array}$ & $3,66(1,49)$ & $3,83(1,50)$ & 0,7146 \\
& $2,0-6,0$ & $0,0-8,0$ & \\
Renda familiar & Mediana & 400,0 & 430,0 & \\
(reais) & Média (DP*) & $429,09(245,09)$ & $489,4(287,6$ & 0,5057 \\
& Min - Máx** & $120,0-1000,0$ & $120,0-5000$ & \\
No de cigarros & Mediana & 4,0 & 5,0 & \\
fumados / dia & Média (DP*) & $3,75(2,21)$ & $9,8(7,93)$ & 0,2431 \\
& Min - Máx** & $1,0-6,0$ & $2,0-20,0$ & \\
No de xícaras de & Mediana & 2,0 & 1,0 & \\
café /dia & Média (DP*) & $1,90(0,94)$ & $2,0(1,69)$ & 0,3273 \\
& Min - Máx** & $1,0-4,0$ & $0,0-10,0$ & \\
\hline
\end{tabular}

*DP= desvio padrão

** Min-Máx = valores minimos e máximos

*** $\mathrm{p}=$ nivel descritivo do teste de diferença das médias de Mann-Whitney

Tabela 26 - Distribuição do número e porcentagem de mães da área Amarela, segundo o peso ao nascer, Maringá-Pr,1998.

\begin{tabular}{|c|c|c|c|c|c|c|c|c|c|}
\hline Variável & Categoria & & & $\begin{array}{l}>=2 \\
N=1\end{array}$ & & $\begin{array}{r}\text { Tota } \\
\mathrm{N}\end{array}$ & & $\mathrm{X}^{2}$ & $\mathrm{P} * *$ \\
\hline & & $\mathrm{N}^{\circ}$ & $\%$ & $\mathrm{~N}^{\mathrm{o}}$ & $\%$ & $\mathrm{~N}^{\circ}$ & $\%$ & & \\
\hline $\begin{array}{l}\text { Idade da mãe } \\
\text { (anos) }\end{array}$ & $\begin{array}{l}<20 \\
>=20\end{array}$ & $\begin{array}{l}4 \\
8\end{array}$ & $\begin{array}{l}33,3 \\
66,7\end{array}$ & $\begin{array}{r}43 \\
124\end{array}$ & $\begin{array}{l}25,7 \\
74,3\end{array}$ & $\begin{array}{r}47 \\
132\end{array}$ & $\begin{array}{l}26,3 \\
73,7\end{array}$ & 0,06 & 0,8125 \\
\hline $\begin{array}{l}\text { Estatura da } \\
\text { mãe }(\mathrm{m})\end{array}$ & $\begin{array}{l}<1,50 \\
>=1,50\end{array}$ & $\begin{array}{r}0 \\
12\end{array}$ & 100,0 & $\begin{array}{r}9 \\
158\end{array}$ & $\begin{array}{r}5,4 \\
94,6\end{array}$ & $\begin{array}{r}9 \\
170\end{array}$ & $\begin{array}{r}5,0 \\
95,0\end{array}$ & 0,02 & 0,8875 \\
\hline $\begin{array}{l}\text { Peso pré- } \\
\text { gestacional } \\
(\mathrm{Kg})\end{array}$ & $\begin{array}{l}<50 \\
>=50\end{array}$ & $\begin{array}{r}2 \\
10\end{array}$ & $\begin{array}{l}16,7 \\
83,3\end{array}$ & $\begin{array}{r}43 \\
124\end{array}$ & $\begin{array}{l}25,7 \\
74,3\end{array}$ & $\begin{array}{r}45 \\
134\end{array}$ & $\begin{array}{l}25,1 \\
74,9\end{array}$ & 0,13 & 0,7218 \\
\hline $\begin{array}{l}\text { Ganho de } \\
\text { peso na } \\
\text { gestação } \\
(\mathrm{Kg})\end{array}$ & $\begin{array}{l}<=9 \\
>9 \\
\text { S/inform* }\end{array}$ & $\begin{array}{l}6 \\
6\end{array}$ & $\begin{array}{l}50,0 \\
50,0\end{array}$ & $\begin{array}{r}48 \\
115 \\
4\end{array}$ & $\begin{array}{r}28,7 \\
68,9 \\
2,4\end{array}$ & $\begin{array}{r}54 \\
121 \\
4\end{array}$ & $\begin{array}{r}30,2 \\
67,6 \\
2,2\end{array}$ & 1,35 & 0,2445 \\
\hline $\begin{array}{l}\text { Intervalos } \\
\text { partal } \\
\text { (meses) }\end{array}$ & $\begin{array}{l}<12 \\
>=12 \\
\text { S/inform* }\end{array}$ & $\begin{array}{l}- \\
8 \\
4\end{array}$ & $\begin{array}{c}- \\
66,7 \\
33,3\end{array}$ & $\begin{array}{r}- \\
98 \\
69\end{array}$ & $\begin{array}{c}- \\
58,7 \\
41,3\end{array}$ & $\begin{array}{l}- \\
106 \\
73\end{array}$ & $\begin{array}{c}- \\
59,2 \\
40,8\end{array}$ & 0,00 & 1,0000 \\
\hline
\end{tabular}




\begin{tabular}{|c|c|c|c|c|c|c|c|c|c|}
\hline $\begin{array}{l}\text { IMC pré- } \\
\text { gestacional } \\
\left(\mathrm{Kg} / \mathrm{m}^{2}\right)\end{array}$ & $\begin{array}{l}<19 \\
>=19 \\
\text { S/inform* }\end{array}$ & $\begin{array}{l}0 \\
12\end{array}$ & 100,0 & $\begin{array}{l}21 \\
145 \\
1\end{array}$ & $\begin{array}{r}12,6 \\
86,8 \\
0,6\end{array}$ & $\begin{array}{l}21 \\
157 \\
1\end{array}$ & $\begin{array}{r}11,7 \\
87,7 \\
0,6\end{array}$ & 0,72 & 0,3961 \\
\hline $\begin{array}{l}\text { Renda } \\
\text { familiar } \\
\text { (reais }\end{array}$ & $\begin{array}{l}<=130 \\
>130 \\
\text { S/inform* }\end{array}$ & $\begin{array}{l}2 \\
9 \\
1\end{array}$ & $\begin{array}{r}16,7 \\
75,0 \\
8,3\end{array}$ & $\begin{array}{c}7 \\
152 \\
8\end{array}$ & $\begin{array}{r}4,2 \\
91,0 \\
4,8\end{array}$ & $\begin{array}{r}9 \\
161 \\
9\end{array}$ & $\begin{array}{r}5,0 \\
90,0 \\
5,0\end{array}$ & 1,63 & 0,2013 \\
\hline $\begin{array}{l}\text { Escolaridade } \\
\text { da mãe }\end{array}$ & $\begin{array}{l}<=4^{\mathrm{a}} \text { série } \\
>4^{\mathrm{a}} \text { série }\end{array}$ & $\begin{array}{l}3 \\
9\end{array}$ & $\begin{array}{c}25,0 \\
75,0\end{array}$ & $\begin{array}{r}22 \\
145\end{array}$ & $\begin{array}{l}13,2 \\
86,8\end{array}$ & $\begin{array}{r}25 \\
154\end{array}$ & $\begin{array}{l}14,0 \\
86,0\end{array}$ & 0,50 & 0,4774 \\
\hline $\begin{array}{l}\text { Escolaridade } \\
\text { do pai }\end{array}$ & $\begin{array}{l}<=4^{\mathrm{a}} \text { série } \\
>4^{\mathrm{a}} \text { série } \\
\text { S/inform* }\end{array}$ & $\begin{array}{l}3 \\
9\end{array}$ & $\begin{array}{l}25,0 \\
75,0\end{array}$ & $\begin{array}{r}18 \\
143 \\
6\end{array}$ & $\begin{array}{r}10,8 \\
85,6 \\
3,6\end{array}$ & $\begin{array}{r}21 \\
152 \\
6\end{array}$ & $\begin{array}{r}11,7 \\
84,9 \\
3,4\end{array}$ & 0,91 & 0,3390 \\
\hline $\begin{array}{l}\mathrm{N}^{\circ} \text { de } \\
\text { consultas de } \\
\text { pré-natal }\end{array}$ & $\begin{array}{l}<6 \\
>=6 \\
\text { S/inform* }\end{array}$ & $\begin{array}{r}0 \\
11 \\
1\end{array}$ & $\begin{array}{r}91,7 \\
8,3\end{array}$ & $\begin{array}{r}8 \\
156 \\
3\end{array}$ & $\begin{array}{r}4,8 \\
93,4 \\
1,8\end{array}$ & $\begin{array}{r}8 \\
167 \\
4\end{array}$ & $\begin{array}{r}4,5 \\
93,3 \\
2,2\end{array}$ & 0,00 & 0,9966 \\
\hline $\begin{array}{l}\mathrm{N}^{\circ} \text { de } \\
\text { cigarros } \\
\text { fumados / } \\
\text { dia }\end{array}$ & $\begin{array}{l}>5 \\
<=5 \\
\text { S/inform* }\end{array}$ & $\begin{array}{l}1 \\
3 \\
8\end{array}$ & $\begin{array}{r}8,3 \\
25,0 \\
66,7\end{array}$ & $\begin{array}{c}8 \\
10 \\
149\end{array}$ & $\begin{array}{r}4,8 \\
6,0 \\
89,2\end{array}$ & $\begin{array}{l}9 \\
13 \\
157\end{array}$ & $\begin{array}{r}5,0 \\
7,3 \\
87,7\end{array}$ & 0,02 & 0,8781 \\
\hline $\begin{array}{l}\mathrm{N}^{\circ} \text { de xícaras } \\
\text { de café/dia }\end{array}$ & $\begin{array}{l}>3 \\
<=3 \\
\text { S/inform* }\end{array}$ & $\begin{array}{r}1 \\
10 \\
1\end{array}$ & $\begin{array}{r}8,3 \\
83,4 \\
8,3\end{array}$ & $\begin{array}{r}16 \\
110 \\
41\end{array}$ & $\begin{array}{r}9,6 \\
65,9 \\
24,5\end{array}$ & $\begin{array}{r}17 \\
120 \\
42\end{array}$ & $\begin{array}{r}9,5 \\
67,0 \\
23,5\end{array}$ & 0,02 & 0,8975 \\
\hline
\end{tabular}




\section{ANEXO 08}

\section{3. Área Vermelha}

Para esta área, 4 postos de saúde foram selecionados com 68 mães $(12,3 \%)$ do total da amostra. Na Figura 19, são apresentados os percentuais de crianças BPN segundo o número de atendimento. Esta área se caracteriza como a área de renda mais baixa, no entanto, não houve diferença de médias estatisticamente significativa entre as variáveis estudadas. (Tabela 27).Na análise pelo teste de associação pelo Qui-quadrado também não observou-se significância. (Tabela 28)

Figura 19- Distribuição (\%) de crianças da Área Vermelha segundo o baixo peso ao nascer e posto de atendimento, Maringá-Pr,1998

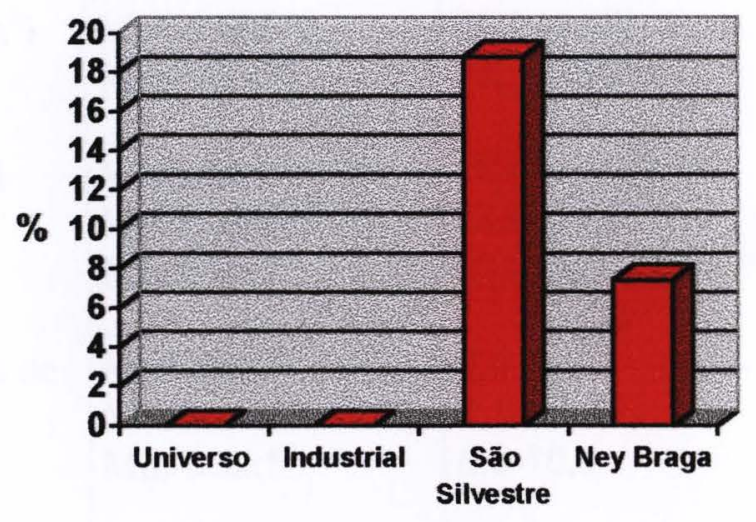

Postos de Saúde

Tabela 27 - Mediana, média e desvio padrão das variáveis da Área Vermelha segundo peso ao nascer, Maringá-Pr, 1998.

\begin{tabular}{l|l|l|l|l}
\hline Variável & Parâmetro & $\begin{array}{l}<2500 \mathrm{~g} \\
\mathrm{~N}=5\end{array}$ & $\begin{array}{l}>=2500 \mathrm{~g} \\
\mathrm{~N}=63\end{array}$ & $\mathrm{P} * * *$ \\
\hline $\begin{array}{l}\text { Idade da mãe } \\
\text { (anos) }\end{array}$ & $\begin{array}{l}\text { Mediana } \\
\text { Média (DP*) }\end{array}$ & $\begin{array}{l}20,0 \\
21,0(6,16)\end{array}$ & $\begin{array}{l}23,0 \\
23,71(5,68) \\
16,0-31,0\end{array}$ & 0,3109 \\
& Min-Máx** & $14,0-39,0$ & \\
Estatura da mãe & Mediana & 1,60 & 1,58 & \\
$(\mathrm{~m})$ & Média (DP*) & $1,58(0,06)$ & $\begin{array}{l}1,59(0,06) \\
1,44-1,75\end{array}$ & 0,9488 \\
& Min-Máx** & $1,52-1,68$ & &
\end{tabular}




\begin{tabular}{|c|c|c|c|c|}
\hline $\begin{array}{l}\text { Peso } \\
\text { pré=gestacional } \\
(\mathrm{Kg})\end{array}$ & $\begin{array}{l}\text { Mediana } \\
\text { Média (DP*) } \\
\text { Min-Máx** }\end{array}$ & $\begin{array}{l}53,0 \\
54,20(7,56) \\
46,0-62,0\end{array}$ & $\begin{array}{l}55,0 \\
56,66(8,56) \\
43,0-60,0\end{array}$ & 0,5417 \\
\hline $\begin{array}{l}\text { Peso no final da } \\
\text { gestação }(\mathrm{Kg})\end{array}$ & $\begin{array}{l}\text { Mediana } \\
\text { Média (DP*) } \\
\text { Min-Máx** }\end{array}$ & $\begin{array}{l}55,5 \\
59,50(10,66) \\
52,0-75,0\end{array}$ & $\begin{array}{l}67,0 \\
69,03 \\
(10,93) \\
43,0-106,0\end{array}$ & 0,0916 \\
\hline $\begin{array}{l}\text { Ganho de peso na } \\
\text { gestação }(\mathrm{Kg})\end{array}$ & $\begin{array}{l}\text { Mediana } \\
\text { Média (DP*) } \\
\text { Min-Máx** }\end{array}$ & $\begin{array}{l}5,50 \\
7,25(3,86) \\
5,0-13,0\end{array}$ & $\begin{array}{l}11,5 \\
12,15(6,06) \\
(-3)-39,0\end{array}$ & 0,3683 \\
\hline $\begin{array}{l}\text { IMC pré- } \\
\text { gestacional } \\
\left(\mathrm{Kg} / \mathrm{m}^{2}\right)\end{array}$ & $\begin{array}{l}\text { Mediana } \\
\text { Média (DP*) } \\
\text { Min-Máx** }\end{array}$ & $\begin{array}{l}26,1 \\
26,1(0,00) \\
26,1-26,1\end{array}$ & $\begin{array}{l}22,50 \\
22,66(2,94) \\
15,8-31,2\end{array}$ & 0,2557 \\
\hline $\begin{array}{l}\text { IMC final da } \\
\text { gestação }\left(\mathrm{Kg} / \mathrm{m}^{2}\right)\end{array}$ & $\begin{array}{l}\text { Mediana } \\
\text { Média (DP*) } \\
\text { Min-Máx** }\end{array}$ & $\begin{array}{l}26,1 \\
26,1(4,52) \\
22,90-29,30\end{array}$ & $\begin{array}{l}30,1 \\
29,02(4,79) \\
16,80-35,10\end{array}$ & 0,5727 \\
\hline $\begin{array}{l}\text { Intervalo Partal } \\
\text { (meses) }\end{array}$ & $\begin{array}{l}\text { Mediana } \\
\text { Média (DP*) } \\
\text { Min-Máx** }\end{array}$ & $\begin{array}{l}28,0 \\
28,0(11,31) \\
20,0-36,0\end{array}$ & $\begin{array}{l}36,0 \\
38,4(19,82) \\
12,0-96,0\end{array}$ & 0,6549 \\
\hline $\begin{array}{l}\mathrm{N}^{\circ} \text { de consultas de } \\
\text { pré-natal }\end{array}$ & $\begin{array}{l}\text { Mediana } \\
\text { Média (DP*) } \\
\text { Min-Máx** }\end{array}$ & $\begin{array}{l}9,0 \\
8,50(1,73) \\
6,0-10,0\end{array}$ & $\begin{array}{l}8,0 \\
7,96(2,03) \\
1,0-15,0\end{array}$ & 0,6173 \\
\hline $\begin{array}{l}\text { Escolaridade da } \\
\text { mãe }\end{array}$ & $\begin{array}{l}\text { Mediana } \\
\text { Média (DP*) } \\
\text { Min-Máx** }\end{array}$ & $\begin{array}{l}5,0 \\
4,60,(0,54) \\
4,0-5,0\end{array}$ & $\begin{array}{l}4,0 \\
3,77(1,56) \\
1,0-7,0\end{array}$ & 0,1829 \\
\hline $\begin{array}{l}\text { Escolaridade do } \\
\text { pai }\end{array}$ & $\begin{array}{l}\text { Mediana } \\
\text { Média (DP*) } \\
\text { Min-Máx** }\end{array}$ & $\begin{array}{l}5,0 \\
4,20(1,64) \\
20,-6,0\end{array}$ & $\begin{array}{l}3,0 \\
3,81(1,62) \\
0,0-8,0\end{array}$ & 0,6156 \\
\hline $\begin{array}{l}\text { Renda familiar } \\
\text { (reais) }\end{array}$ & $\begin{array}{l}\text { Mediana } \\
\text { Média (DP*) } \\
\text { Min-Máx** }\end{array}$ & $\begin{array}{l}400,0 \\
418,0(227,20) \\
240,0-800,0\end{array}$ & $\begin{array}{l}400,0 \\
489,9(309,0 \\
130,0-1800\end{array}$ & 0,6194 \\
\hline $\begin{array}{l}N^{\circ} \text { de cigarros } \\
\text { fumados / dia }\end{array}$ & $\begin{array}{l}\text { Mediana } \\
\text { Média (DP*) } \\
\text { Min-Máx** }\end{array}$ & $\begin{array}{l}20,0 \\
20,0(0,00) \\
20,0-20,0\end{array}$ & $\begin{array}{l}5,0 \\
8,84(7,27) \\
2,0-20,0\end{array}$ & 0,1629 \\
\hline
\end{tabular}




\begin{tabular}{l|l|l|l|l} 
& & \\
$N^{\circ}$ de xícaras de & Mediana & 4,0 & 2,0 & \\
café /dia & Média (DP*) & $8,33(10,21)$ & $2,45(1,83)$ & 0,2882 \\
& Min-Máx** & $1,0-20,0$ & $1,0-10,0$ & \\
\hline
\end{tabular}

${ }^{*} \mathrm{DP}=$ desvio padrão

**Min-Máx = valores mínimos e máximos

${ }^{* * *} \mathrm{p}=$ nivel descritivo do teste de diferença das médias de Mann-Whitney.

Tabela 28- Distribuição do número e porcentagem de mães da área Vermelha, segundo peso ao nascer, Maringá- Pr, 1998.

\begin{tabular}{|c|c|c|c|c|c|c|c|c|c|}
\hline Variável & Categoria & $\begin{array}{l}< \\
N=\end{array}$ & & $\begin{array}{l}>=2 \\
\mathrm{~N}=6\end{array}$ & & $\begin{array}{l}\text { Tot: } \\
\mathrm{N}=\end{array}$ & & $\mathrm{X}^{2}$ & \\
\hline $\begin{array}{l}\text { Idade da mãe } \\
\text { (anos) }\end{array}$ & $\begin{array}{l}<20 \\
>=20\end{array}$ & $\begin{array}{l}2 \\
3\end{array}$ & $\begin{array}{l}40,0 \\
60,0\end{array}$ & $\begin{array}{l}15 \\
48\end{array}$ & $\begin{array}{l}23,8 \\
76,2\end{array}$ & $\begin{array}{l}17 \\
51\end{array}$ & $\begin{array}{l}25,0 \\
75,0\end{array}$ & 0,07 & 0,7885 \\
\hline $\begin{array}{l}\text { Estatura da } \\
\text { mãe (m) }\end{array}$ & $\begin{array}{l}<1,50 \\
>=1,50 \\
\text { S/inform* }\end{array}$ & $\begin{array}{l}0 \\
5\end{array}$ & $\begin{array}{r}0,0 \\
100,0\end{array}$ & $\begin{array}{r}3 \\
59 \\
1\end{array}$ & $\begin{array}{r}4,8 \\
93,6 \\
15,6\end{array}$ & $\begin{array}{r}3 \\
64 \\
1\end{array}$ & $\begin{array}{r}4,4 \\
94,1 \\
1,5\end{array}$ & 0,39 & 0,5348 \\
\hline $\begin{array}{l}\text { Peso pré- } \\
\text { gestacional } \\
(\mathrm{Kg})\end{array}$ & $\begin{array}{l}<50 \\
>=50\end{array}$ & $\begin{array}{l}2 \\
3\end{array}$ & $\begin{array}{l}40,0 \\
60,0\end{array}$ & $\begin{array}{l}11 \\
52\end{array}$ & $\begin{array}{c}17,5 \\
82,5\end{array}$ & $\begin{array}{l}13 \\
55\end{array}$ & $\begin{array}{l}19,1 \\
80,9\end{array}$ & 0,41 & 0,5202 \\
\hline $\begin{array}{l}\text { Ganho de } \\
\text { peso na } \\
\text { gestação } \\
(\mathrm{Kg})\end{array}$ & $\begin{array}{l}<=9 \\
>9 \\
\text { S/inform* }\end{array}$ & $\begin{array}{l}3 \\
1 \\
1\end{array}$ & $\begin{array}{l}60,0 \\
20,0 \\
20,0\end{array}$ & $\begin{array}{r}17 \\
43 \\
3\end{array}$ & $\begin{array}{r}27,0 \\
68,2 \\
4,8\end{array}$ & $\begin{array}{r}20 \\
44 \\
4\end{array}$ & $\begin{array}{r}29,4 \\
64,7 \\
5,9\end{array}$ & 1,94 & 0,1637 \\
\hline $\begin{array}{l}\text { Intervalo } \\
\text { Partal } \\
\text { (meses) }\end{array}$ & $\begin{array}{l}<12 \\
>=12 \\
\text { S/inform* }\end{array}$ & $\begin{array}{l}- \\
2 \\
3\end{array}$ & $\begin{array}{c}- \\
40,0 \\
60,0\end{array}$ & $\begin{array}{r}- \\
25 \\
38\end{array}$ & $\begin{array}{l}- \\
39,7 \\
60,3\end{array}$ & $\begin{array}{r}- \\
27 \\
41\end{array}$ & $\begin{array}{l}- \\
39,7 \\
60,3\end{array}$ & 0,00 & 1,0000 \\
\hline $\begin{array}{l}\text { IMC pré- } \\
\text { gestacional } \\
\left(\mathrm{Kg} / \mathrm{m}^{2}\right)\end{array}$ & $\begin{array}{l}<19 \\
>=19 \\
\text { S/inform* }\end{array}$ & $\begin{array}{l}2 \\
3\end{array}$ & $\begin{array}{l}40,0 \\
60,0\end{array}$ & $\begin{array}{r}6 \\
56 \\
1\end{array}$ & $\begin{array}{r}9,5 \\
88,9 \\
1,6\end{array}$ & $\begin{array}{r}8 \\
59 \\
1\end{array}$ & $\begin{array}{r}11,8 \\
86,8 \\
1,4\end{array}$ & 1,68 & 0,1954 \\
\hline $\begin{array}{l}\text { Renda } \\
\text { familiar } \\
\text { (reais) }\end{array}$ & $\begin{array}{l}<=130 \\
>130 \\
\text { S/inform* }\end{array}$ & $\begin{array}{l}0 \\
5\end{array}$ & 100,0 & $\begin{array}{r}1 \\
60 \\
2\end{array}$ & $\begin{array}{r}1,6 \\
95,2 \\
3,2\end{array}$ & $\begin{array}{r}1 \\
65 \\
2\end{array}$ & $\begin{array}{r}4,4 \\
95,6 \\
2,9\end{array}$ & 2,61 & 0,1061 \\
\hline $\begin{array}{l}\text { Escolaridade } \\
\text { da mãe }\end{array}$ & $\begin{array}{l}<=4^{\mathrm{a}} \text { série } \\
>4^{\mathrm{a}} \text { série }\end{array}$ & $\begin{array}{l}0 \\
5\end{array}$ & 100,0 & $\begin{array}{l}12 \\
51\end{array}$ & $\begin{array}{l}19,0 \\
.81,0\end{array}$ & $\begin{array}{l}12 \\
56\end{array}$ & $\begin{array}{l}17,6 \\
82,4\end{array}$ & 0,22 & 0,6412 \\
\hline
\end{tabular}




\begin{tabular}{|c|c|c|c|c|c|c|c|c|c|}
\hline Escolaridade & $<=4^{\mathrm{a}}$ série & 1 & 20,0 & 8 & 12,7 & 9 & 13,2 & 0,08 & 0,7753 \\
\hline do pai & $\begin{array}{l}>4^{\mathrm{a}} \text { série } \\
\text { S/inform* }\end{array}$ & 4 & 80,0 & $\begin{array}{l}50 \\
5\end{array}$ & $\begin{array}{r}.79,4 \\
7,9\end{array}$ & $\begin{array}{l}54 \\
5\end{array}$ & $\begin{array}{r}79,4 \\
7,4\end{array}$ & & \\
\hline $\begin{array}{l}\mathrm{N}^{\circ} \text { de } \\
\text { consultas de } \\
\text { pré-natal }\end{array}$ & $\begin{array}{l}<6 \\
>=6 \\
\text { S/inform* }\end{array}$ & $\mid \begin{array}{l}0 \\
4 \\
1\end{array}$ & $\begin{array}{l}80,0 \\
20,0\end{array}$ & $\begin{array}{l}5 \\
58\end{array}$ & $\begin{array}{r}7,9 \\
92,1\end{array}$ & $\begin{array}{r}5 \\
62 \\
1\end{array}$ & $\begin{array}{r}7,3 \\
91,2 \\
1,5\end{array}$ & 0,16 & 0,6925 \\
\hline $\begin{array}{l}N^{\circ} \text { de } \\
\text { cigarros } \\
\text { fumados / } \\
\text { dia }\end{array}$ & $\begin{array}{l}>5 \\
<=5 \\
\text { S/inform* }\end{array}$ & $\begin{array}{l}1 \\
0 \\
4\end{array}$ & $\begin{array}{l}20,0 \\
80,0\end{array}$ & $\begin{array}{l}6 \\
7 \\
50\end{array}$ & $\begin{array}{r}9,5 \\
11,1 \\
79,4\end{array}$ & $\begin{array}{l}7 \\
7 \\
54\end{array}$ & $\begin{array}{l}10,3 \\
10,3 \\
79,4\end{array}$ & 0,00 & 1,0000 \\
\hline $\begin{array}{l}N^{\circ} \text { de xícaras } \\
\text { café /dia }\end{array}$ & $\begin{array}{l}>3 \\
<=3 \\
\text { S/inform* }\end{array}$ & $\begin{array}{l}2 \\
1 \\
2\end{array}$ & $\begin{array}{l}40,0 \\
20,0 \\
40,0\end{array}$ & $\begin{array}{l}9 \\
37 \\
17 \\
\end{array}$ & $\begin{array}{l}14,3 \\
58,7 \\
27,0\end{array}$ & $\begin{array}{l}11 \\
38 \\
19 \\
\end{array}$ & $\begin{array}{l}16,2 \\
55,9 \\
27,9\end{array}$ & 1,39 & 0,2378 \\
\hline
\end{tabular}

$\mathrm{X}^{2}=$ qui-quadrado

* = excluídos os casos $\mathrm{S} /$ informação

${ }^{*} \mathrm{p}$ = nivel descritivo do teste de associação pelo qui-quadrado. 